\title{
An investigation into rule of thumb behaviour in New Zealand
}

by

Adam Malanchak

A thesis

submitted to the Victoria University of Wellington

in fulfilment of the

requirements for the degree of

Masters in Commerce and Administration

in Economics

Victoria University of Wellington

2010 


\begin{abstract}
In recent times, macroeconomic models have begun to describe aggregate consumer and firm behaviour by allowing some proportion to behave in a rule of thumb manner. This dissertation attempts to address two main issues that are concurrent in the literature. First I test for the proportion of aggregate behaviour that deviates from Classical consumer allocation theory and New Keynesian firm pricing theory in New Zealand. Rule of thumb consumers are assumed to consume out of current income as opposed to obeying the Permanent Income Hypothesis, while rule of thumb firms set prices in a backward looking manner. Using the GMM estimation procedure, I examine the sensitivity of estimates across a range of instrumental variables. After positive GMM specification tests I find the proportion of rule of thumb consumers is 0.21 and the proportion of backward looking price setters is 0.82 . These results suggest that specifications which fail to allow for rule of thumb behaviour cannot fully reflect consumer and firm decisions. The second main issue seeks to address how these estimates compare to those estimated in a small open economy DSGE model. Monte Carlo Markov Chain (MCMC) estimation finds an estimated degree of external habit persistence of 0.9 , proportion of rule of thumb consumers of 0.34 , and the proportion of backward looking price setters falls to 0.7 . A full range of MCMC diagnostics is subsequently computed. The diagnostic tests are largely favourable.
\end{abstract}




\section{Acknowledgements}

I wish to acknowledge and thank the following people for their contributions to the research which has culminated in this thesis:

Dr. Viv Hall for his support and insight into relevant macroeconomic theory and literature referred to in this thesis. I would like to also thank him for his role as primary supervisor and enthusiasm which he imparted to me during the research process. Viv has a wealth of knowledge I was fortunate to be given the opportunity to work with him.

Adjunct Professor Dr. John McDermott for his support and encouragement in his role as assistant supervisor. His research experience in applied econometrics has been invaluable and constructive criticism has been greatly appreciated.

Victoria University of Wellington for presenting me with their Masters (by thesis) scholarship for the 2009 calendar year to pursue this research.

My Mum and Dad, Sheena and Michael, and my sister Lisa for putting up with me and being there to bounce ideas off. 


\section{Contents}

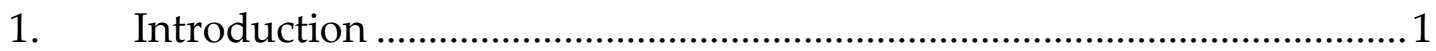

2. The Permanent Income Hypothesis and Rule of Thumb Consumers...3

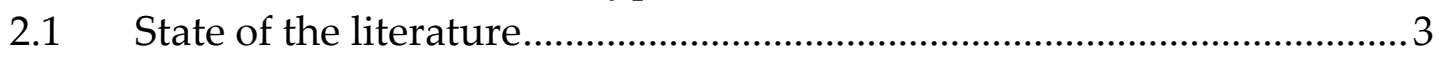

2.1.1 Evolution of the literature over time ............................................ 3

2.1.2 New Zealand literature .............................................................. 7

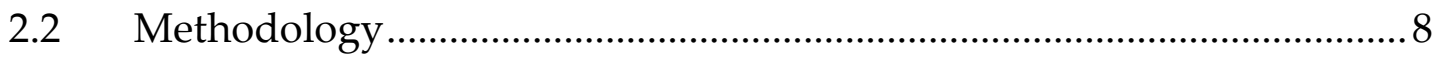

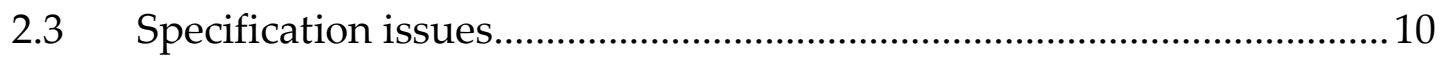

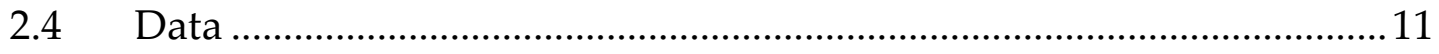

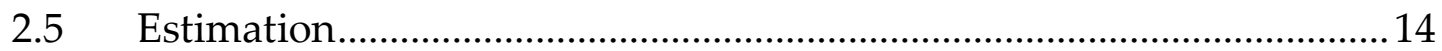

2.5.1 Rule of thumb consumers ........................................................ 15

2.5.2 Consumption and the real interest rate ..................................... 18

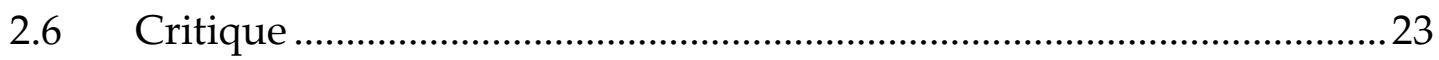

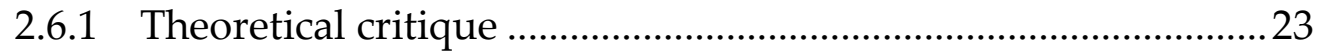

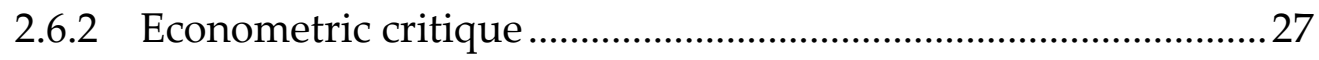

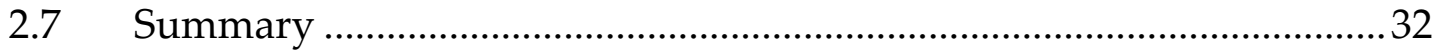

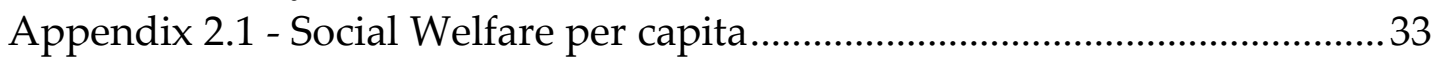

3. The New Zealand New Keynesian Phillips Curve .................................37

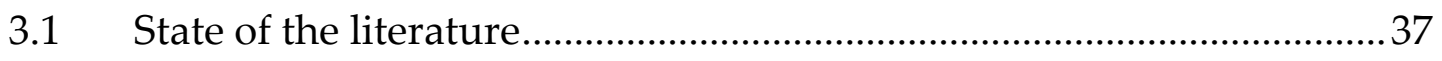

3.2 The Forward looking Phillips Curve....................................................39

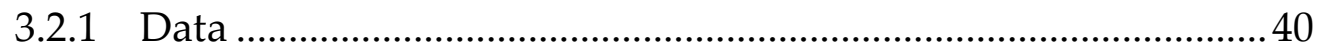

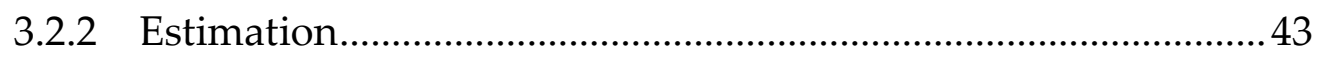

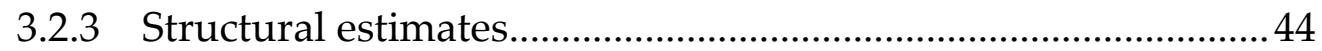

3.3 The Hybrid New Keynesian Phillips Curve...........................................50

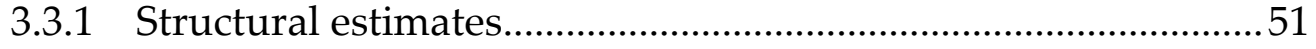

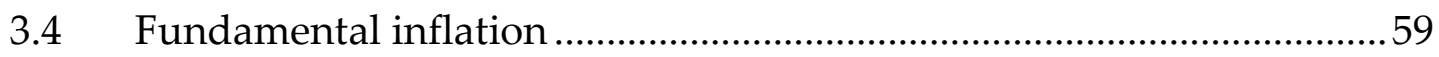

3.4.1 The Forward Looking Phillips Curve .......................................5 59

3.4.2 The Hybrid New Keynesian Phillips Curve...............................61 


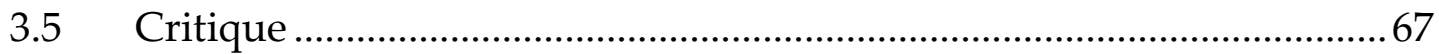

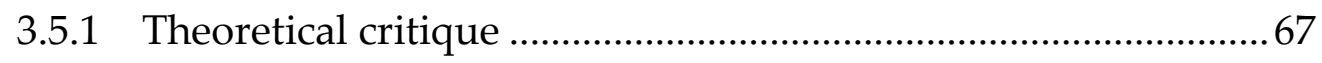

3.5.2 Econometric critique .................................................................

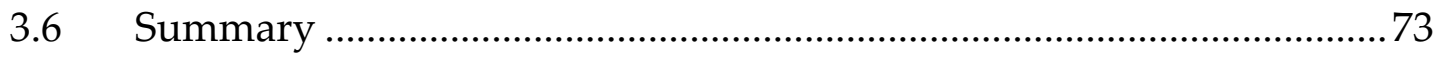

Appendix 3.1 - Forward Looking NKPC .........................................................

Appendix 3.2 - Hybrid NKPC ...........................................................................

Appendix 3.3 - Forward Looking NKPC Fundamental Inflation .....................79

Appendix 3.4 - Hybrid NKPC Fundamental Inflation ........................................ 81

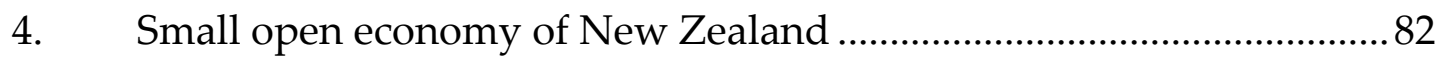

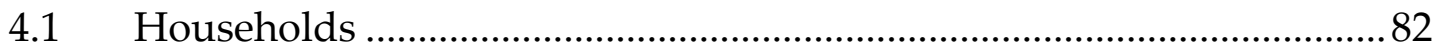

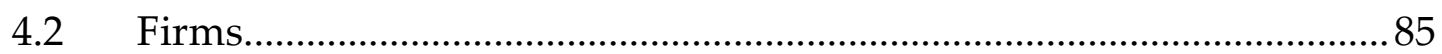

4.3 Domestic inflation, CPI inflation, and the real exchange rate ................86

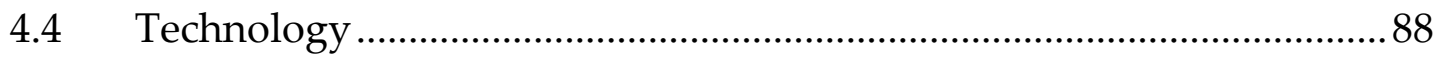

4.5 The Central Monetary Authority ……………………………………..... 90

4.6 Aggregate demand and output determination ......................................90

$4.7 \quad$ Foreign Sector ……………………………………............................ 91

$4.8 \quad$ Linearised System ……………………………………………...... 92

4.9 Bayesian Estimation .......................................................................... 95

4.9.1 Data and Priors …………………………………………........95

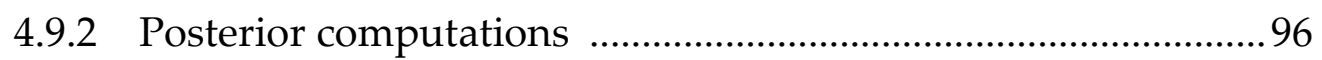

4.10 Estimation results ............................................................................ 100

4.11 Impulse Response Functions …………………………………….......102

4.11.1 Domestic inflation shock ..........................................................102

4.11.2 Domestic interest rate shock .....................................................103

4.11.3 Domestic productivity shock …………………….....................104

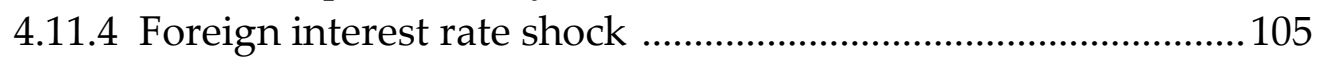

4.11.5 Foreign output shock ................................................................. 106 
4.11.6 Foreign inflation shock .............................................................107

4.12 Monte Carlo Markov Chain diagnostics ...............................................111

4.12.1 Heidelberger-Welch ..................................................................111

4.12.2 Gelman-Rubin ......................................................................112

4.12.3 Raferty-Lewis ........................................................................113

4.12.4 Parameter distribution ..............................................................114

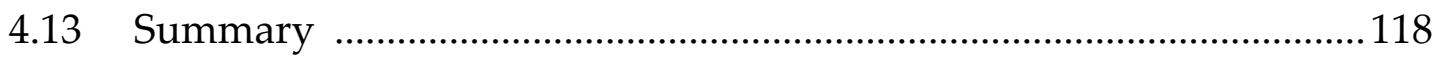

Appendix 4.1 - CPI Inflation..........................................................................120

Appendix 4.2 - Goods Market Equilibrium .......................................................122

Appendix 4.3 - Data description ......................................................................130

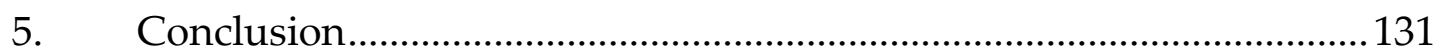

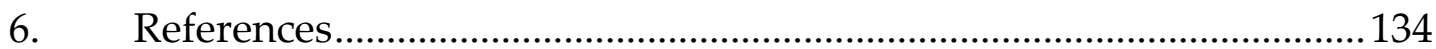




\section{Tables}

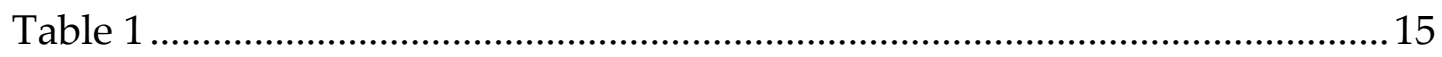

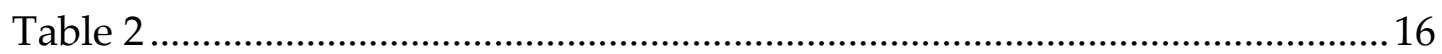

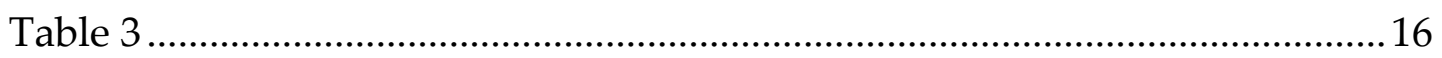

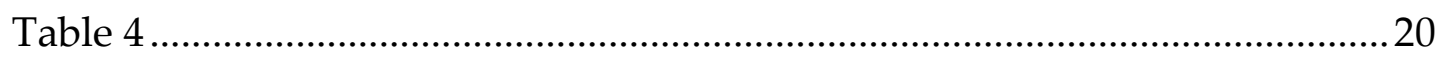

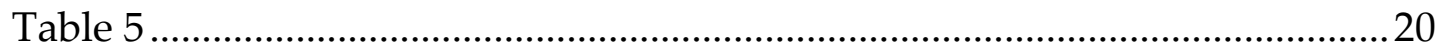

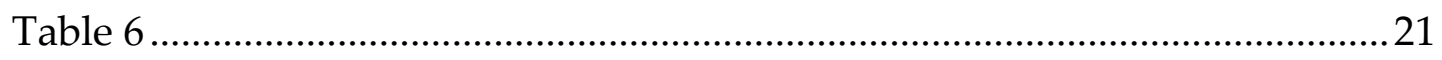

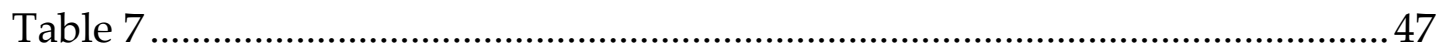

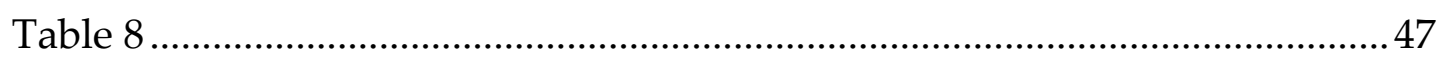

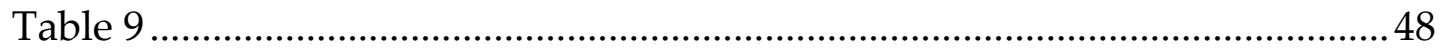

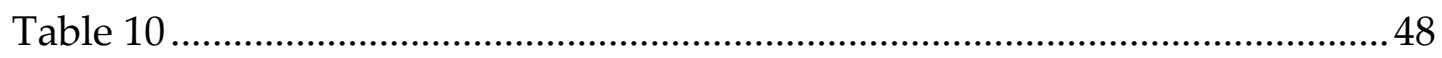

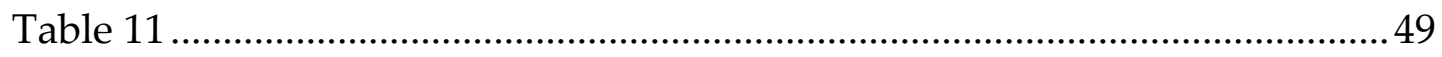

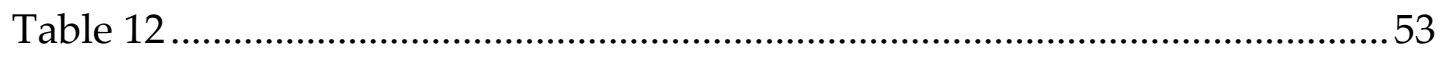

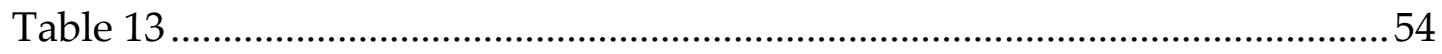

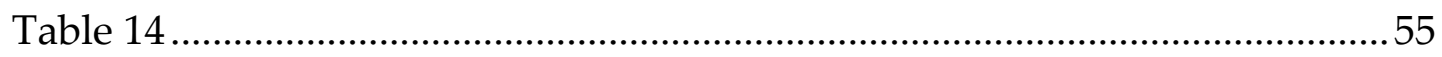

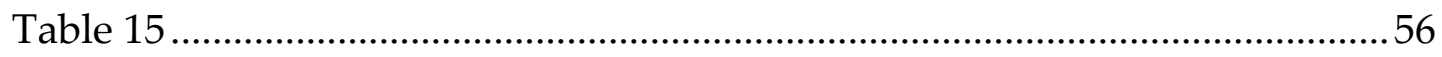

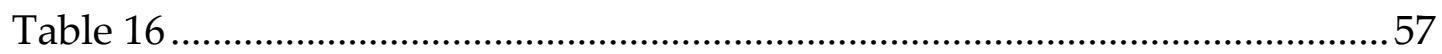

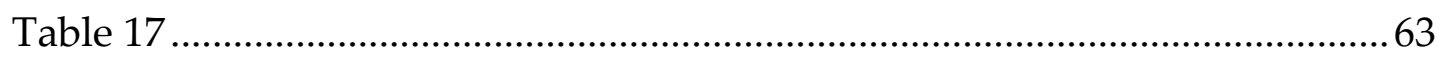

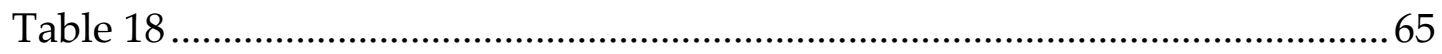

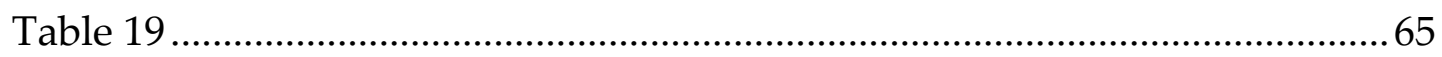

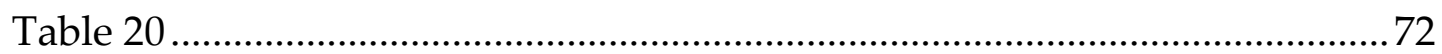

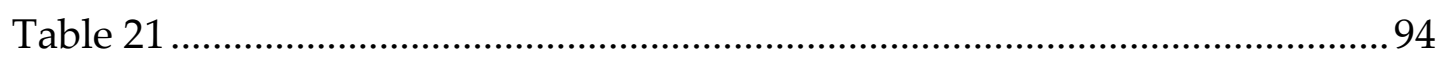

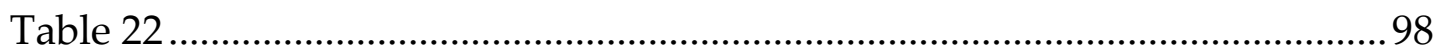

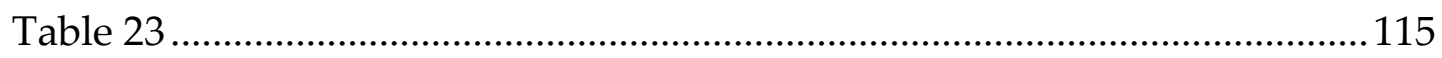

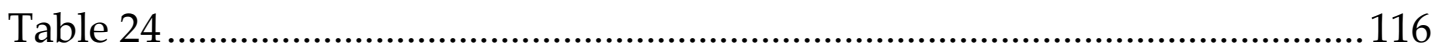




\section{Figures}

Figure 1 - Real Consumption and Income per capita ....................................... 13

Figure 2 - Expected change in Consumption and the Real Interest rate......... 22

Figure 3 - Total value of benefits and pensions payments............................... 33

Figure 4 - Total number of benefits and pension recipients ............................. 34

Figure 5 - Disaggregated total value of Social Welfare payments ....................36

Figure 6 - Disaggregated total number of Social Welfare recipients ................ 36

Figure 7 - NZ Forward looking NKPC fundamental inflation ........................60

Figure 8 - NZ Hybrid NKPC fundamental inflation........................................66

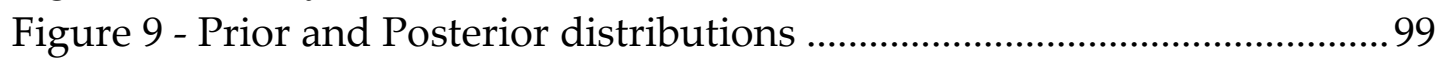

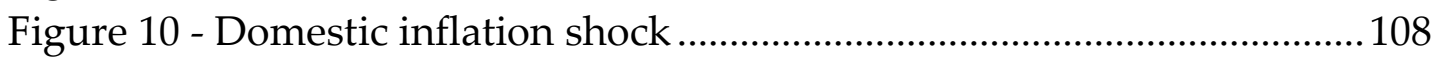

Figure 11 - Domestic interest rate shock ...................................................... 108

Figure 12 - Domestic productivity shock ...................................................... 109

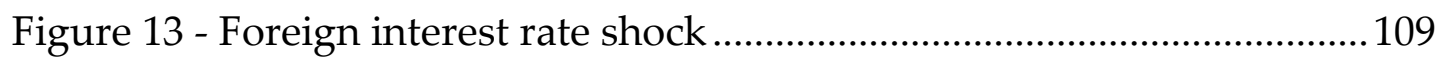

Figure 14 - Foreign output shock ............................................................... 110

Figure 15 - Foreign inflation shock ........................................................... 110

Figure 16 - Gelman and Rubin diagnostic tests ....................................116-117

Figure 17 - Parameter distribution diagnostic ...........................................117 


\section{Introduction}

This dissertation seeks to evaluate how well New Zealand (NZ) data is consistent with permanent income theory from Classical macroeconomics and New Keynesian firm pricing theory

The degree of departure from pure forward looking theory is often called a rule of thumb, and for completeness I use that term throughout this dissertation. The only prior work addressing this issue in NZ was work conducted by Rae (1996) into the validity of the permanent income hypothesis. His work is now considered dated seeing as he used a relatively older dataset. So, an important goal of this dissertation is to update parameter estimates of the degree of departure from classical theory. With respect to estimations of the New Keynesian Phillips Curve (NKPC), an assessment of the New Zealand literature finds no benchmark estimate has been conducted to date. On many occasions the degree of price stickiness (parameter within the NKPC) has been estimated. However none have attempted to estimate whether pure forward looking New Keynesian theory sufficiently describes inflation movements.

In the last decade each of these model specifications have been gradually implemented more regularly in economy wide models. In addition, estimating these models using Metropolis-Hastings algorithms has become more widely accepted. As a result it would be of greater assistance to the targeted literature to estimate the degree of departure from both Classical and New Keynesian theory described above, when these model components interact with other sectors often omitted in smaller scale models. A further method implemented in this dissertation for testing the relevance of 
departure from theory, is to examine impulse response functions when such parameters are restricted. More realistic responses indicate greater relevance of having departure from theory in a particular model.

The parameter estimates obtained vary somewhat according to estimation method. The proportion of rule of thumb consumers is estimated to be 0.21 in the small scale model, and estimates from a small open DSGE economy model of NZ yield a posterior mean of 0.34 . Both estimates are statistically significant, and one can infer rule of thumb consumer behaviour has a larger impact in a general equilibrium framework. The estimated proportion of backward looking (rule of thumb) price setters was estimated and subsequently evaluated at 0.82 using a GMM framework. Posterior mean estimates from the DSGE model came out relatively smaller at 0.7 .

This dissertation is divided into three sections. The first section introduces the permanent income hypothesis and describes a method for obtaining rule of thumb estimates. The next section is devoted to New Keynesian firm pricing theory. Here the NKPC is examined and a Hybrid alternative is evaluated. The last section aims at deriving and estimating a linearised small open economy model of NZ. A full range of diagnostic tests are conducted which seek to evaluate estimated parameters. 
2. The Permanent Income Hypothesis and Rule of Thumb behaviour

This chapter investigates whether there is any aggregate consumer behaviour which deviates from the permanent income hypothesis in NZ. Current income is used as a possible explanation to explain why changes in consumption do not conform to random disturbances. Furthermore, two datasets are used to measure the degree of departure from the permanent income hypothesis. Real interest rates are then incorporated into the model to see whether changes in consumption are affected.

\subsection{State of the literature}

\subsubsection{Evolution of the literature over time}

One interpretation of the permanent income hypothesis of consumption is that households consider their entire lifetime disposable income in deciding the amount to consume today. Until Robert Lucas' famous 1976 paper, it was conventional for econometric practice to use a fixed distributed lag of current and past disposable income to proxy permanent income. Lucas criticized past treatments by arguing there was no theoretical reason why expectations formed by intelligent economic agents about future realisations can be explained by past data. At the time, Lucas' remarks were taken seriously as most derivations originated from intertemporal optimization of expected future economic variables. Under rational expectations Lucas (1976) argued the permanent income hypothesis does not lead to a structural relationship between consumption and income. Instead it was claimed it leads to a statistical relationship that should change when there is a change in the stochastic process generating income. Given this realisation, Lucas (1976) 
subsequently called for estimation methodologies to incorporate both consumption and income. Since then a majority of the literature has attempted to incorporate forward looking permanent income households with rational expectations.

Following Lucas, Hall (1978) developed a simple econometric model to test the permanent income hypothesis under rational expectations. Hall (1978) showed that under certain assumptions only surprises in permanent income should affect current consumption (having controlled for lagged consumption). Furthermore by assuming agents: (i) can freely borrow and lend at the same rate of interest, (ii) form expectations rationally, (iii) have identical, time-separable preferences, with a quadratic or isoelastic instantaneous utility function, and (iv) cannot die in debt Hall shows the marginal utility of consumption behaves close to a first order Markov process.

Hall (1978) attempted to clarify his findings by regressing consumption on lagged consumption and tested whether other lagged variables, such as disposable income and stock indices, had any significant predictive power. Using United States (US) data he found disposable income has no predictive power in the regression of consumption on first lagged consumption and disposable income. The explanation offered by Hall on the relevant slope coefficient is one that was revolutionary and has since encouraged a new range of literature on the subject. Given the coefficient was statistically different from zero, Hall believed the population consists of two groups of households receiving shares of $1-\lambda$ and $\lambda$ of total disposable income. Households of the first group are forward looking and behave according to the lifecycle / permanent income hypotheses, while households in the second 
behave in a rule of thumb fashion and instead spend out of current disposable income because they are liquidity constrained.

Since Hall (1978), several authors have attempted to empirically assess the now established forward looking permanent income hypothesis with rational expectations. The most notable was Sargent (1978) who assumed consumption and disposable income are generated by a bivariate autoregressive process and tested the restrictions implied by the permanent income hypothesis. While the econometric exercise had been done before, it was Sargent's definition of permanent income which set it apart from his predecessors. In his paper, Sargent defines permanent income as the present discounted value of current and future disposable income. Hall's advantage was he managed to avoid explicitly defining permanent income while deriving a testable model.

In response, Flavin (1981) showed a consumption function using Sargent's (1978) definition of permanent income cannot be derived from the household's intertemporal optimisation problem. Flavin's justification was future disposable income includes returns from savings, which should not affect current consumption decisions. Instead, Flavin defines permanent income as a constant multiplied by the sum of human and nonhuman wealth. She also constrained the discount rate for future labour income to equal the rate of return from nonhuman wealth. Only when these conditions were imposed was it shown the consumption function satisfied Hall's random walk equation. As a means to test the validity of the random walk, consumption was regressed on lagged consumption with the addition of an autoregressive process for disposable income. It was subsequently found consumption is more sensitive to current income than predicted by Hall 
(1978). Dornbusch and Fischer (1987) believe this confirms why liquidity constraints are important for understanding consumer spending.

The founding literature investigating the permanent income hypothesis under rational expectations (Hall (1978), Sargent (1978), and Flavin (1981)), stimulated an immense and increasing domain of research into the econometric implications of optimal consumption behaviour. Since the early 1980s, econometric testing of the permanent income hypothesis has taken two distinct directions. The first has been labelled as the Euler equation approach by Cushing (1992) which has been employed in recent times by Hansen and Singleton (1982, 1983), Nelson (1987), Campbell and Mankiw $(1989,1990)$, Weber $(2000,2002)$, and Gomes and Issler (2006). The common approach by this group follows Hall (1978) by testing the unpredictability of changes in aggregate consumption. The other approach attempts to examine the permanent income hypothesis from a different view point. Hall and Mishkin (1982), West (1988), Deaton (1987), and Quah (1990) tended to focus on innovations in disposable income and examine the volatility of consumption implied by the permanent income hypothesis. Campbell (1987) researched the implications of permanent income theory for savings behaviour, while Campbell and Deaton (1989) and West (1988) followed Deaton (1987) and looked at the theory's implications for the smoothness (the standard deviation of the change) of consumption.

While these publications argue only some of the qualitative implications of the model are fulfilled, it is widely found consumption appears to be too smooth. This finding contrasts to that documented by Flavin (1981) who found consumption moved excessively, relative to changes in income. Furthermore, given the smoothness of consumption Campbell and Deaton 
(1989) and West (1988) found weak evidence savings moves too little to be consistent with the theory. While the papers cited differ in terms of implemented variables and econometric methods, each relate in some form to Hall's (1978) random walk model. Rejection of his version of the permanent income hypothesis (given the excess smoothness and excess sensitivity conclusions) has also been believed to rest on the failure of the crucial assumption that the real rate of interest is constant. Research by Michener (1984) using US data showed how time variation in the real interest rate can make consumption appear excessively sensitive to income. This result was confirmed even when agents optimise intertemporally in the absence of borrowing constraints.

\subsubsection{New Zealand Literature}

Unlike the US, research addressing the issues discussed to this point with a $\mathrm{NZ}$ focus is very rare. The most recent independent work in this area is provided by Rae (1996). In his model rule of thumb consumers and forward looking consumers are incorporated into a consumption function similar to that of Campbell and Mankiw (1989). Letting $C_{1}$ represent consumption by forward looking consumers and $C_{2}$ consumption of rule of thumb consumers, Rae (1996) imposed the following structural equations to describe the development of consumption within these groups:

$$
\begin{gathered}
\log \left(C_{1}\right)=\beta E(\log (Y L A B))+(1-\beta) E(\log (\text { WLTH }))-\gamma r+\text { const } \\
\log \left(C_{2}\right)=\log (Y L A B)+\text { const }
\end{gathered}
$$

YLAB represents real labour income which is defined by Rae (1996) as the sum of compensation of employees and social welfare payments (after tax) less lump sum taxes on households. WLTH represents real net wealth which includes financial assets (M0), private sector holdings of government bonds, 
and the private sectors net foreign debt level. As for the parameters, $\beta$ represents a weighting between real labour income and real net wealth, and $\gamma$ measures the elasticity of consumption to a change real interest rates. The consumption function which encompasses both types of consumers, where $\alpha$ measures the proportion of income which accrues to rule of thumb consumers, is as follows:

$$
\log (C O N)=(1-\alpha) \log \left(C_{1}\right)+\alpha \log \left(C_{2}\right)
$$

Estimation of this three equation system by generalised method of moments found $\alpha=0.2286$ with a standard error of 0.06 , and $\gamma=0.00451$ with a standard error of 0.0015 . The hypothesis of a pure forward looking model $(\alpha=0)$ was strongly rejected, as was a test of a pure rule of thumb model

$(\alpha=1)$. The length of the data is hard to determine upon examination of Rae's paper as he indicates many of the variables he incorporated came from different sources. However he claimed most series start in 1965 and all before 1978 and end at 1993:Q4. Contrasting to research in other countries all data was seasonally adjusted. Given New Zealand has a large agriculture sector, Rae (1996) claims seasonality is an important characteristic which must be controlled for.

\subsection{Methodology}

My procedure for estimating whether NZ data is consistent with this theoretical proposition is the same as that implemented by Campbell and Mankiw $(1989,1990)$. The model will be estimated using two approaches used in the literature. The first will estimate equation (1) below using Instrumental Variable (IV) Least Squares estimation, while the second estimates the first stage regression of the first approach. The first approach follows Campbell and Mankiw, who estimate a conjoint model in which the 
permanent income hypothesis is incorporated into a model of two living representative agents. In this model some fraction, $\lambda$, accrues to agents who consume out of current income (commonly known as rule of thumb households), and the remainder $1-\lambda$ accrues to those who are forward looking and thus consume out of their lifetime wealth. Hence if the two income groups are $Y_{1 t}$ and $Y_{2 t}$ respectively then total income is simply $Y_{t}=Y_{1 t}+Y_{2 t}$. Given rule of thumb consumers receive $\lambda$ of total income we can simplify further, whereby $Y_{1 t}=\lambda Y_{t}$ and $Y_{2 t}=(1-\lambda) Y_{t}$. Since rule of thumb agents consume out of current income, $C_{1 t}=Y_{1 t}$. As a result of these deductions we can obtain a statement identifying the change in aggregate consumption:

$\Delta C_{t}=\Delta C_{1 t}+\Delta C_{2 t}=\lambda \Delta Y_{t}+(1-\lambda) \varepsilon_{t}$

Under the alternative hypothesis the change in consumption is a weighted average of changes in current income and random disturbances. As a special case equation (1) reduces to the permanent income hypothesis when $\lambda=0$. The benefit of using this particular model is it is relatively simple to estimate $\lambda$ and test whether $\lambda=0$. However one cannot use Ordinary Least Squares (OLS) since the error component may be correlated with changes in income. Instead I use IV estimation. By definition of the approach, ideal instruments must be correlated with $\Delta Y_{t}$ but independent from $\Delta C_{t}$.

The second approach which will be adopted to test the permanent income hypothesis is that pioneered by Hall (1978). In his paper, Hall regresses the change in consumption on relevant instruments to see whether changes in consumption can be explained. The two approaches are equivalent as Hall's method is essentially the first stage regression of the procedure implemented 
in IV estimation. If we consider having $k$ instruments represented by variables $X_{k}$ then Hall's system of equations is:

$\Delta C_{t}=\gamma_{0}+\gamma_{1} X_{1, t}+\ldots+\gamma_{k} X_{k, t}=X_{t} \Gamma+\xi_{c, t}$

$\Delta Y_{t}=\theta_{0}+\theta_{1} X_{1, t}+\ldots+\theta_{k} X_{k, t}=X_{t} \Theta+\xi_{y, t}$

The permanent income hypothesis implies the vector $\Gamma=0$. This can be tested by OLS. When there are multiple instruments, equation (1) places over identifying restrictions on the prior two equation system and thus the vectors $\Gamma$ and $\Theta$ are proportional to each other. The test of whether $\lambda=0$ is essentially a test of $\Gamma=0$ under the assumption that over identifying restrictions hold.

The reason for producing two different approaches is a matter of dealing with the issue regarding power of tests. Since the reduced form equations may contain many instruments, IV estimation is often preferred as it conserves degrees of freedom which raises the power of testing restrictions. The method I have adopted to test the over identifying restrictions is by regressing the residuals from IV estimation on the instruments. The test statistic is to compare T. $R^{2}$ (sample size $\times$ regression squared coefficient), which is distributed $\chi^{2}$ with $K-1$ degrees of freedom.

\subsection{Specification Issues}

Recently the permanent income hypothesis has been tested using consumption of only non durables and services. The assumption underlying this choice is forward looking households have a utility function that is separable between durables and non durables. However the adoption of this assumption causes two issues. Unless the data is rescaled, $\lambda$ can no longer be interpreted as the fraction of income allocated to current income consumers. 
Furthermore, the difference between consumption and income will become nonstationary. Campbell and Mankiw (1990) avoid this by multiplying nondurables and services by the mean ratio of total consumption expenditure to nondurables and services expenditure. This rescaling method preserves the original interpretation of $\lambda$, although affects statistical tests when savings $\left(C_{t}-Y_{t}\right)$ are used as an instrument.

Campbell and Mankiw (1989) suggest using raw series of $C_{t}$ and $Y_{t}$ is inappropriate as often aggregate time series appear log linear as opposed to linear. As a means to correct this they take logarithms of each variable. Another approach which has been used by Campbell and Deaton (1989) is to divide $\Delta C_{t}$ and $\Delta Y_{t}$ by $Y_{t-1}$. Both methods are used in the estimation of equation (1).

For most OECD countries, consumption and income are measured as quarterly averages as opposed to at points in time. NZ data are expressed as quarterly flow variables which are an accumulation of points. The main question lies in whether discrete time series data can approximate continuous time? Accepting this assumption, if the permanent income hypothesis holds in continuous time then the change in consumption will be serially correlated. If we do not correct our instruments serial correlation could lead to false rejection of the model. Therefore by lagging instruments by two or more periods the time average of a continuous time random walk is uncorrelated with all lagged variables (Campbell and Mankiw, 1989).

\subsection{Data}

To estimate the model devised in Campbell and Mankiw $(1989,1990)$ I have used two different datasets which cover the period 1991:Q1 to 2008:Q4. The 
first is constructed in the spirit of Rae (1996). Since there is no direct measure of labour income in New Zealand I employed a proxy in the form of the average hourly wage across all recognised New Zealand industries (within the ANZSIC classification) multiplied by the average weekly hours of work. This data is available on a quarterly basis from Statistics New Zealand and provides an estimate of average weekly earnings. So as to obtain quarterly estimates I simply multiplied by 12 which is based on the assumption there are four weeks in a month. In addition to Labour Income, Rae (1996) includes a measure of after tax Social Welfare. The problem with using this approach is this particular data is only reported on an annual basis and since the Department of Social Welfare no longer exists it has not been reported on since 2007. Annual data for the components of Social Welfare expenditure and the number of Social Welfare recipients (total and per sub group) were reported at each June quarter between 1990 and 2007. Data for the value and number of recipients of National Superannuation, Invalidity Benefits, Widows' Benefits, Sickness Benefits, Orphans' Benefits, Veterans' Pensions, Domestic Purposes Benefit, and Unemployment Benefits were used as a proxy for Social Welfare. The full method of obtaining quarterly estimates can be found in Appendix 2.1.

Using the estimated quarterly series one can obtain a measure of nominal Total Income per capita by adding Labour Income per capita and Social Welfare payments per capita. After tax Total Income is obtained by assuming a constant marginal income tax rate of $30 \%$. In order to obtain an estimate of Real Income per capita and Real Consumption of non durables and services per capita I adjusted the data using the National Expenditure deflator with a base year of 2000:Q1. This deflator was chosen because its movements are related to both income and consumption. The National Expenditure deflator 
is reported by Statistics New Zealand on a quarterly basis. So as to seasonally adjust the data I employed TRAMO (Time Series Regression with ARIMA Noise, Missing Observations and Outliers) and SEATS (Signal Extraction in ARIMA Time Series). TRAMO is a program for estimation and forecasting of regression models with possibly nonstationary ARIMA errors and any sequence of missing values. SEATS is a program for estimation of unobserved components in time series following ARIMA processes. The trend-cycle, seasonal, irregular and transitory components are estimated and forecasted with signal extraction techniques applied to ARIMA models. Figure 1 below shows both real seasonally adjusted series and their unadjusted counterparts of Total Income (after tax) and Consumption of nondurables and services (adjusted as per Campbell and Mankiw (1989, 1990)).

Figure 1 - Real Consumption and Income per capita

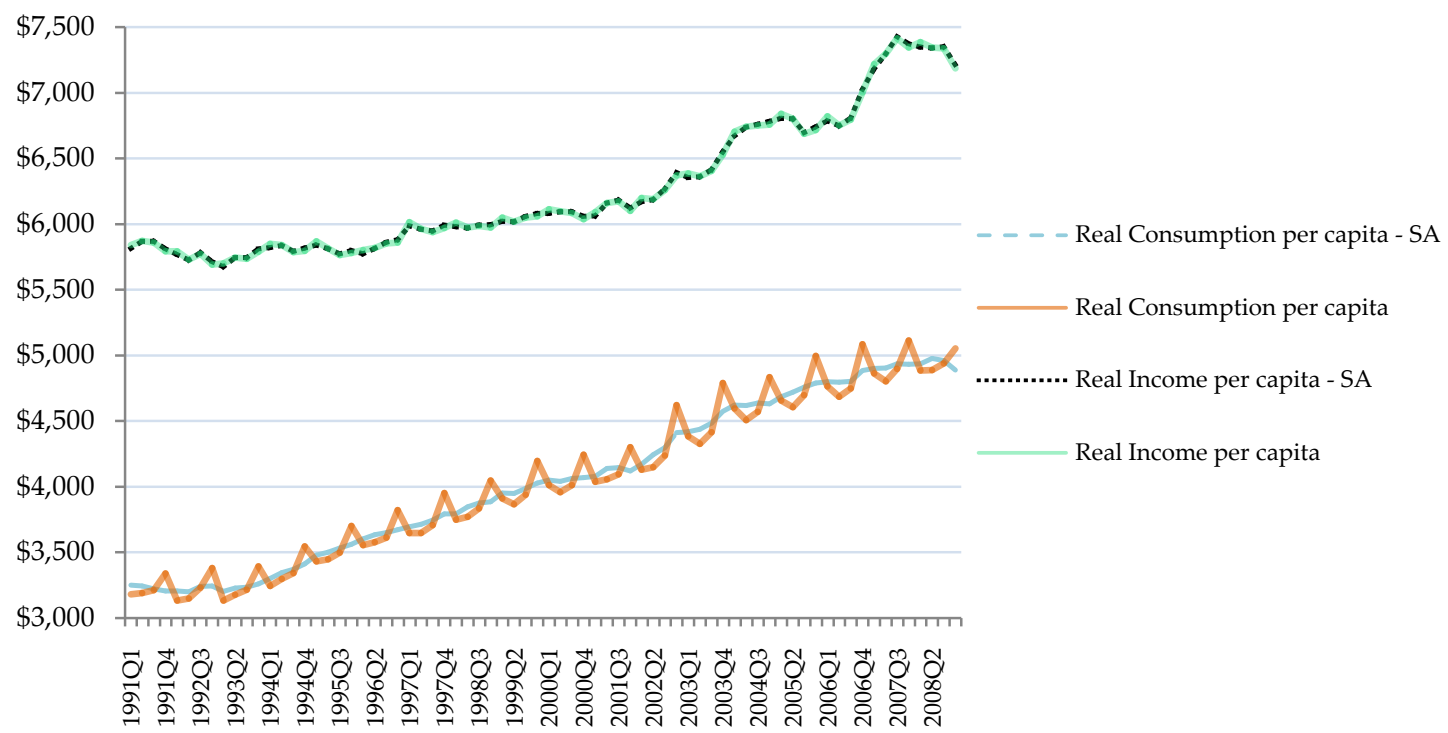

The second dataset relies upon disaggregating Household Disposable Income as a proxy for Aggregate Disposable Income. This data is publicly 
accessible from Statistics New Zealand. The origin of this series comes from Treasury New Zealand's Long Term Database. Per capita estimates are obtained by dividing each individual value by the estimated resident population of New Zealand. Statistics New Zealand defines this as New Zealand residents currently in New Zealand plus those temporarily overseas. Overseas tourists visiting New Zealand are excluded from this measure.

The nominal interest rate used in this model was the quarterly 90 Day Treasury Bill rate. In order to obtain after tax returns I assume a constant Resident Withholding Tax Rate of 19\%, that which was current in April 2009. I obtained a measure of the real interest rate by using Fisher's hypothesis, which states the real interest rate equals the nominal interest rate minus inflation.

\subsection{Estimation}

Results are reported according to the dataset to which they relate followed by a discussion of results. As discussed previously dataset 1 relates to the manually calculated series of seasonally adjusted Real Labour Income and Real Consumption of Non Durables and Services relative to a base year of 2000:Q1. Dataset 2 differs only by the use of disaggregated Household Disposable Income instead of my constructed series. The sample period covers the interval 1991:Q1 to 2008:Q4. This time period was chosen so as to avoid any influence of structural breaks in the data caused by the inauguration of the Reserve Bank Act 1989 and Recession in New Zealand between 1990 and 1991. 


\subsubsection{Rule of thumb consumers}

In this section I estimate Campbell and Mankiw's model by taking logs of all variables. Logs are denoted by the use of lower case letters. One can also scale the data by dividing $\Delta C_{t}$ and $\Delta Y_{t}$ by $Y_{t-1}$, however I only report estimates by log approximation as estimates from the scaling method are very similar. Table 2 and Table 3 below report results from dataset 1 and 2 respectively. Each of the results are given according to the set of instrumental variables used in estimation. For both first stage regressions the adjusted $R^{2}$ for OLS regressions are provided with the $\mathrm{p}$-value for a joint hypothesis test that all coefficients except the intercept are zero in the parenthesis. The fourth column reports the instrumental variable estimate of $\lambda$ with its $p$-value. The fifth column reports the critical value for a test of over identifying restrictions, while the parenthesis reports the p-value under the null hypothesis that all coefficients are zero. The purpose of this test is to consider the possibility the permanent income hypothesis fails because rule of thumb behaviour adequately explains consumption behaviour. Instruments which make up each respective set are shown in Table 1 below:

Table 1

\begin{tabular}{ll}
\hline Instrument Set & Instruments \\
\hline A & $\Delta y_{t-2}, \Delta y_{t-3}, \Delta y_{t-4}$ \\
B & $\Delta y_{t-2}, \Delta y_{t-3}, \Delta y_{t-4}, \Delta y_{t-5}, \Delta y_{t-6}$ \\
C & $\Delta c_{t-2}, \Delta c_{t-3}, \Delta c_{t-4}$ \\
D & $\Delta c_{t-2}, \Delta c_{t-3}, \Delta c_{t-4}, \Delta c_{t-5}, \Delta c_{t-6}$ \\
E & $\Delta i_{t-2}, \Delta i_{t-3}, \Delta i_{t-4}$ \\
F & $\Delta i_{t-2}, \Delta i_{t-3}, \Delta i_{t-4}, \Delta i_{t-5}, \Delta i_{t-6}$ \\
G & $\Delta y_{t-2}, \Delta y_{t-3}, \Delta y_{t-4}, \Delta c_{t-2}, \Delta c_{t-3}, \Delta c_{t-4}$ \\
H & $\Delta y_{t-2}, \Delta y_{t-3}, \Delta y_{t-4}, \Delta c_{t-2}, \Delta c_{t-3}, \Delta c_{t-4}, \Delta i_{t-2}, \Delta i_{t-3}, \Delta i_{t-4}$ \\
\hline
\end{tabular}


Table 2

\begin{tabular}{|c|c|c|c|c|}
\hline \multirow[b]{2}{*}{$\begin{array}{c}\text { Instrument } \\
\text { Set }\end{array}$} & \multicolumn{2}{|c|}{$\underline{\text { First-stage regressions }}$} & \multirow[b]{2}{*}{$\lambda$} & \multirow[b]{2}{*}{$\begin{array}{c}\text { Test of } \\
\text { restrictions }\end{array}$} \\
\hline & $\Delta c$ equation & $\Delta y$ equation & & \\
\hline None (OLS) & - & - & $\begin{array}{c}0.247920 \\
(0.2041)\end{array}$ & - \\
\hline A & $\begin{array}{c}-0.015125 \\
(0.5537)\end{array}$ & $\begin{array}{c}-0.196660 \\
(0.2474)\end{array}$ & $\begin{array}{c}0.190627 \\
(0.8002)\end{array}$ & $\begin{array}{c}1.498174 \\
(0.6827)\end{array}$ \\
\hline B & $\begin{array}{c}-0.043062 \\
(0.7668)\end{array}$ & $\begin{array}{c}-0.046760 \\
(0.0182)\end{array}$ & $\begin{array}{c}0.464100 \\
(0.5448)\end{array}$ & $\begin{array}{c}3.014008 \\
(0.6978)\end{array}$ \\
\hline $\mathrm{C}$ & $\begin{array}{c}0.038529 \\
(0.1420)\end{array}$ & $\begin{array}{c}-0.035900 \\
(0.0030)\end{array}$ & $\begin{array}{c}0.293681 \\
(0.6056)\end{array}$ & $\begin{array}{c}4.349627 \\
(0.2261)\end{array}$ \\
\hline $\mathrm{D}$ & $\begin{array}{c}0.021811 \\
(0.2767)\end{array}$ & $\begin{array}{c}-0.023707 \\
(0.0097)\end{array}$ & $\begin{array}{c}0.442185 \\
(0.2553)\end{array}$ & $\begin{array}{c}3.451254 \\
(0.6308)\end{array}$ \\
\hline $\mathrm{E}$ & $\begin{array}{c}0.021684 \\
(0.2259)\end{array}$ & $\begin{array}{c}-0.184866 \\
(0.1901)\end{array}$ & $\begin{array}{r}0.346519 \\
(0.5695)\end{array}$ & $\begin{array}{c}3.663812 \\
(0.3001)\end{array}$ \\
\hline $\mathrm{F}$ & $\begin{array}{c}0.028711 \\
(0.2404)\end{array}$ & $\begin{array}{c}-0.199622 \\
(0.4315)\end{array}$ & $\begin{array}{c}0.529947 \\
(0.1825)\end{array}$ & $\begin{array}{c}6.511508 \\
(0.2596)\end{array}$ \\
\hline G & $\begin{array}{c}0.020962 \\
(0.3064)\end{array}$ & $\begin{array}{c}-0.043824 \\
(0.0151)\end{array}$ & $\begin{array}{c}0.237878 \\
(0.6305)\end{array}$ & $\begin{array}{c}7.169528 \\
(0.3054)\end{array}$ \\
\hline $\mathrm{H}$ & $\begin{array}{c}-0.020620 \\
(0.5671)\end{array}$ & $\begin{array}{c}0.010255 \\
(0.0033)\end{array}$ & $\begin{array}{r}0.229131 \\
(0.5704)\end{array}$ & $\begin{array}{c}11.250179 \\
(0.2589)\end{array}$ \\
\hline
\end{tabular}

Note: The test of the overidentifying restrictions involves regressing the residuals from the

IV regression on the instruments and then comparing $T$ (sample size) multiplied by the $R^{2}$

from the regression. The statistic is distributed $\chi^{2}$ with $k-1$ degrees of freedom.
Table 3

$\Delta c_{y}=\mu+\lambda \Delta y_{t}$

\begin{tabular}{ccccc}
\hline & \multicolumn{2}{c}{ First-stage regressions } & & \\
Instrument & & & & \\
Set & $\Delta c$ equation & $\Delta y$ equation & $\lambda$ & $\begin{array}{c}\text { Test of } \\
\text { restrictions }\end{array}$ \\
\hline None (OLS) & & & & \\
& & & $\mathbf{0 . 2 0 1 9 2 1}$ & - \\
$\mathrm{A}$ & 0.003840 & 0.382132 & 0.186537 & 0.118484 \\
& $(0.3540)$ & $(0.0000)$ & $(0.0544)$ & $(0.9895)$ \\
$\mathrm{B}$ & -0.027160 & 0.408839 & 0.186869 & 0.181863 \\
& $(0.6527)$ & $(0.0000)$ & $(0.0531)$ & $(0.9993)$ \\
$\mathrm{C}$ & -0.007401 & 0.041720 & 0.138533 & 2.337857 \\
& $(0.4726)$ & $(0.0843)$ & $(0.5241)$ & $(0.5053)$ \\
$\mathrm{D}$ & 0.069398 & 0.006539 & $\mathbf{0 . 4 3 6 4 8 0}$ & 4.489554 \\
& $(0.0819)$ & $(0.2282)$ & $\mathbf{( 0 . 0 4 7 2 )}$ & $(0.4813)$ \\
$\mathrm{E}$ & 0.010222 & 0.049636 & 0.351481 & 1.032855 \\
& $(0.2980)$ & $(0.0649)$ & $(0.1046)$ & $(0.7933)$ \\
$\mathrm{F}$ & 0.057038 & 0.064424 & 0.303004 & 5.864955 \\
& $(0.1143)$ & $(0.0506)$ & $(0.0793)$ & $(0.3196)$ \\
$\mathrm{G}$ & 0.076777 & 0.484130 & $\mathbf{0 . 2 0 4 3 3 2}$ & 4.535322 \\
& $(0.0744)$ & $(0.0000)$ & $\mathbf{( 0 . 0 2 0 0 )}$ & $(0.6046)$ \\
$\mathrm{H}$ & 0.083300 & 0.477675 & $\mathbf{0 . 2 1 2 2 4 5}$ & 6.626969 \\
& $(0.0910)$ & $(0.0000)$ & $\mathbf{( 0 . 0 1 3 4 )}$ & $(0.6759)$ \\
\hline
\end{tabular}
$(0.0910)$

(0.0134)

$(0.6759)$ 
A majority of estimates of $\lambda$ from dataset 1 come within the interval of 0.2 to 0.5. However they are statistically insignificant from zero for all sets of instrumental variables. In contrast, three estimates using dataset 2 are statistically significant at a 5\% level of significance with three others marginally above this threshold. Both sets of estimations from the two datasets yield estimates that are similar in size with the exception of differences in statistical significance. One could infer the difference between the two definitions of Household Disposable Income lies in the exclusion of interest income, the smoothness of random events by disaggregation, and the use of average income series in dataset 1 . One is likely to find average wage income may be smoothing out significant deviations in industry specific labour shocks.

Most often the estimated proportion of rule of thumb consumers $(\lambda)$ is statistically significant when lagged income growth rates are used as instruments. Given the volatility of estimates it is difficult to establish a preferred set of instruments. My IV estimation procedure with set $\mathrm{H}$ estimates $\lambda$ at approximately 0.21 and rejects the permanent income hypothesis at the $2 \%$ level of significance. The rejection of the permanent income hypothesis should be treated cautiously, as the IV procedure can be statistically unreliable when the instruments have weak forecasting power. This estimate was chosen because it rejects overidentifying restrictions at a higher probability and has a higher critical value (via t-test) than the estimate under IV set G.

One also notices as more lags of lagged consumption growth are used as instruments (IV set D) I obtain larger estimates of $\lambda$ which are statistically significant at the 5\% level of significance. Campbell and Mankiw (1989) also 
find lagged consumption forecasts income growth more strongly than lagged income itself using US data. One can interpret this as suggesting there are some consumers who have better information in regards to future income growth than in the past. When the 90 day Treasury Bill rate is used as an instrument the magnitude of $\lambda$ increases but is statistically insignificant at the $5 \%$ level of significance. As more lags of quarterly changes to the nominal interest rate are included in the set of IV's, estimates of $\lambda$ tend to decline. As a special case, I estimated $\lambda$ when eight lags of changes to the nominal interest rate are used as instruments. Here the estimate of $\lambda$ equalled 0.25 (very close to Rae (1996) estimate of 0.24 ) which is statistically significant at the $5 \%$ level of significance. One could view this result as signalling the importance of term structure of interest rates in forming consumption decisions.

\subsubsection{Consumption and the real interest rate}

Hall's (1978) random walk theorem for consumption growth relies upon the assumption that the real interest rate is constant. In this section we relax that assumption. Campbell and Mankiw (1989) consider this particular extension as they believed the failure of the permanent income hypothesis may have been attributable to a failure of this assumption. Furthermore, this testing procedure enables me to compute a measure of the intertemporal elasticity of substitution both with and without rule of thumb consumers.

Campbell and Mankiw (1989) generalise their Euler equation with rule of thumb consumers to allow for changes in the real interest rate. The log linearised version is as follows: 
$\Delta c_{t}=\mu+\lambda \Delta y_{t}+v r_{t}+\varepsilon_{t}$

where $v=(1-\lambda) \sigma$

Equation (3) states that high real interest rates should be associated with greater growth rates in consumption. The intertemporal elasticity of substitution is represented by the coefficient $\sigma$. Results obtained using dataset 1 and 2 are presented below in Table 4 and Table 5 respectively. The list of instrumental variables used the estimation of equation 3 are shown in Table 6. 
Table 4

\begin{tabular}{ccccccc}
\hline \multirow{6}{c}{$\begin{array}{c}\text { Instrument } \\
\text { Set }\end{array}$} & $\begin{array}{c}\Delta c \\
\text { equation }\end{array}$ & $\begin{array}{c}\Delta y \\
\text { equation }\end{array}$ & $\begin{array}{c}r \\
\text { equation }\end{array}$ & $\lambda$ & $\sigma$ & $\begin{array}{c}\text { Test of } \\
\text { restrictions }\end{array}$ \\
\hline None & - & - & - & 0.1724 & $1.58 \mathrm{e}-4$ & - \\
(OLS) & & & & $(0.1249)$ & $(0.8065)$ & \\
A & -0.01952 & 0.02012 & 0.2922 & 0.4183 & $-3.13 \mathrm{e}-4$ & 4.412 \\
& $(0.5780)$ & $(0.2199)$ & $(0.0000)$ & $(0.2723)$ & $(0.8540)$ & $(0.6213)$ \\
B & 0.06206 & -0.03939 & 0.2654 & 0.6728 & $1.941 \mathrm{e}-3$ & 9.790 \\
& $(0.1100)$ & $(0.8664)$ & $(0.0000)$ & $(0.2287)$ & $(0.6466)$ & $(0.1338)$ \\
C & -0.03616 & -0.01562 & 0.3015 & 0.4111 & $4.09 \mathrm{e}-4$ & 6.995 \\
& $\oplus(0.7176)$ & $(0.4437)$ & $(0.00000)$ & $(0.4029)$ & $(0.8383)$ & $(0.3213)$ \\
D & -0.006756 & -0.05392 & -0.9437 & 0.3685 & $1.896 \mathrm{e}-3$ & 11.39 \\
& $(0.4746)$ & $(0.7584)$ & $(0.0000)$ & $(0.4109)$ & $(0.5560)$ & $(0.0770)$ \\
E & -0.03292 & -0.02698 & 0.4501 & 0.4597 & $8.35 \mathrm{e}-4$ & 46.07 \\
& $(0.6479)$ & $(0.5661)$ & $(0.0000)$ & $(0.2050)$ & $(0.6524)$ & $(0.0000)$ \\
\hline
\end{tabular}

Table 5

$\Delta c_{y}=\mu+\lambda \Delta y_{t}$

\begin{tabular}{|c|c|c|c|c|c|c|}
\hline \multirow[b]{2}{*}{$\begin{array}{l}\text { Instrument } \\
\text { Set }\end{array}$} & \multicolumn{4}{|c|}{ First-stage regressions } & \multirow[b]{2}{*}{$\sigma$} & \multirow[b]{2}{*}{$\begin{array}{c}\text { Test of } \\
\text { restrictions }\end{array}$} \\
\hline & $\begin{array}{c}\Delta c \\
\text { equation }\end{array}$ & $\begin{array}{c}\Delta y \\
\text { equation }\end{array}$ & $\begin{array}{c}r \\
\text { equation }\end{array}$ & $\lambda$ & & \\
\hline None & - & - & - & 0.2066 & -0.000303 & - \\
\hline (OLS) & & & & $(0.0039)$ & $(0.6282)$ & \\
\hline \multirow[t]{2}{*}{ A } & 0.01857 & 0.5125 & 0.3304 & 0.2353 & -0.000409 & 1.135 \\
\hline & $(0.2985)$ & $(0.0000)$ & $(0.0000)$ & $(0.0126)$ & $(0.6607)$ & $(0.9800)$ \\
\hline \multirow[t]{2}{*}{ B } & -0.02561 & 0.05717 & 0.4700 & 0.1951 & $-5.00 e-5$ & 3.592 \\
\hline & $(0.6292)$ & $(0.0948)$ & $(0.0000)$ & $(0.2614)$ & $(0.9555)$ & $(0.7317)$ \\
\hline \multirow[t]{2}{*}{ C } & 0.007311 & -0.001072 & 0.3015 & 0.2285 & -0.001145 & 3.127 \\
\hline & $(0.0007)$ & $(0.5065)$ & $(0.0000)$ & $(0.3227)$ & $(0.1875)$ & $(0.7927)$ \\
\hline \multirow[t]{2}{*}{$\mathrm{D}$} & 0.07678 & 0.484130 & -1.501 & 0.1892 & 0.001313 & 3.743 \\
\hline & $(0.0744)$ & $(0.0000)$ & $(0.0000)$ & $(0.0469)$ & $(0.4835)$ & $(0.7114)$ \\
\hline \multirow[t]{2}{*}{$\mathrm{E}$} & 0.004991 & 0.5535 & 0.4640 & 0.2014 & $-7.49 e-5$ & 4.092 \\
\hline & $(0.4073)$ & $(0.0000)$ & $(0.0000)$ & $(0.0196)$ & $(0.9308)$ & $(0.9053)$ \\
\hline
\end{tabular}


Table 6

\begin{tabular}{ll}
\hline Instrument Set & Instruments \\
\hline A & $\Delta y_{t-2}, \Delta y_{t-3}, \Delta y_{t-4}, r_{t-2}, r_{t-3}, r_{t-4}$ \\
B & $\Delta c_{t-2}, \Delta c_{t-3}, \Delta c_{t-4}, r_{t-2}, r_{t-3}, r_{t-4}$ \\
C & $\Delta i_{t-2}, \Delta i_{t-3}, \Delta i_{t-4}, r_{t-2}, r_{t-3}, r_{t-4}$ \\
D & $\Delta c_{t-2}, \Delta c_{t-3}, \Delta c_{t-4}, \Delta y_{t-2}, \Delta y_{t-3}, \Delta y_{t-4}$ \\
E & $\Delta c_{t-2}, \Delta c_{t-3}, \Delta c_{t-4}, \Delta y_{t-2}, \Delta y_{t-3}, \Delta y_{t-4}, r_{t-2}, r_{t-3}, r_{t-4}$ \\
\hline
\end{tabular}

The main difference between the estimates of structural parameters between dataset 1 and dataset 2 lies in the size and statistical significance of $\lambda$. As with the estimates of $\lambda$ in section 1.5.1, none of the estimates are statistically significant from zero at a $5 \%$ level of significance using dataset 1 . In contrast three out of the five sets of instruments yield estimates of $\lambda$ that are statistically different from zero at a 5\% level of significance. Henceforth my discussion relates only to the estimates from dataset 2 .

The central finding using dataset 2 is that the proportion of rule of thumb consumers in New Zealand is unaffected by allowing for the real interest rate to change over time. By allowing real interest rates to vary with time I have obtained a measure of $\lambda$ which is more refined and statistically significant from zero. The implication of this result is there is no evidence the ex ante real interest rate is associated with the growth rate of consumption after allowing for rule of thumb consumers. This is because $\sigma$ estimates are consistently statistically insignificant from zero. A small estimated coefficient on the real interest rate indicates the intertemporal elasticity of substitution for forward looking consumers is very small. This conclusion is consistent as there is no evidence of any misspecification of the instrumental variables used in estimation. 
Figure 2 illustrates the finding of a small elasticity of substitution by plotting the expected change in consumption and the expected real interest rate for forward looking consumers assuming $\lambda=0.21$. If one recalls this estimate was the one recommended from section 1.5.1. No estimates from this section were chosen given the inclusion of real interest rates does not improve the estimation of rule of thumb consumers.

Figure 2 - Expected change in Consumption and the Real Interest rate

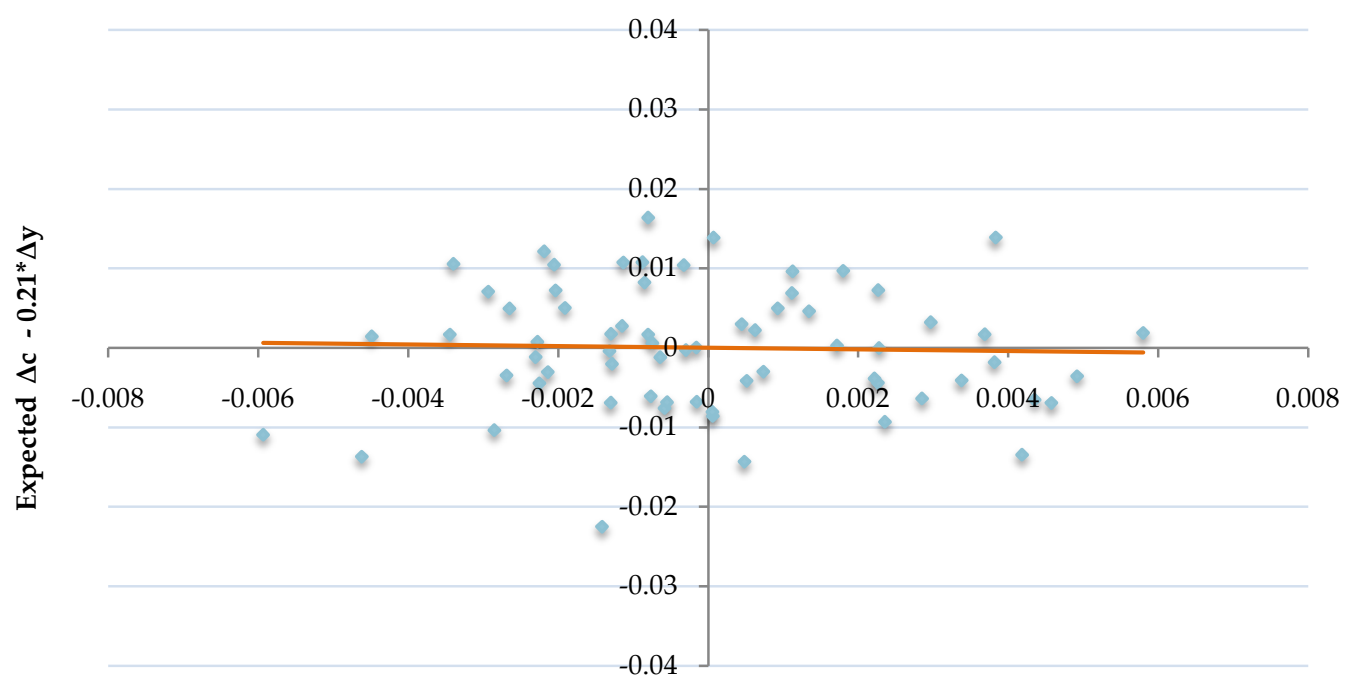

Expected Real Interest Rate

Figure 2 regresses $\Delta c_{t}-0.21 \Delta y_{t}$ on $r_{t}$ using the following instruments; $r_{t-2}, r_{t-3}, r_{t-4}, \Delta c_{t-2}, \Delta c_{t-3}, \Delta c_{t-4}, \Delta i_{t-2}, \Delta i_{t-3}$, and $\Delta i_{t-4}$. The fitted values from each regression form estimates of the expected change in consumption and the expected real interest rate. Upon examination of figure 2 one finds the fitted values lie almost along a horizontal line, as required for an intertemporal elasticity close to zero.

In this section I find that the real interest rate is not associated with changes in consumption. As a result predictable movements in consumption cannot 
be explained as a response to movements in real interest rates. A direct consequence is the intertemporal elasticity of substitution of consumption is insignificant from zero. When this elasticity is close to zero consumers are unwilling to substitute consumption across time periods.

\subsection{Critique}

\subsubsection{Theoretical critique}

While the permanent income / lifecycle model constitutes the most flexible modelling structure, there is no consensus reached by economists as to its empirical relevance. As we have seen from the derivation of Campbell and Mankiw's permanent income model; agents are set in what Attanasio (1995) calls an empty box which gives the researcher freedom to impose assumptions about preferences, expectations, and other key defining characteristics. A fundamental drawback with this approach has been a lack of agreement in regards to preference specifications that are necessary to describe agent behaviour .

The main theoretical criticism of my approach relates to a label that has been attached to the rule of thumb modelling approach. It has been widely interpreted that rule of thumb consumers, those who consume out of current income, are liquidity constrained. In response to these claims Attanasio (1995) investigated whether liquidity constraints are capable of explaining deviations from the permanent income hypothesis. He begins by employing two definitions of liquidity constraints to begin his argument. According to his first definition an agent who is liquidity constrained is unable to borrow against future earnings beyond a certain limit. His second definition is somewhat weaker in that it is where an agent faces borrowing and lending 
interest rates that are not independent of their net asset position. In this case, the interest rate used to discount future marginal utility is subject to the behaviour of the agent. As an example, the discount rate for a borrower is at a relevant borrowing rate and the same for a lender. Therefore to say that there exists a portion of the population that are liquidity constrained can be misleading as one is essentially trying to capture a variety of discount rates and preferences.

Campbell and Mankiw $(1989,1990)$ find there is a great deal of correlation in their dataset with respect to expected consumption and income. The presence of liquidity constraints has been appealed to as a possible explanation for this anomaly. However under rational behaviour, Attanasio (1995) suggests there is no reason to expect an increase in disposable income would be fully reflected as an increase in consumption in the presence of liquidity constraints. For this to be true, these constraints must be binding. According to Attanasio's first definition of a liquidity constraint; agents must want to consume more than they earn in order to run down their net asset positions. Under the second definition agents must have no holdings in assets. Only when these conditions have been met will liquidity constrained individuals consume their current disposable income. However this does not imply that if liquidity constraints are not binding consumption is unaffected. Hayashi (1987) argues the expectation of a future binding liquidity constraint with no borrowing is equivalent to shortening households planning horizon. It has been shown that these effects cancel out when one considers first differences of discounted marginal utilities, with the exception for periods where liquidity constraints are binding. As a result of this finding it is very difficult to econometrically verify the presence of liquidity constraints using the Euler equation approach. 
Attanasio (1995) concludes his theoretical argument by presenting a series of key points which relate to recent applied work and a theoretical model he derives in his paper. Firstly, in the presence of binding liquidity constraints some individuals will be unable to smooth consumption over time. As a result there is no stable relationship between changes in current aggregate disposable income and consumption. At the very least this point confirms rule of thumb consumers are thought to exist. His second major point suggests liquidity constraints affect changes in consumption only when they are binding. The level of consumption will be affected by constraints which are not presently bound, although the magnitude of a given shock to consumption will be affected by the degree of binding.

Attanasio (1995) proposes that the effect of liquidity constraints depends on the dynamic behaviour of the agents earning profile and intertemporal preferences. Carroll (1992) suggests consumers with a strong precautionary motive may have an additional incentive to save by the impossibility to borrow in the event of a negative shock in the future. One could also consider impulsive agents are more likely to be liquidity constrained as they spend a very small period of their existence allocating resources to maximise their utility, while the remainder of their life is spent allocating consumption to satisfy their budget constraint. Impatience prevents agents from accumulating excessive amounts of wealth; while a prudent agent prevents them from having very low amounts of wealth. Given the previous argument one could consider liquidity constraints depend on the degree of impatience, variability of idiosyncratic shocks, and types of assets available for self insurance. 
Many of the most influential empirical papers discussed thus far (including Hall (1978), Flavin (1981), Hansen and Singleton (1982), Hayashi (1982), Mankiw, Rotemberg, and Summers (1985), Campbell (1987), Hall (1988), and Campbell and Mankiw $(1989,1990))$ have used aggregate time series data to test the implications of the permanent income / lifecycle hypothesis. The common assumption of with all of the cited papers is that a representative consumer maximises expected utility over a given time period.

As we have seen from my analysis Campbell and Mankiw (1989) regress aggregate consumption growth on aggregate income growth and real interest rates and interpret the coefficient on income growth as the fraction of individuals subject to liquidity constraints. The model is justified by assuming: (i) consumption and leisure are separable in the utility function, (ii) the fraction of consumers who are liquidity constrained is constant over time, and (iii) liquidity constrained individuals always consume their labour income, irrespective of overall economic conditions. Given none of these conditions are realistic or plausible, Attanasio (1995) suggests the empirical methodology of Campbell and Mankiw (1989) leaves much to be desired. It is claimed it is not easy to test for the presence of liquidity constraints as aggregation issues preclude the use of aggregate time series data. Attanasio (1995) refers to work conducted by Dolde (1971) and Flemming (1973) who have suggested one must evaluate the distributional effects of various types of shocks and the composition of the population, in assessing the effect of liquidity constraints when aggregate consumption reacts to changes in income.

Attanasio (1995) presents a series of arguments which look at the theoretical and empirical issues which face researchers in measuring the effects of liquidity constraints. He believes it is particularly difficult to test hypotheses 
about the assets available to an individual using either microeconomic or macroeconomic data. When evaluating the relevance of liquidity constraints one is also attempting to assess the opportunity set available to agents in an intertemporal optimisation problem. What we have learned up to this point is that in order to derive a testable framework one needs extremely strong and near untestable identification assumptions. In addition, one needs an extremely rich dataset to be able to say anything useful on these issues. Overall these suggestions cast doubt into being able to explain, with any clarity, behaviour which deviates permanent income theory.

\subsubsection{Econometric critique}

Hall and Mishkin (1982) were the first to estimate an empirical model of consumption in which a constant fraction of disposable income is allocated to households that follow the simple rule of thumb of consuming all current income. Since then numerous authors have estimated similar models in which liquidity constrained households coexist with conventional forward looking consumers. A majority of research has used log linear Euler equations as opposed to estimating Euler equations in their original non linear form.

Weber $(2000,2002)$ identifies two main misspecification issues, one of which has already been acknowledged by Campbell and Mankiw (1989). Firstly, one is unable to interpret $\lambda$ as the proportion of disposable income allocated to those who consume out of current income without correcting income and consumption data. If one recalls $\lambda$ will retain its interpretation if the Euler equation were specified in differences of levels as opposed to differences of logs (Weber, 2000). Because of this, the literature has started to move away 
from estimating log linear specifications of Euler equations. The second issue Weber (2000) discusses relates to the inclusion of other regressors in a log linear Euler equation regression. He believes when the net real interest rate and income growth are regressed with other variables, it unnecessarily combines the intertemporal elasticity of substitution and coefficient of risk aversion in a single coefficient. This becomes inconsistent with theory as it is required a permanent income agent's relative risk aversion coefficient must equal the reciprocal of its intertemporal elasticity of substitution. Otherwise the log linear Euler equation, such as the one estimated by Campbell and Mankiw $(1989,1990)$, is misspecified.

In Weber's 2002 paper he aims to generalize the rule of thumb model employed by Cushing (1992) to permit intertemporal nonseparability in the representative household's preferences. Weber's (2002) approach extends the approach taken by Cushing (1992) by: (i) allowing the expected real interest rate to vary through time, and (ii) follow the recommendations of Lewbel (1987) and Cushing (1992) to experiment with alternative forms of utility functions (other than quadratic utility). The second direction follows Nelson (1987) who also finds evidence against quadratic single period utility functions. Nelson found favourable results using an isoelastic function for utility, which is one of the functions Weber (2002) uses to measure the empirical relevance of rule of thumb agents. As with his 2000 article, Weber (2002) uses GMM to estimate the Euler equations given three different sets of preferences using various sets of instrumental variables. GMM is initially employed to estimate an Euler equation derived from an intertemporally separable lifetime utility function, then two cases where lifetime utility is time non separable. 
Each Euler equation was micro-founded using different sets of preferences. The first was derived from Cobb-Douglas preferences, the second from Gallant-Tauchen preferences, while the third was derived using isoelastic distributed lag preferences, as suggested by Nelson (1987). Using these equations Weber (2002) finds similar evidence to his year 2000 paper, in which the estimated proportion of rule of thumb consumers is predominantly statistically insignificant from zero for the US. In addition, it was found intertemporal non separability is empirically important and is mainly responsible for the small and negative statistically insignificant estimates of $\lambda$. The main contribution from Weber $(2000,2002)$ is that rule of thumb behaviour may not be the necessary characteristic which causes the permanent income hypothesis to fail. Once the model accounts for intertemporal non separability in the utility function, US time series data is consistent with the absence of any rule of thumb behaviour. This result contradicts all prior evidence in the literature which uses log linear Euler equations to estimate $\lambda$.

When Campbell and Mankiw (1989) tested for the presence of rule of thumb consumers, the auxiliary assumption is the validity of the first order log linearised version of the Euler Equation for optimizing consumers. Rejecting the null that there is no rule of thumb behaviour in this context may be due to either the inappropriateness of optimizing behaviour or the first order log linearised approximation of the Euler Equation or a combination of both. The main issue which Gomes and Issler (2006) raise is all prior literature has ignored the possibility that rejecting optimizing behaviour may result from the first order log linearised approximation of the Euler equation. 
Gomes and Issler (2006) believe ignoring higher order terms results in an inconsistent estimates of $\lambda$, which invalidates hypothesis testing. The central finding of their paper was current income variation is highly correlated with omitted higher order terms of the Taylor expansion. This has the capability of explaining why rule of thumb behaviour is found in the literature.

While Weber (2002) allows for intertemporal non separability in agents preferences using various utility functions, Gomes and Issler's (2006) approach is more direct. Instead, they analyse the relevance of higher order terms in the presence of external habits. External habit formation allows for agents marginal utility to increase when other agents consumption increases (Dennis, 2004). Initial results find no evidence of habit formation using US data. Upon its removal, results confirm there is no evidence in favour rule of thumb agents. This conclusion gives Gomes and Issler (2006) reason to believe income is a proxy for omitted higher order terms from a Taylor series expansion. This conclusion raises doubt into the validity of habit formation and also raises two questions. Firstly, does a simple utility function give rise to habit persistence? or does a more sophisticated set of consumer preferences that allow for risk aversion eliminate the need to provide for habits?

Gomes and Issler (2006) complete their analysis by summarising two key findings of their paper. First they agree with Weber (2002) that estimating non linear Euler equations is a better econometric model than its log linearised version. Second, using US data, they believe there is no significant evidence of either credit constraints or habit formation. This point is highly important given the considerable amount of work regarding habit formation within the US. Empirical work into habit formation by Dennis (2004) using 
US data found allowing for some form of habit formation (internal or external) improves closed economy New Keynesian models' ability to fit the data. However estimates of habit formation, irrespective of type, are highly significant and contradict the findings of Gomes and Issler (2006). The fundamental difference between the two approaches is Dennis (2004) employs a small New Keynesian closed economy model, which includes a forward looking IS curve, Hybrid New Keynesian Phillips Curve, and a policy objective function. Gomes and Issler (2006) estimate a permanent income model with varying forms of preferences and higher order Taylor expansion terms. While there is great discussion between the relative merits of Dynamic Stochastic General Equilibrium (DSGE) simultaneous equation models and closed form macroeconomic models, such as Campbell and Mankiw (1989), both studies provide sufficient evidence that quantifying consumer behaviour is difficult. The big question is whether Weber and Gomes and Issler findings apply to other countries' estimates of rule of thumb consumers. Once a thorough examination of each method is conducted, only then can we being to understand how consumers allocate their consumption. 


\subsection{Summary}

The criticism Campbell and Mankiw $(1989,1990)$ amongst others have received over time can be summarised into four key arguments. Firstly, when evaluating the relevance of liquidity constraints one is also attempting to assess the opportunity set available to agents in an intertemporal optimisation problem. In doing so one is also making extremely strong and near untestable identification assumptions. Secondly the estimation of log linear Euler equations, instead of their original non linear form, can result in inconsistent and biased estimates. Thirdly, preliminary evidence by Weber (2002) suggests that if one models household preferences sufficiently one has the potential of explaining away rule of thumb behaviour. Lastly, ignoring higher order terms from a Taylor series expansion in nonlinear Euler equations has the capability of explaining the observed correlation between income and consumption.

Econometric evidence that I have collated, based on standard approaches, suggests that approximately $79 \%$ of consumers in New Zealand behave in a forward looking manner. This proportion is very similar to the last study conducted in New Zealand by Rae (1996). However one must be cautious in explaining whether the remaining portion are subject to liquidity constraints, or simply behave in such a way that is too complicated to explain using existing theories. There may be some other exogenous influences which current income fails to capture. Estimation of $\lambda$ when there are other interacting sectors is carried out in Chapter 4. Together these findings cast doubt into the robustness of estimates obtained in this section. 
Appendix 2.1 - Social Welfare per capita

Quarterly estimates for Social Welfare can be obtained by following two steps. First I fitted a series of models to determine which model fitted the total number of recipients and value of Social Welfare payments. After simple diagnostic tests it was found a $6^{\text {th }}$ order polynomial for each series was deemed appropriate. Figures 3 and 4 below plot each respective series (with fitted empirical fit) and provide the estimated equations of each fitted series:

Figure 3 - Total value of benefits and pension payments

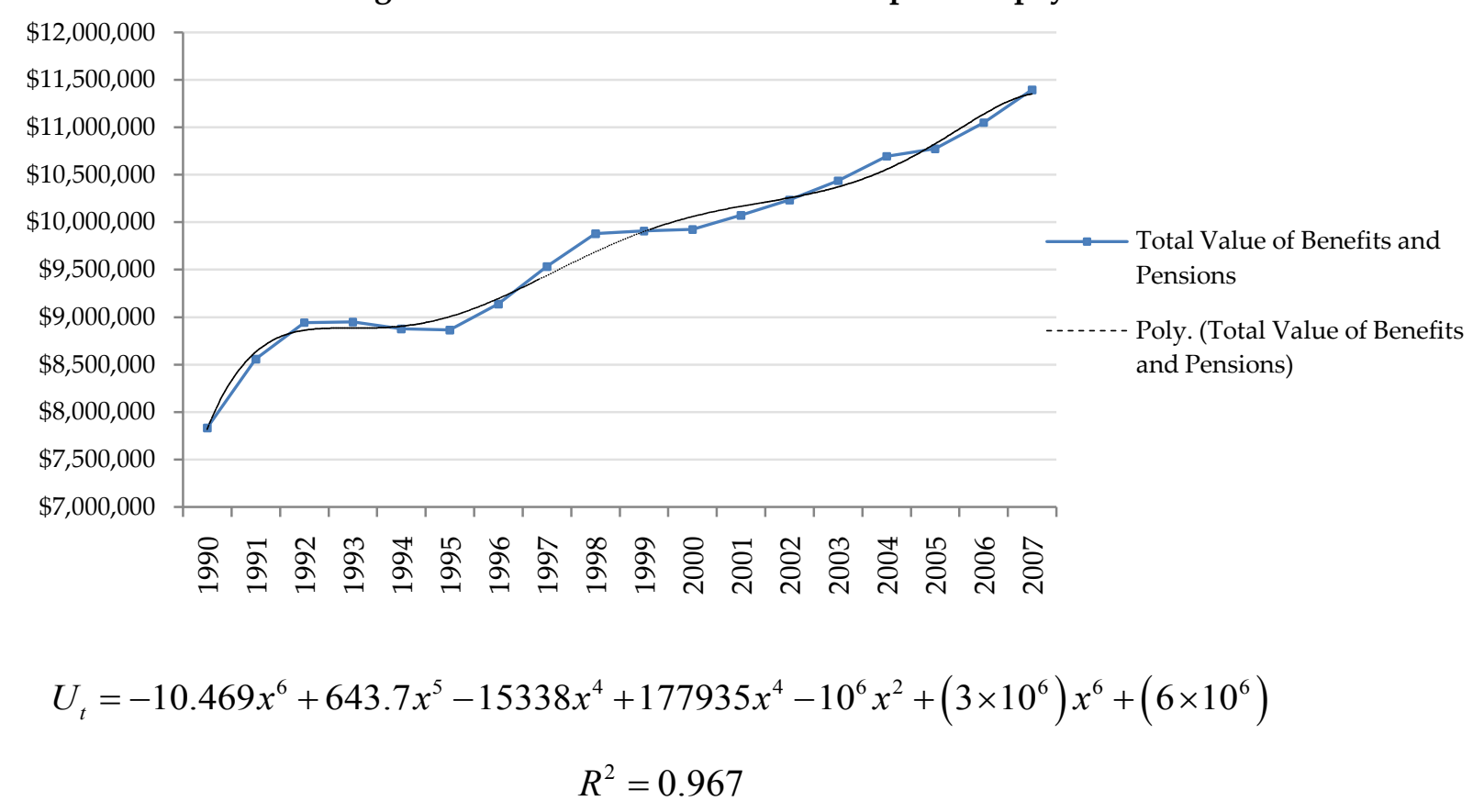


Figure 4 - Total number of benefits and pension recipients

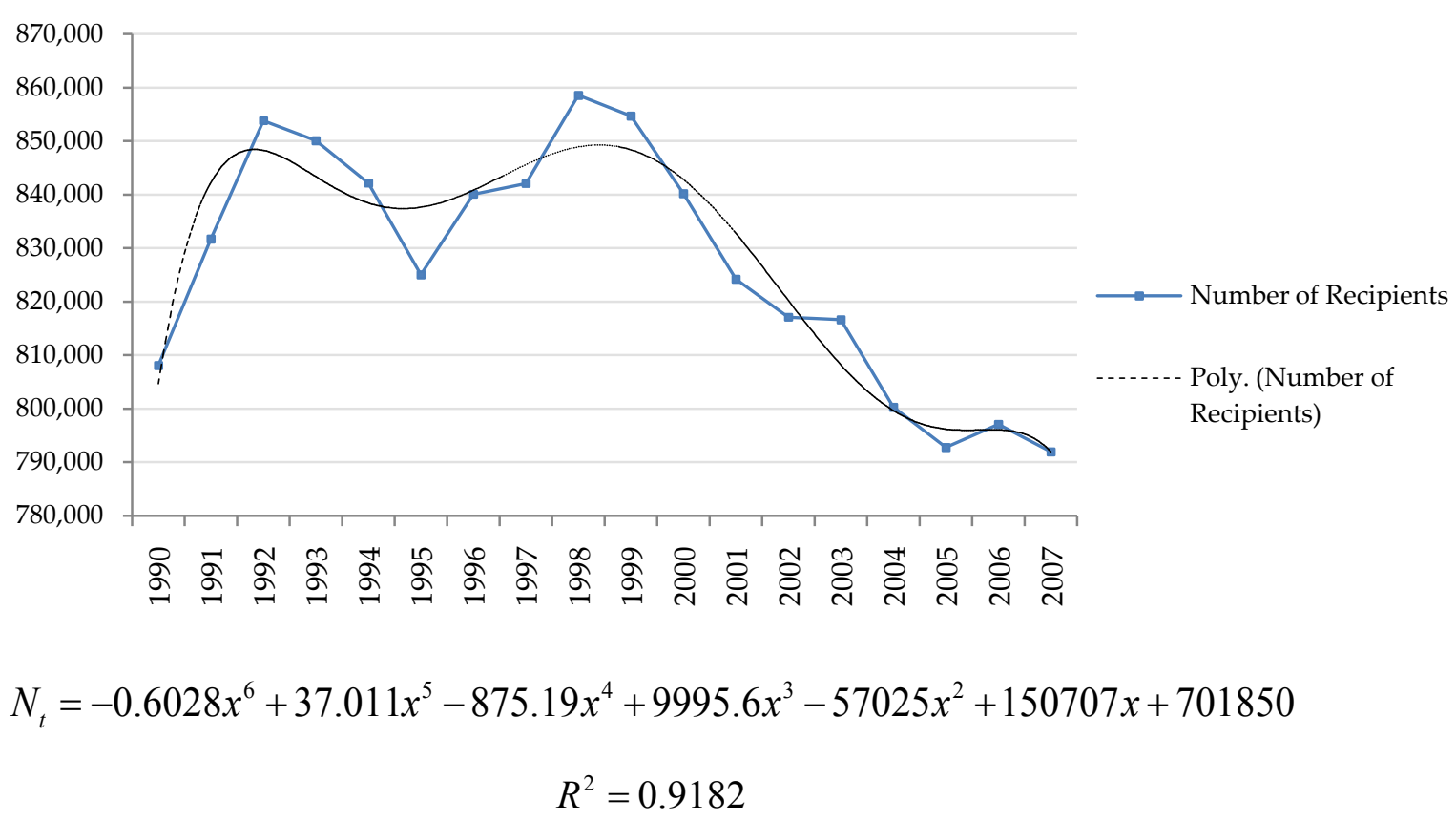

Using the fitted equations I extrapolated forwards one period to obtain estimates for 2008. Surprisingly, both models predict an increase in the total volume and total number receiving Social Welfare payments. At the time of writing, data obtained from Statistics New Zealand's National Accounts confirms the value of Social Welfare payments increased. This supports the validity of the model chosen. The 2008 value of unemployment benefits amounted to $\$ 218,984,137.91$ and the number of recipients 53,487 . While there is great uncertainty into the forecasting ability of polynomial models, the one step ahead forecasts from the $6^{\text {th }}$ order polynomial had a lower mean square error than those from an $\mathrm{AR}(1), \mathrm{AR}(2), \mathrm{AR}(3), \mathrm{AR}(4), \mathrm{MA}(1)$, MA(2), MA(3), MA(4), ARMA(1,1), ARMA(1,2), and an $\operatorname{ARMA}(2,1)$ model when using data between 1990 and 2006 to forecast 2007 values.

The next step is to disaggregate each annual series into quarterly representations. The disaggregation method I have decided to implement was developed by Boot, Feibes, and Lisman in 1967. Their approach is based 
on the concept that the unknown sub-annual trend can be described by a mathematical function of time. There are two predominant versions of Boot et al (1967); the first difference model and the second difference model.

The objective of the first difference model is to minimize inter-period changes in the level of final quarterly or sub-annual estimate $\Delta x_{t}$ subject to the annual constraints. Formally, the problem is to:

$$
\operatorname{Min}_{x} P(x)=\sum_{t=2}^{T}\left(x_{t}-x_{t-1}\right)^{2} \text { s.t } y=B^{\prime} x
$$

The objective of the second difference model is to keep the inter-period change in $\Delta x_{t}$ as linear as possible. This objective is achieved by minimizing the sum of squares of $\Delta^{2} x_{t}=\left(\Delta x_{t}-\Delta x_{t-1}\right)$ subject to annual constraints. Formally, the problem is to:

$$
\operatorname{Min}_{x} P(x)=\sum_{t=2}^{T}\left[\Delta\left(x_{t}-x_{t-1}\right)^{2}\right] \text { s.t } y=B^{\prime} x
$$

Like other smoothing methods such as Denton (1971), Fernández (1981), Chow-Lin (1971), Litterman (1983) and Santos-Cardoso (2001); Boot et al (1967) does not allow extrapolation of sub-annual estimates. This is for the reason temporal disaggregation methods are fundamentally designed to give breakdowns of available annual data. If one wanted to produce current year estimates, a forecast value using another method is required. Using the Temporal Disaggregation Toolbox for Matlab developed by Enrique M. Quilis, I calculated the quarterly time series for the value of unemployment benefits and number of recipients for both first and second difference models. Figures 5 and 6 below illustrate the disaggregated series of both Total Value and number of recipients of Social Welfare using the First and Second difference methods. 
Figure 5 - Disaggregated total value of Social Welfare payments

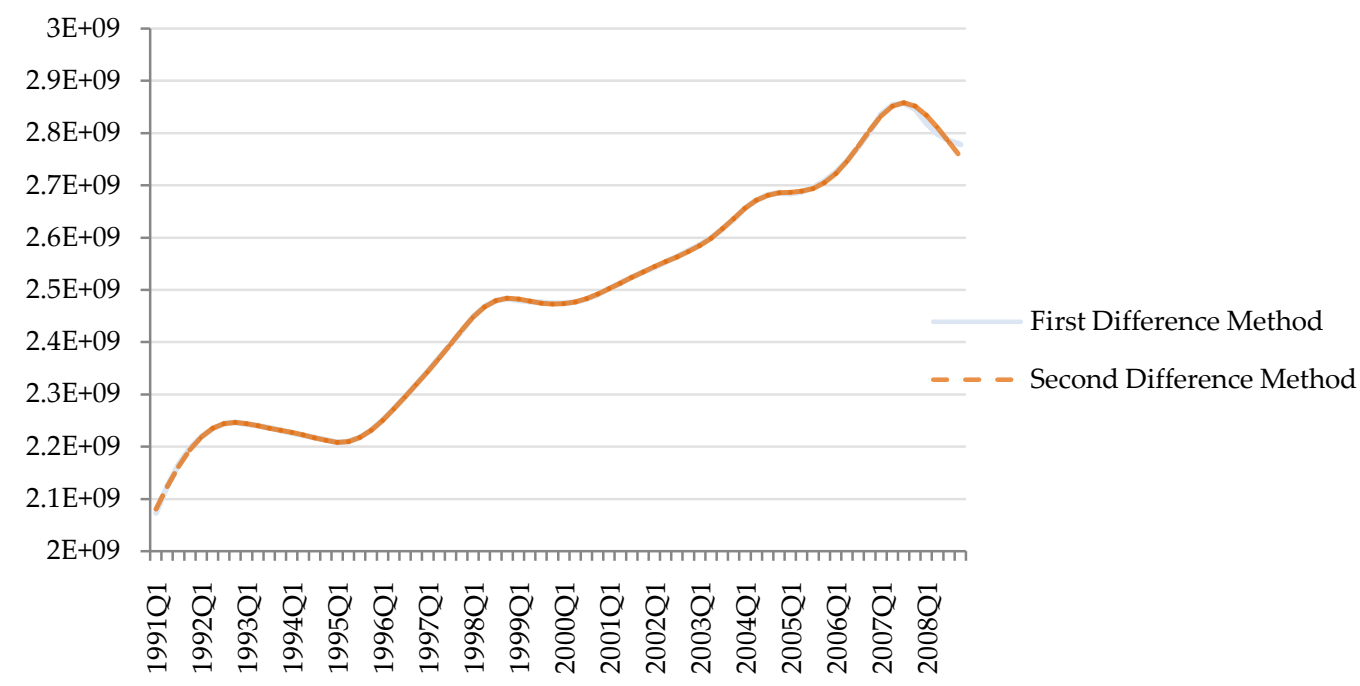

Figure 6 - Disaggregated total number of Social Welfare recipients

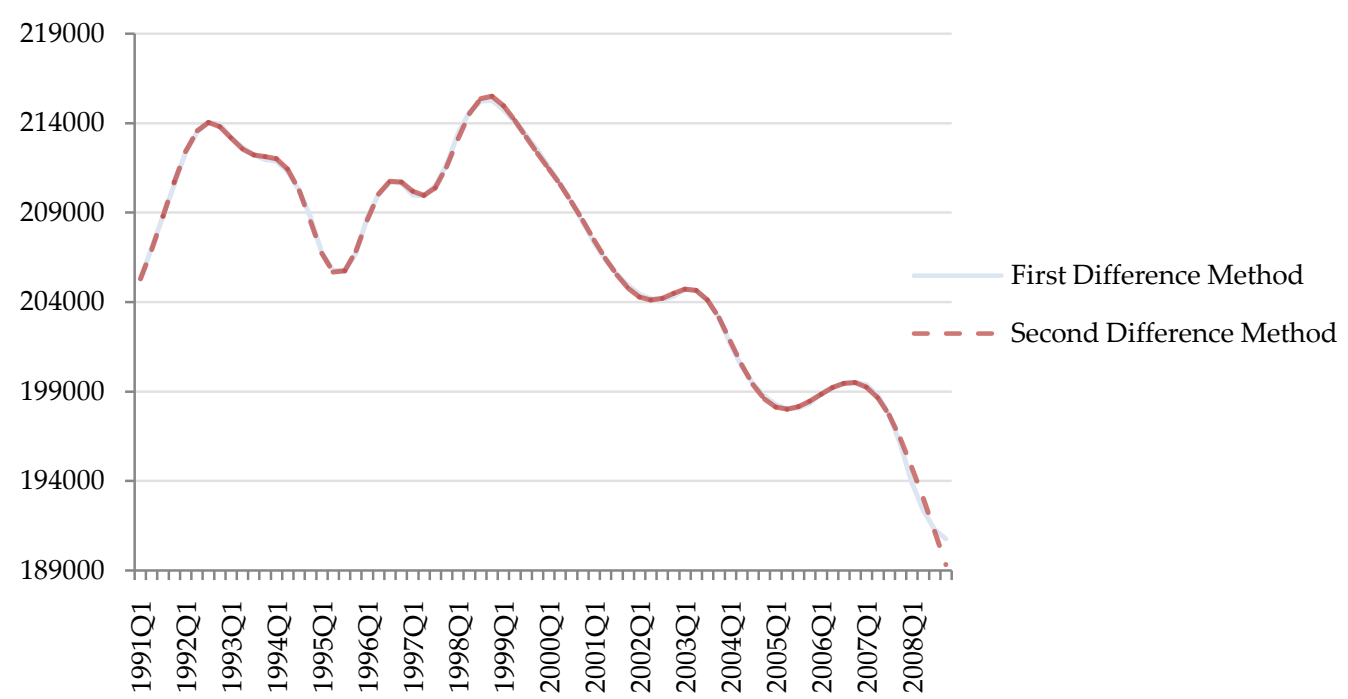

Visually, the two methods yield series which differ little from one another. Since a majority of macroeconomic time series are usually estimated by the first difference method I will use the estimated series using that approach. A per capita estimate of Social Welfare expenditure is found by dividing the total value of Social Welfare expenditure by the total number of recipients. 


\section{The New Zealand New Keynesian Phillips Curve}

This chapter looks at New Keynesian aggregate firm pricing theory (the New Keynesian Phillips curve) formulated in the early 1990s. The theory states firms are forward looking in anticipation of future marginal cost movements. NZ data is used to estimate key parameters of the model. Each model is estimated using GMM and a discussion of results follows each round of estimation. The model is subsequently extended to allow for backward looking price setters, who are called rule of thumb price setters. I then fit the desired model using a range of statistical tools to establish an optimal pair of parameters that satisfy theoretical orthogonality conditions.

\subsection{State of the literature}

Phillips (1958) originally found there was a negative relationship between British wage inflation and the change in unemployment. It was believed at the time that employers were forced to raise wage rates more rapidly when there were fewer unemployed, thus raising costs of production and price levels. In theory the relationship suggested one could lower the inflation rate by tolerating greater unemployment. However, Friedman (1968) and Phelps (1967) warned the observed correlation fails to incorporate any role for expectations, as agents are likely to adapt any inflationary expectations to policy induced change. They both argue in the long run the economy will be unable to deviate from the natural rate of unemployment unless inflation expectations are systematically incorrect.

In response, Friedman and Phelps devised the expectations-augmented Phillips curve. The model is justified on the basis of conditional expectations given the failure of the empirical Phillips curve for the US because of 
significant systematic forecast errors. The famous oil shock induced recession of the mid 1970s, in which there were high levels of inflation and unemployment, helped to further reduce the credibility of the Phillips curve.

Over the last twenty years one finds for most if not all international inflation time series, annual and sub annual movements are difficult to predict and measure. The problem of inflation persistence was first brought to the attention of economists by Fuhrer and Moore (1995), who proposed a relative contracting model to explain the phenomenon. Another explanation is proposed by Christiano, Eichenbaum and Evans (2005) and Smets and Wouters (2003) who argue firms use an indexation rule which adjusts prices automatically in line with inflation rates from the recent past. Milani (2004) argues that adaptive learning by agents could also explain the finding of persistence, at least while agents have not yet converged to the rational expectations equilibrium. As an alternative to bounded rationality, inflation inertia has been modelled on the basis of sticky information by Mankiw and Reis (2001), adaptive expectations by Roberts (1997), and as a signal extraction problem by Erceg and Levin (2001).

The NKPC differs from traditional Phillips curves in that it is purely forward looking. While the traditional Phillips curve was a backward looking relationship consisting of unemployment or the output gap, the NKPC maps current inflation with movements in expected future inflation and firms marginal costs. However, models incorporating the forward looking NKPC have been subject to criticism based mainly on empirical grounds. Apart from being unable to explain real costs of disinflations the forward looking NKPC, derived in the spirit of Calvo (1983), has been shown to have difficulties in reproducing the observed dynamics of both inflation and 
output when a plausible degree of price stickiness is assumed. Calvo (1983) assumed prices are fixed until some exogenous price signal enables firms to adjust their individual price. The waiting time or price stickiness is modelled as a geometric probability distribution. Failure of the NKPC has motivated the elaboration of alternative models which account for inflation inertia based on individual behaviour. One particular model was derived by Gali and Gertler (1999), who introduce inflation inertia based on a backward looking rule of thumb in the price adjustments of firms.

\subsection{The forward looking New Keynesian Phillips Curve}

The forward looking NKPC is derived on the assumption that prices are staggered and all firms conduct their behaviour in a monopolistically competitive manner. Price stickiness is enforced into the model by assuming a fraction $(1-\vartheta)$ of firms are capable of resetting their prices at a given point in time. Combining this assumption with each firm in the economy maximising expected discounted profits conditional on expected future demand conditions and the possibility of future price stickiness we can obtain the following representation:

$$
\begin{aligned}
& \pi_{t}=\beta E_{t} \pi_{t+1}+\frac{(1-\vartheta)(1-\vartheta \beta)}{\vartheta}\left(\mu+m c_{t}-p_{t}\right) \\
& \pi_{t}=\beta E_{t} \pi_{t+1}+\lambda_{H} r m c_{t}
\end{aligned}
$$

Further details can be found in Appendix 3.1. In this model $\beta$ reflects the intertemporal discount factor and $\vartheta$ represents the degree of price stickiness. The equation above is the baseline forward looking NKPC relating inflation to current expectations of future inflation and a measure of real activity, represented by firms real marginal costs. 


\subsubsection{Data}

Since expected future inflation is included in the right hand side of the forward looking NKPC, ex-post observed values of inflation are used to approximate expected inflation. As for the data length, I have used New Zealand quarterly data for the period 1992:Q4 - 2008:Q4. The reason for considering this period relates to the lack of data for the Labour Cost Index prior to 1992:Q4.

Until Gali and Gertler (1999) incorporated real unit labour costs as a proxy for real marginal cost, it was common practice to implement a measure of the output gap as a proxy. Given the widespread empirical failure of the forward looking NKPC, many have considered the measure of the output gap as the cause of such failure. Gali and Gertler (1999) argue the unobservability of the natural rate of output is largely at fault for measurement errors in the output gap and hence the poor performance of the forward looking NKPC. Work by Fuhrer and Moore (1995), Fuhrer (1997), and Roberts (1998) find the forward looking NKPC, relating inflation and a measure of the output gap, is unable to generate the type of persistence observed in actual US data. As a result it has been argued one should avoid using the output gap as a proxy for real marginal cost and instead employ a measure which is consistent with theory.

To empirically test the forward looking NKPC it is essential we have a measure of the latent variable, real marginal cost. The exact definition of marginal cost has been a critical issue in the literature and created significant debate as to the validity of results. Gali and Gertler (1999) and Sbordone (2002) found US data seems to be largely consistent with a pricing equation relating inflation and marginal cost from a forward-looking model. Rather 
than using the output gap as a proxy for real marginal cost, they use log real unit labour cost or log labour share in output. Both papers are widely quoted and have instigated a number of papers that explore their findings further.

Preliminary findings to this section found slope estimates of the forward looking NKPC are often negative when the output gap is used as a proxy for real marginal cost. Given this it is imperative I estimate the model using a proxy which is capable of reflecting movements in firms real marginal costs. For many firms in New Zealand, the cost of intermediate inputs (domestic and abroad) and labour are important factors which should be taken into consideration when deriving a proxy for marginal cost. Of total costs from intermediate inputs, a large fraction are imported (such as oil) which means my proxy and instrument set, $z_{t}$, must contain variables which reflect potential causes of movements in the real volume of imported intermediate inputs. Bearing this in mind my proxy for marginal cost is taken as $70 \%$ of New Zealand's Labour Cost Index and 30\% of the Intermediate Goods Index from a base year of 2000:Q1. The estimation undertaken in this section of the thesis was also tentatively conducted using proportions of 80-20. It was found those results differed little from estimates using the 70-30 split. The Labour Cost Index series was obtained from the International Monetary Fund's International Financial Statistics database, while the Intermediate Goods Index was obtained from Statistics New Zealand's Infoshare database. Real marginal cost is obtained by taking the log ratio of marginal cost to the Consumers Price Index with the same base year. The real marginal cost gap which will be used in empirical estimation is subsequently defined as the demeaned series of real marginal cost. In this case average marginal cost is assumed to reflect marginal cost deviations. 
One of the main issues with GMM estimation relates to the instrumental variables defined by the user. Ignorance of the econometrician to instrument relevance can lead to inaccurate conclusions and misleading guidance for future research. The instrumental variables which I have incorporated follow Gali and Gertler (1999), Rubene and Guarda (2004), and Ramos-Francia and Garcia (2006). These studies contain various lags of the Consumers Price Index and Real Marginal Cost gap, with the addition of lags in the output gap, wage inflation, commodity price inflation, and the 90 day Treasury Bill rate.

A measure of the output gap was obtained as the difference between the logarithm of Real GDP and its Hodrick-Prescott trend with a smoothing parameter set to 1600 . Wage inflation was taken as the percentage change between the average hourly earnings across all Australia New Zealand Standard Industry Classification (ANZSIC) industries in New Zealand. Commodity price inflation reflects the quarterly percentage change in the ANZ Commodity Price Index. This index is a measure of spot prices for New Zealand commodity exports in offshore markets converted into New Zealand dollars at spot exchange rates. Prices are collected for the following commodities: Wool, Beef, Lamb, Skins, Butter, Cheese, Wholemilk Powder, Skimmilk Powder, Casein, Apples, Kiwifruit, Wood Pulp, Sawn Timber, Logs, Fish, and Aluminium. The real exchange rate between the United States and New Zealand will also be used as an instrument given the presence of imported intermediate inputs in my definition of real marginal cost. 


\subsubsection{Estimation}

The predominant estimation method in the literature to evaluate the structural parameters of the forward looking NKPC is the generalised method of moments (GMM). As Fuhrer and Moore (1995) document; "GMM is ideal in principle because it is strongly consistent, asymptotically normal, and requires minimal assumptions about exogenous variables". Nevertheless, it is widely accepted structural parameters are extremely sensitive to asymptotically irrelevant aspects of the econometric specification, such as parameter normalization or the choice of the weighting matrix. Furthermore, in small samples GMM usually experiences large efficiency declines relative to the asymptotic distribution. As a result estimates can be considerably biased and associated hypothesis tests unreliable.

There is a large range of literature addressing the problems of finite sample GMM estimation due to poor instrument choice. Instruments are considered irrelevant if they do not explain enough of the variation in the variables they are supposed to instrument, and invalid if they are not exogenous to the error term. Therefore a potential issue which may influence estimation relates to the possible biasedness of GMM estimates in the presence of many instruments (whether relevant or not) and the low power of specification tests based on overidentifying restrictions.

As a means to identify poor instruments I computed Hansen's J-statistic, which is simply the value of the objective function evaluated at the point estimates and distributed as chi-square in the number of overidentifying restrictions. If the J-statistic's p-value is smaller than 0.05 (a 5\% level of significance) it means the orthogonality conditions, or other assumptions 
such as linearity or stationarity, do not hold. Another issue in small samples is nonlinear GMM estimators are sometimes sensitive to the way orthogonality conditions are normalised. For this reason I follow Gali and Gertler (1999) who used two alternative specifications of the orthogonality conditions as the basis for my GMM estimation procedure.

Specification 1: $E_{t}\left[\left(\vartheta \pi_{t}-(1-\vartheta)(1-\beta \vartheta) m c_{t}-\vartheta \beta \pi_{t+1}\right)\right]=0$

Specification 2: $E_{t}\left[\left(\pi_{t}-\vartheta^{-1}(1-\vartheta)(1-\beta \vartheta) m c_{t}-\beta \pi_{t+1}\right)\right]=0$

My estimation strategy is consistent with that employed in the literature in three ways. First, the two specification equations form the basis of estimating the model by two step GMM. Estimation is conducted using an Iterated coefficients routine and Sequential updating routine which is available in Eviews. Second, I employ a range of instrumental variables which are implemented by most in the field. Thirdly, I use a 12-lag Newey-West estimate of the covariance matrix to obtain standard errors for the model parameters.

\subsubsection{Structural estimates}

Estimation of the structural parameters $\vartheta$ and $\beta$ is conducted using a nonlinear instrumental variables estimator, with twelve different sets of instrumental variables. As discussed in the previous section I initially considered two alternative benchmark cases. In the first I estimate each unrestricted specification using the two different normalised conditions. While in the second I restrict the estimate of the intertemporal discount factor $(\beta)$ to 0.99 . The results from the two different GMM optimising routines are reported in Table $7,8,9$, and 10 . The instrumental variables used in estimating of each specification equation are shown in Table 11. For a 
majority of estimates I was unable to estimate $\beta$ less than one. Therefore I only present estimates of $\vartheta$ when $\beta$ is set to 0.99 . One finds restricting $\beta$ increases the estimates of $\vartheta$ by an average of $8.4 \%$ across both estimation routines. This implies that on average all estimates are upward biased, which implies estimates must be corrected so as to remain consistent. Each table also provides the implied estimate of $\lambda$, the reduced form slope coefficient on real marginal cost, and the relevant J-statistic as defined earlier with its respective p-value in the parentheses.

Upon inspecting Tables 7, 8, 9, and 10 one can see $\vartheta$ estimates vary between 0.73 and 0.94 across estimation routines, orthogonality conditions, and sets of instrumental variables. One obvious issue is estimates between specifications differ and at times with great size. In particular the greatest differential comes from the iterated coefficient routine using instrumental variable set eight. Here the first specification estimates $\vartheta$ as 0.76 , while the second specification estimates $\vartheta$ as 0.92 . While most estimates are close, results which produce sizable differentials from valid instruments highlight the issues regarding GMM estimation in small samples. This exercise also yields positive estimates of $\lambda$ which are statistically different from zero.

One startling aspect of these estimates relative to those from international datasets, is that I have obtained high estimates of the degree of price stickiness. One could believe estimates are upward biased because of the correction made to $\beta$. There is also the possibility that my proxy for real marginal cost may be a potential source of bias as it does not truly capture firms marginal costs. The estimated slope coefficient, $\lambda$, is likely to be biased toward zero if labour costs and imported intermediate inputs do not fully capture firms marginal costs. This translates into upward bias of $\vartheta$ given the 
inverse relationship between the two parameters. Gali and Gertler (1999) also argue the theory used to identify $\vartheta$ from estimates of $\lambda$ assumes a constant mark-up of price over marginal cost in the absence of price rigidities. If the mark-up in the frictionless benchmark model were countercyclical, desired price setting is less sensitive to movements in marginal cost which lowers overall sensitivity of inflation to real marginal cost, thus raising $\vartheta$. In short, there are various reasons as to why we observe relatively high price stickiness in New Zealand.

The model appears to be estimated without fault as I do not reject the overidentifying restrictions at a $5 \%$ level of significance. However, this kind of test has low power as it is not applied against any specific alternative hypothesis. The next section builds on the model developed thus far. 
Table 7

\begin{tabular}{|c|c|c|c|}
\hline \multicolumn{3}{|c|}{ Iterated Coefficients routine } & \multirow{2}{*}{$\frac{\text { Specification }}{\text { J Statistic }}$} \\
\hline Instrument set & $\vartheta$ & $\lambda$ & \\
\hline 1 & $\begin{array}{c}0.825630 \\
(0.0000)\end{array}$ & 0.03857 & $\begin{array}{c}5.370 \\
(0.1467)\end{array}$ \\
\hline 2 & $\begin{array}{c}0.828105 \\
(0.0000)\end{array}$ & 0.037400 & $\begin{array}{c}7.1644 \\
(0.2087)\end{array}$ \\
\hline 3 & $\begin{array}{c}0.782044 \\
(0.0000)\end{array}$ & 0.0629240 & $\begin{array}{c}8.5238 \\
(0.3840)\end{array}$ \\
\hline 4 & $\begin{array}{c}0.795269 \\
(0.0000)\end{array}$ & 0.0547524 & $\begin{array}{c}8.8707 \\
(0.3533)\end{array}$ \\
\hline 5 & $\begin{array}{c}0.779203 \\
(0.0000)\end{array}$ & 0.0647736 & $\begin{array}{c}9.0885 \\
(0.6137)\end{array}$ \\
\hline 6 & $\begin{array}{c}0.759670 \\
(0.0000)\end{array}$ & 0.0784344 & $\begin{array}{l}10.2079 \\
(0.8947)\end{array}$ \\
\hline 7 & $\begin{array}{c}0.743104 \\
(0.0000)\end{array}$ & 0.0913796 & $\begin{array}{l}11.3005 \\
(0.9381)\end{array}$ \\
\hline 8 & $\begin{array}{c}0.758782 \\
(0.0000)\end{array}$ & 0.0790958 & $\begin{array}{c}9.7836 \\
(0.9124)\end{array}$ \\
\hline 9 & $\begin{array}{c}0.812662 \\
(0.0000)\end{array}$ & 0.0450593 & $\begin{array}{c}8.1883 \\
(0.1462)\end{array}$ \\
\hline 10 & $\begin{array}{c}0.763988 \\
(0.0000)\end{array}$ & 0.0752692 & $\begin{array}{c}9.4788 \\
(0.5778)\end{array}$ \\
\hline 11 & $\begin{array}{c}0.743869 \\
(0.0000)\end{array}$ & 0.0907530 & $\begin{array}{l}10.6848 \\
(0.8725)\end{array}$ \\
\hline 12 & $\begin{array}{c}0.731065 \\
(0.0000)\end{array}$ & 0.101622 & $\begin{array}{c}10.0657 \\
(0.9909)\end{array}$ \\
\hline
\end{tabular}

Table 8

Iterated Coefficients routine Specification 2

\begin{tabular}{|c|c|c|c|}
\hline Instrument set & $\vartheta$ & $\lambda$ & $\vartheta$ \\
\hline 1 & $\begin{array}{c}0.891255 \\
(0.0000)\end{array}$ & 0.0143557 & $\begin{array}{c}5.7026 \\
(0.1270)\end{array}$ \\
\hline 2 & $\begin{array}{c}0.933526 \\
(0.0000)\end{array}$ & 0.00539818 & $\begin{array}{c}6.8517 \\
(0.1439)\end{array}$ \\
\hline 3 & $\begin{array}{c}0.883661 \\
(0.0000)\end{array}$ & 0.0164801 & $\begin{array}{c}9.7339 \\
(0.2842)\end{array}$ \\
\hline 4 & $\begin{array}{c}0.917578 \\
(0.0000)\end{array}$ & 0.00822782 & $\begin{array}{c}9.2219 \\
(0.3239)\end{array}$ \\
\hline 5 & $\begin{array}{c}0.922324 \\
(0.0000)\end{array}$ & 0.00731845 & $\begin{array}{l}10.2318 \\
(0.5097)\end{array}$ \\
\hline 6 & $\begin{array}{c}0.869856 \\
(0.0000)\end{array}$ & 0.0207730 & $\begin{array}{l}12.5543 \\
(0.7655)\end{array}$ \\
\hline 7 & $\begin{array}{c}0.885617 \\
(0.0000)\end{array}$ & 0.0159171 & $\begin{array}{l}13.3310 \\
(0.8627)\end{array}$ \\
\hline 8 & $\begin{array}{c}0.915188 \\
(0.0000)\end{array}$ & 0.00870779 & $\begin{array}{l}12.4086 \\
(0.7748)\end{array}$ \\
\hline 9 & $\begin{array}{c}0.887955 \\
(0.0000)\end{array}$ & 0.0152587 & $\begin{array}{c}7.8229 \\
(0.1663)\end{array}$ \\
\hline 10 & $\begin{array}{c}0.856127 \\
(0.0000)\end{array}$ & 0.0256167 & $\begin{array}{l}12.1661 \\
(0.3513)\end{array}$ \\
\hline 11 & $\begin{array}{c}0.878139 \\
(0.0000)\end{array}$ & 0.0181295 & $\begin{array}{c}12.9678 \\
(0.7383)\end{array}$ \\
\hline 12 & $\begin{array}{c}0.885326 \\
(0.0000)\end{array}$ & 0.0160002 & $\begin{array}{c}13.7554 \\
(0.9337)\end{array}$ \\
\hline
\end{tabular}


Table 9

Sequential Updating routine

Specification 1

\begin{tabular}{|c|c|c|c|}
\hline Instrument set & $\vartheta$ & $\lambda$ & J Statistic \\
\hline 1 & $\begin{array}{c}0.846362 \\
(0.0000)\end{array}$ & 0.0294259 & $\begin{array}{c}5.8876 \\
(0.1172)\end{array}$ \\
\hline 2 & $\begin{array}{c}0.856021 \\
(0.0000)\end{array}$ & 0.0256564 & $\begin{array}{c}7.3562 \\
(0.1955)\end{array}$ \\
\hline 3 & $\begin{array}{c}0.788964 \\
(0.0000)\end{array}$ & 0.0585593 & $\begin{array}{l}10.5331 \\
(0.2296)\end{array}$ \\
\hline 4 & $\begin{array}{c}0.826664 \\
(0.0000)\end{array}$ & 0.0380787 & $\begin{array}{l}10.1003 \\
(0.2581)\end{array}$ \\
\hline 5 & $\begin{array}{c}0.809398 \\
(0.0000)\end{array}$ & 0.0467902 & $\begin{array}{l}11.0781 \\
(0.1973)\end{array}$ \\
\hline 6 & $\begin{array}{c}0.808839 \\
(0.0000)\end{array}$ & 0.0470906 & $\begin{array}{l}12.2622 \\
(0.7840)\end{array}$ \\
\hline 7 & $\begin{array}{c}0.784400 \\
(0.0000)\end{array}$ & 0.0614158 & $\begin{array}{l}13.0470 \\
(0.8754)\end{array}$ \\
\hline 8 & $\begin{array}{c}0.812241 \\
(0.0000)\end{array}$ & 0.0452803 & $\begin{array}{l}12.3711 \\
(0.7772)\end{array}$ \\
\hline 9 & $\begin{array}{c}0.852709 \\
(0.0000)\end{array}$ & 0.0269149 & $\begin{array}{c}8.2154 \\
(0.1448)\end{array}$ \\
\hline 10 & $\begin{array}{c}0.799900 \\
(0.0000)\end{array}$ & 0.0520573 & $\begin{array}{l}11.5544 \\
(0.3980)\end{array}$ \\
\hline 11 & $\begin{array}{c}0.784509 \\
(0.0000)\end{array}$ & 0.0613466 & $\begin{array}{l}12.5146 \\
(0.7680)\end{array}$ \\
\hline 12 & $\begin{array}{c}0.781083 \\
(0.0000)\end{array}$ & 0.0635458 & $\begin{array}{l}13.5098 \\
(0.9401)\end{array}$ \\
\hline
\end{tabular}

Table 10

Sequential Updating routine Specification 2

\begin{tabular}{|c|c|c|c|}
\hline Instrument set & $\vartheta$ & $\lambda$ & J Statistic \\
\hline 1 & $\begin{array}{c}0.883200 \\
(0.0000)\end{array}$ & 0.0166144 & $\begin{array}{c}5.7177 \\
(0.1262)\end{array}$ \\
\hline 2 & $\begin{array}{c}0.934625 \\
(0.0000)\end{array}$ & 0.0052266 & $\begin{array}{c}6.8459 \\
(0.2323)\end{array}$ \\
\hline 3 & $\begin{array}{c}0.851863 \\
(0.0000)\end{array}$ & 0.0272421 & $\begin{array}{c}9.9659 \\
(0.2674)\end{array}$ \\
\hline 4 & $\begin{array}{c}0.902712 \\
(0.0000)\end{array}$ & 0.0114579 & $\begin{array}{c}9.3786 \\
(0.3114)\end{array}$ \\
\hline 5 & $\begin{array}{c}0.918910 \\
(0.0000)\end{array}$ & 0.0079668 & $\begin{array}{l}10.2496 \\
(0.5081)\end{array}$ \\
\hline 6 & $\begin{array}{c}0.810800 \\
(0.0000)\end{array}$ & 0.0460418 & $\begin{array}{c}12.0988 \\
(0.7941)\end{array}$ \\
\hline 7 & $\begin{array}{c}0.816604 \\
(0.0000)\end{array}$ & 0.0430217 & $\begin{array}{l}13.0109 \\
(0.8769)\end{array}$ \\
\hline 8 & $\begin{array}{c}0.845070 \\
(0.0000)\end{array}$ & 0.0299532 & $\begin{array}{l}12.2589 \\
(0.7842)\end{array}$ \\
\hline 9 & $\begin{array}{c}0.894282 \\
(0.0000)\end{array}$ & 0.0135547 & $\begin{array}{c}7.7562 \\
(0.1702)\end{array}$ \\
\hline 10 & $\begin{array}{c}0.805186 \\
(0.0000)\end{array}$ & 0.0490832 & $\begin{array}{l}11.5301 \\
(0.4000)\end{array}$ \\
\hline 11 & $\begin{array}{c}0.817964 \\
(0.0000)\end{array}$ & 0.0423321 & $\begin{array}{l}12.4588 \\
(0.7716)\end{array}$ \\
\hline 12 & $\begin{array}{c}0.803985 \\
(0.0000)\end{array}$ & 0.0497495 & $\begin{array}{l}13.5165 \\
(0.9399)\end{array}$ \\
\hline
\end{tabular}




\section{Table 11}

\begin{tabular}{|c|c|}
\hline Instrument Set & Instruments \\
\hline 1 & $\pi_{t-1}, \pi_{t-2}, m c_{t-1}, m c_{t-2}$ \\
\hline 2 & $\pi_{t-1}, \pi_{t-2}, \pi_{t-3}, m c_{t-1}, m c_{t-2}, m c_{t-3}$ \\
\hline 3 & $\pi_{t-1}, \pi_{t-2}, \pi_{t-3}, m c_{t-1}, m c_{t-2}, m c_{t-3}, x_{t-1}, x_{t-2}, x_{t-3}$ \\
\hline 4 & $\pi_{t-1}, \pi_{t-2}, \pi_{t-3}, m c_{t-1}, m c_{t-2}, m c_{t-3}, \varepsilon_{t-1}, \varepsilon_{t-2}, \varepsilon_{t-3}$ \\
\hline 5 & $\pi_{t-1}, \pi_{t-2}, \pi_{t-3}, m c_{t-1}, m c_{t-2}, m c_{t-3}, x_{t-1}, x_{t-2}, x_{t-3}, \varepsilon_{t-1}, \varepsilon_{t-2}, \varepsilon_{t-3}$ \\
\hline 6 & $\begin{array}{l}\pi_{t-1}, \pi_{t-2}, \pi_{t-3}, m c_{t-1}, m c_{t-2}, m c_{t-3}, x_{t-1}, x_{t-2}, x_{t-3}, \varepsilon_{t-1}, \varepsilon_{t-2}, \varepsilon_{t-3} \\
i_{t-1}, i_{t-2}, i_{t-3}, c i_{t-1}, c i_{t-2}, c i_{t-3}\end{array}$ \\
\hline 7 & $\begin{array}{l}\pi_{t-1}, \pi_{t-2}, \pi_{t-3}, m c_{t-1}, m c_{t-2}, m c_{t-3}, x_{t-1}, x_{t-2}, x_{t-3}, \varepsilon_{t-1}, \varepsilon_{t-2}, \varepsilon_{t-3} \\
i_{t-1}, i_{t-2}, i_{t-3}, c i_{t-1}, c i_{t-2}, c i_{t-3}, w i_{t-1}, w i_{t-2}, w i_{t-3}\end{array}$ \\
\hline 8 & $\begin{array}{l}\pi_{t-1}, \pi_{t-2}, \pi_{t-3}, m c_{t-1}, m c_{t-2}, m c_{t-3}, x_{t-1}, x_{t-2}, x_{t-3}, \varepsilon_{t-1}, \varepsilon_{t-2}, \varepsilon_{t-3} \\
i_{t-1}, i_{t-2}, i_{t-3}, w i_{t-1}, w i_{t-2}, w i_{t-3}\end{array}$ \\
\hline 9 & $\pi_{t-1}, m c_{t-1}, x_{t-1}, i_{t-1}, w i_{t-1}, c i_{t-1}$ \\
\hline 10 & $\pi_{t-1}, \pi_{t-2}, m c_{t-1}, m c_{t-2}, x_{t-1}, x_{t-2}, i_{t-1}, i_{t-2}, w i_{t-1}, w i_{t-2}, c i_{t-1}, c i_{t-2}$ \\
\hline 11 & $\begin{array}{l}\pi_{t-1}, \pi_{t-2}, \pi_{t-3}, m c_{t-1}, m c_{t-2}, m c_{t-3}, x_{t-1}, x_{t-2}, x_{t-3}, i_{t-1}, i_{t-2}, i_{t-3} \\
w i_{t-1}, w i_{t-2}, w i_{t-3}, c i_{t-1}, c i_{t-2}, c i_{t-3}\end{array}$ \\
\hline 12 & $\begin{array}{l}\pi_{t-1}, \pi_{t-2}, \pi_{t-3}, \pi_{t-4}, m c_{t-1}, m c_{t-2}, m c_{t-3}, m c_{t-4}, x_{t-1}, x_{t-2}, x_{t-3}, x_{t-4} \\
i_{t-1}, i_{t-2}, i_{t-3}, i_{t-4}, w i_{t-1}, w i_{t-2}, w i_{t-3}, w i_{t-4}, c i_{t-1}, c i_{t-2}, c i_{t-3}, c i_{t-4}\end{array}$ \\
\hline
\end{tabular}

Note: $\pi_{t}$ represents CPI inflation, $m c_{t}$ the real marginal cost gap, $x_{t}$ the output gap, $\varepsilon_{t}$ the real exchange rate with the US, $i_{t}$ the 90 day Treasury Bill Rate, $c i_{t}$ commodity price inflation, and $w i_{t}$ wage inflation. 


\subsection{The Hybrid New Keynesian Phillips Curve}

Across a range of international datasets the NKPC has failed to adequately explain price stickiness when confronted with data. The curve has since been developed into a more practical hybrid form. Gali and Gertler (1999) develop and estimate a structural model of inflation that allows for a fraction of firms that use a backward-looking rule to set prices. This model builds on early work by Fischer (1977), Taylor (1980) and Calvo (1983) who emphasized staggered nominal wage and price setting by forward looking individuals and firms. At the time Gali and Gertler's approach differed from the literature in two fundamental ways. Firstly, they implemented a measure of real marginal cost as opposed to an ad hoc measure of the output gap. Gali and Gertler (1999) claim their measure accounts for the impact of productivity gains on inflation, which is a factor measure and one the output gap fails to reflect. Second, they extended the baseline theory to allow for a fraction of firms that set prices according to a backward looking rule of thumb. This particular approach allows one to estimate the degree of departure from a forward looking model needed to account for the observed inflation persistence.

Another advantage of proceeding this way is that the coefficients of the Hybrid Phillips Curve will be functions of two key parameters: the frequency of price adjustment and the fraction of backward looking price setters. These two parameters provide a direct measure of the departure from a pure forward looking model needed to account for the persistence in inflation. The Hybrid New Keynesian Phillips Curve nests the forward looking NKPC as a special case while allowing for a fraction of backward looking rule of thumb firms. Gali and Gertler's Hybrid NKPC is as follows and its proof can be found in Appendix 3.2. 


$$
\pi_{t}=\left(\frac{\vartheta \beta}{\vartheta+\omega(1-\vartheta(1-\beta))}\right) E_{t} \pi_{t+1}+\left(\frac{\varpi}{\vartheta+\omega(1-\vartheta(1-\beta))}\right) \pi_{t-1}+\left(\frac{(1-\omega)(1-\beta \vartheta)(1-\vartheta)}{\vartheta+\omega(1-\vartheta(1-\beta))}\right) r m c_{t}
$$

or

$$
\pi_{t}=\gamma_{f} E_{t} \pi_{t+1}+\gamma_{b} \pi_{t-1}+\lambda_{H} r m c_{t}
$$

All the coefficients are explicit functions of three model parameters: $\vartheta$, measures the degree of price stickiness; $\omega$, the degree of 'backwardness' in price setting; and $\beta$ is the intertemporal discount factor. As a special case when $\omega=0$, all firms are forward looking and the model converges to the forward looking NKPC model derived earlier. To be credible, this model relies on the existence of some exogenous costs of gathering information that make the $\omega$ fraction of firms base their inflation forecasts on the recently observed rate of inflation. We also find disinflation in this model becomes costly. Even in the presence of a perfectly credible monetary authority, the presence of the lagged inflation term in the hybrid curve implies that the driving variable has to decrease to bring about sufficient reduction in inflation.

\subsubsection{Structural estimates}

Similarly to the estimation of the forward looking NKPC, I again use a weighting of the Labour Cost Index and the Intermediate Imported Goods Index to form an estimate of marginal cost. Unlike deriving marginal costs from a theoretical production function as Gali and Gertler (1999) construct, I obtain marginal costs by simply adding together two factors which are widely considered as driving variables. As a means to address the small sample normalisation problem with GMM discussed earlier, I have used two alternative specifications of the orthogonality conditions; one which does not normalise the coefficient on inflation to be one (specification 1) and one which does (specification 2). Similar to when I estimated the forward looking 
NKPC, $\beta$ was restricted to 0.99 as the model failed to consistently estimate $\beta$ below 1 . Furthermore it was found estimates of $\vartheta$ were $2.8 \%$ higher and estimates of $\omega$ were $4.7 \%$ lower on average when $\beta$ was restricted.

Each specification equation is detailed below. Table 12, 13, 14, and 15 show the estimates of the Hybrid NKPC. Table 16 lists the instrumental variables used in estimating each specification equation.

Specification 1: $E_{t}\left[\left(\phi \pi_{t}-(1-\omega)(1-\vartheta)(1-\beta \vartheta) m c_{t}-\beta \vartheta \pi_{t+1}-\omega \pi_{t-1}\right)\right]=0$

Specification 2: $E_{t}\left[\left(\pi_{t}-\phi^{-1}(1-\omega)(1-\vartheta)(1-\beta \vartheta) m c_{t}-\beta \vartheta \pi_{t+1}-\phi^{-1} \omega \pi_{t-1}\right)\right]=0$

Where $\phi=\vartheta+\omega(1-\vartheta(1-\beta))$ 
Table 12

Iterated coefficients routine

\begin{tabular}{|c|c|c|c|c|c|c|}
\hline Instruments Set & $\vartheta$ & $\omega$ & $\gamma_{b}$ & $\overline{\gamma_{f}}$ & $\lambda$ & J Statistic \\
\hline 1 & $\begin{array}{c}0.766034 \\
(0.0000)\end{array}$ & $\begin{array}{c}0.597183 \\
(0.0000)\end{array}$ & 0.4395439 & 0.5581849 & 0.01676099 & $\begin{array}{c}6.3933 \\
(0.04090)\end{array}$ \\
\hline 2 & $\begin{array}{c}0.747247 \\
(0.0000)\end{array}$ & $\begin{array}{c}0.614860 \\
(0.0000)\end{array}$ & 0.4529314 & 0.5449486 & 0.0186604 & $\begin{array}{c}7.3990 \\
(0.1162)\end{array}$ \\
\hline 3 & $\begin{array}{c}0.684647 \\
(0.0000)\end{array}$ & $\begin{array}{c}0.618790 \\
(0.0000)\end{array}$ & 0.4762852 & 0.5217059 & 0.02981329 & $\begin{array}{c}9.7379 \\
(0.2039)\end{array}$ \\
\hline 4 & $\begin{array}{c}0.747085 \\
(0.0000)\end{array}$ & $\begin{array}{c}0.502673 \\
(0.0000)\end{array}$ & 0.4034285 & 0.5935896 & 0.02628543 & $\begin{array}{l}11.1308 \\
(0.1330)\end{array}$ \\
\hline 5 & $\begin{array}{c}0.701513 \\
(0.0000)\end{array}$ & $\begin{array}{c}0.500925 \\
(0.0000)\end{array}$ & 0.4178122 & 0.5792677 & 0.03795892 & $\begin{array}{l}12.3739 \\
(0.2608)\end{array}$ \\
\hline 6 & $\begin{array}{c}0.660781 \\
(0.0000)\end{array}$ & $\begin{array}{c}0.482631 \\
(0.0000)\end{array}$ & 0.4232778 & 0.573724 & 0.05322914 & $\begin{array}{l}13.6076 \\
(0.6279)\end{array}$ \\
\hline 7 & $\begin{array}{c}0.650317 \\
(0.0000)\end{array}$ & $\begin{array}{c}0.466044 \\
(0.0000)\end{array}$ & 0.4186036 & 0.5782775 & 0.05973557 & $\begin{array}{l}13.9982 \\
(0.7838)\end{array}$ \\
\hline 8 & $\begin{array}{c}0.669178 \\
(0.0000)\end{array}$ & $\begin{array}{c}0.486632 \\
(0.0000)\end{array}$ & 0.4222207 & 0.5747986 & 0.04973402 & $\begin{array}{c}13.74 \\
(0.6178)\end{array}$ \\
\hline 9 & $\begin{array}{c}0.727408 \\
(0.0000)\end{array}$ & $\begin{array}{c}0.508205 \\
(0.0026)\end{array}$ & 0.4125321 & 0.584564 & 0.03045554 & $\begin{array}{c}10.2080 \\
(0.03707)\end{array}$ \\
\hline 10 & $\begin{array}{c}0.649758 \\
(0.0000)\end{array}$ & $\begin{array}{c}0.507940 \\
(0.0000)\end{array}$ & 0.4400044 & 0.557226 & 0.05325767 & $\begin{array}{l}11.6082 \\
(0.3121)\end{array}$ \\
\hline 11 & $\begin{array}{c}0.650903 \\
(0.0000)\end{array}$ & $\begin{array}{c}0.444410 \\
(0.0000)\end{array}$ & 0.4068123 & 0.5898773 & 0.06313641 & $\begin{array}{l}12.9057 \\
(0.6796)\end{array}$ \\
\hline 12 & $\begin{array}{c}0.650509 \\
(0.0000)\end{array}$ & $\begin{array}{c}0.410464 \\
(0.0000)\end{array}$ & 0.3878512 & 0.6085251 & 0.06930771 & $\begin{array}{l}14.2479 \\
(0.8924)\end{array}$ \\
\hline 13 & $\begin{array}{c}0.649189 \\
(0.0000)\end{array}$ & $\begin{array}{c}0.440235 \\
(0.0000)\end{array}$ & 0.4051618 & 0.5914938 & 0.06457425 & $\begin{array}{l}13.1366 \\
(0.9748)\end{array}$ \\
\hline 14 & $\begin{array}{c}0.673822 \\
(0.0000)\end{array}$ & $\begin{array}{c}0.364843 \\
(0.0000)\end{array}$ & 0.3520948 & 0.6437749 & 0.06656169 & $\begin{array}{l}13.9962 \\
(0.9963)\end{array}$ \\
\hline
\end{tabular}


Table 13

Iterated coefficients routine

\begin{tabular}{|c|c|c|c|c|c|c|}
\hline Instruments Set & $\vartheta$ & $\omega$ & $\overline{\gamma_{b}}$ & $\overline{\gamma_{f}}$ & $\lambda$ & J Statistic \\
\hline 1 & $\begin{array}{c}0.822222 \\
(0.0000)\end{array}$ & $\begin{array}{r}0.700897 \\
(0.0000)\end{array}$ & 0.4619199 & 0.5364593 & 0.006518156 & $\begin{array}{c}6.1779 \\
(0.04555)\end{array}$ \\
\hline 2 & $\begin{array}{c}0.787553 \\
(0.0000)\end{array}$ & $\begin{array}{c}0.737355 \\
(0.0000)\end{array}$ & 0.4853891 & 0.5132493 & 0.008092673 & $\begin{array}{c}7.1117 \\
(0.1301)\end{array}$ \\
\hline 3 & $\begin{array}{c}0.737900 \\
(0.0000)\end{array}$ & $\begin{array}{c}0.766875 \\
(0.0000)\end{array}$ & 0.5115514 & 0.4873011 & 0.01098362 & $\begin{array}{c}9.2308 \\
(0.2365)\end{array}$ \\
\hline 4 & $\begin{array}{c}0.857804 \\
(0.0002)\end{array}$ & $\begin{array}{c}0.851097 \\
(0.0013)\end{array}$ & 0.5001745 & 0.4990749 & 0.001876117 & $\begin{array}{c}10.2197 \\
(0.1765)\end{array}$ \\
\hline 5 & $\begin{array}{c}0.808389 \\
(0.0000)\end{array}$ & $\begin{array}{c}0.869511 \\
(0.0000)\end{array}$ & 0.5203939 & 0.4789748 & 0.00298826 & $\begin{array}{l}12.1980 \\
(0.2720)\end{array}$ \\
\hline 6 & $\begin{array}{c}0.756382 \\
(0.0000)\end{array}$ & $\begin{array}{c}0.783262 \\
(0.0000)\end{array}$ & 0.5106944 & 0.4882367 & 0.008647423 & $\begin{array}{l}13.2512 \\
(0.6543)\end{array}$ \\
\hline 7 & $\begin{array}{c}0.730384 \\
(0.0000)\end{array}$ & $\begin{array}{c}0.788864 \\
(0.0000)\end{array}$ & 0.5018327 & 0.4968143 & 0.01383098 & $\begin{array}{l}14.0239 \\
(0.7823)\end{array}$ \\
\hline 8 & $\begin{array}{c}0.797710 \\
(0.0000)\end{array}$ & $\begin{array}{c}0.819786 \\
(0.0000)\end{array}$ & 0.5088815 & 0.4902261 & 0.004758285 & $\begin{array}{l}13.7629 \\
(0.6164)\end{array}$ \\
\hline 9 & $\begin{array}{c}0.581236 \\
(0.0002)\end{array}$ & $\begin{array}{c}0.903943 \\
(0.0000)\end{array}$ & 0.6108033 & 0.3888195 & 0.01154023 & $\begin{array}{c}8.4173 \\
(0.07743)\end{array}$ \\
\hline 10 & $\begin{array}{c}0.675862 \\
(0.0000)\end{array}$ & $\begin{array}{c}0.827849 \\
(0.0000)\end{array}$ & 0.5525934 & 0.4466299 & 0.01232499 & $\begin{array}{l}11.9625 \\
(0.2876)\end{array}$ \\
\hline 11 & $\begin{array}{c}0.716949 \\
(0.0000)\end{array}$ & $\begin{array}{c}0.776757 \\
(0.0000)\end{array}$ & 0.521966 & 0.4769584 & 0.01232332 & $\begin{array}{l}13.5987 \\
(0.6286)\end{array}$ \\
\hline 12 & $\begin{array}{c}0.708135 \\
(0.0000)\end{array}$ & $\begin{array}{c}0.759940 \\
(0.0000)\end{array}$ & 0.5195483 & 0.4792895 & 0.01431996 & $\begin{array}{l}14.3194 \\
(0.8898)\end{array}$ \\
\hline 13 & $\begin{array}{c}0.724324 \\
(0.0000)\end{array}$ & $\begin{array}{c}0.728501 \\
(0.0000)\end{array}$ & 0.5032654 & 0.4953761 & 0.01462839 & $\begin{array}{l}13.1190 \\
(0.9750)\end{array}$ \\
\hline 14 & $\begin{array}{c}0.752661 \\
(0.0000)\end{array}$ & $\begin{array}{c}0.758456 \\
(0.0000)\end{array}$ & 0.5038208 & 0.4949716 & 0.01011453 & $\begin{array}{l}13.4694 \\
(0.9974)\end{array}$ \\
\hline
\end{tabular}


Table 14

Sequential Updating routine

\begin{tabular}{|c|c|c|c|c|c|c|}
\hline Instruments Set & $\vartheta$ & $\omega$ & $\gamma_{b}$ & $\gamma_{f}$ & $\lambda$ & J Statistic \\
\hline 1 & $\begin{array}{c}0.807852 \\
(0.0000)\end{array}$ & $\begin{array}{c}0.458754 \\
(0.0003)\end{array}$ & 0.3632544 & 0.6332833 & 0.01648858 & $\begin{array}{c}5.7808 \\
(0.05556)\end{array}$ \\
\hline 2 & $\begin{array}{c}0.787391 \\
(0.0000)\end{array}$ & $\begin{array}{c}0.510163 \\
(0.0000)\end{array}$ & 0.3943938 & 0.6026245 & 0.01775126 & $\begin{array}{c}6.5982 \\
(0.1587)\end{array}$ \\
\hline 3 & $\begin{array}{l}0.72668 \\
(0.0000)\end{array}$ & $\begin{array}{c}0.557716 \\
(0.0000)\end{array}$ & 0.4355988 & 0.5618909 & 0.02649192 & $\begin{array}{c}9.1440 \\
(0.2425)\end{array}$ \\
\hline 4 & $\begin{array}{c}0.803853 \\
(0.0000)\end{array}$ & $\begin{array}{c}0.447018 \\
(0.0000)\end{array}$ & 0.3583949 & 0.6380412 & 0.01775638 & $\begin{array}{l}10.1208 \\
(0.1818)\end{array}$ \\
\hline 5 & $\begin{array}{c}0.753988 \\
(0.0000)\end{array}$ & $\begin{array}{c}0.498582 \\
(0.0000)\end{array}$ & 0.3992454 & 0.5977272 & 0.02504531 & $\begin{array}{l}11.9675 \\
(0.2874)\end{array}$ \\
\hline 6 & $\begin{array}{c}0.775171 \\
(0.0000)\end{array}$ & $\begin{array}{c}0.365033 \\
(0.0000)\end{array}$ & 0.3209436 & 0.6747288 & 0.02919266 & $\begin{array}{l}12.4760 \\
(0.7106)\end{array}$ \\
\hline 7 & $\begin{array}{c}0.757627 \\
(0.0000)\end{array}$ & $\begin{array}{c}0.395369 \\
(0.0000)\end{array}$ & 0.3437990 & 0.6522177 & 0.03185140 & $\begin{array}{l}13.3355 \\
(0.8210)\end{array}$ \\
\hline 8 & $\begin{array}{c}0.762461 \\
(0.0000)\end{array}$ & $\begin{array}{c}0.346939 \\
(0.0000)\end{array}$ & 0.3134742 & 0.6820268 & 0.03436318 & $\begin{array}{l}13.1553 \\
(0.6614)\end{array}$ \\
\hline 9 & $\begin{array}{c}0.848219 \\
(0.0000)\end{array}$ & $\begin{array}{c}0.134733 \\
(0.4498)\end{array}$ & 0.1372293 & 0.8552953 & 0.02143751 & $\begin{array}{c}8.1070 \\
(0.08774)\end{array}$ \\
\hline 10 & $\begin{array}{c}0.657084 \\
(0.0000)\end{array}$ & $\begin{array}{c}0.550819 \\
(0.0000)\end{array}$ & 0.4573831 & 0.5401661 & 0.04470037 & $\begin{array}{l}11.6866 \\
(0.3066)\end{array}$ \\
\hline 11 & $\begin{array}{c}0.756607 \\
(0.0000)\end{array}$ & $\begin{array}{c}0.353842 \\
(0.0000)\end{array}$ & 0.3194178 & 0.676169 & 0.03562865 & $\begin{array}{l}12.7954 \\
(0.6877)\end{array}$ \\
\hline 12 & $\begin{array}{c}0.699634 \\
(0.0000)\end{array}$ & $\begin{array}{c}0.494125 \\
(0.0000)\end{array}$ & 0.4151258 & 0.5819008 & 0.03923625 & $\begin{array}{l}14.1255 \\
(0.8970)\end{array}$ \\
\hline 13 & $\begin{array}{c}0.591915 \\
(0.0000)\end{array}$ & $\begin{array}{c}0.534024 \\
(0.0000)\end{array}$ & 0.4756274 & 0.521916 & 0.07011727 & $\begin{array}{l}12.4761 \\
(0.9823)\end{array}$ \\
\hline 14 & $\begin{array}{c}0.543795 \\
(0.0000)\end{array}$ & $\begin{array}{r}0.644127 \\
(0.0000)\end{array}$ & 0.5438336 & 0.4545325 & 0.06327845 & $\begin{array}{l}13.0818 \\
(0.9980)\end{array}$ \\
\hline
\end{tabular}


Table 15

Sequential Updating routine

\begin{tabular}{|c|c|c|c|c|c|c|}
\hline Instruments Set & $\vartheta$ & $\omega$ & $\gamma_{b}$ & $\gamma_{f}$ & $\lambda$ & J Statistic \\
\hline \multirow[t]{2}{*}{1} & 0.819448 & 0.532798 & 0.3952859 & 0.6018737 & 0.01181230 & 5.7439 \\
\hline & $(0.0000)$ & $(0.0000)$ & & & & $(0.05659)$ \\
\hline \multirow[t]{2}{*}{2} & 0.80427 & 0.573473 & 0.417639 & 0.5798627 & 0.01238905 & 6.5243 \\
\hline & $(0.0000)$ & $(0.0000)$ & & & & $(0.1633)$ \\
\hline \multirow[t]{2}{*}{3} & 0.753216 & 0.658855 & 0.4682333 & 0.5299406 & 0.01521607 & 9.0328 \\
\hline & $(0.0000)$ & $(0.0000)$ & & & & $(0.2503)$ \\
\hline \multirow[t]{2}{*}{4} & 0.882298 & 0.769344 & 0.4677278 & 0.531035 & 0.002088322 & 9.9717 \\
\hline & $(0.0000)$ & $(0.0004)$ & & & & $(0.1902)$ \\
\hline 5 & N/A & N/A & N/A & N/A & N/A & N/A \\
\hline \multirow[t]{2}{*}{6} & 0.788328 & 0.540078 & 0.4078682 & 0.5893937 & 0.01614191 & 12.6628 \\
\hline & $(0.0000)$ & $(0.0000)$ & & & & $(0.6972)$ \\
\hline 7 & $\mathrm{~N} / \mathrm{A}$ & $\mathrm{N} / \mathrm{A}$ & $\mathrm{N} / \mathrm{A}$ & $\mathrm{N} / \mathrm{A}$ & $\mathrm{N} / \mathrm{A}$ & $\mathrm{N} / \mathrm{A}$ \\
\hline \multirow[t]{2}{*}{8} & 0.74901 & 0.507235 & 0.4049956 & 0.5920575 & 0.02552492 & 13.5396 \\
\hline & $(0.0000)$ & $(0.0000)$ & & & & $(0.6330)$ \\
\hline \multirow[t]{2}{*}{9} & 0.484917 & 0.972689 & 0.669486 & 0.3304229 & 0.005034183 & 8.1289 \\
\hline & $(0.0057)$ & $(0.0000)$ & & & & $(0.08697)$ \\
\hline \multirow[t]{2}{*}{10} & 0.656422 & 0.688806 & 0.5137634 & 0.4847129 & 0.02792334 & 12.0878 \\
\hline & $(0.0000)$ & $(0.0000)$ & & & & $(0.2792)$ \\
\hline \multirow[t]{2}{*}{11} & 0.727238 & 0.461668 & 0.389413 & 0.6072848 & 0.03468375 & 13.1235 \\
\hline & $(0.0000)$ & $(0.0000)$ & & & & $(0.6637)$ \\
\hline \multirow[t]{2}{*}{12} & 0.714426 & 0.579874 & 0.4494599 & 0.5482136 & 0.02722108 & 14.2675 \\
\hline & $(0.0000)$ & $(0.0000)$ & & & & $(0.8917)$ \\
\hline \multirow[t]{2}{*}{13} & 0.620336 & 0.548289 & 0.470544 & 0.5270512 & 0.05679221 & 12.6469 \\
\hline & $(0.0000)$ & $(0.0000)$ & & & & $(0.9805)$ \\
\hline \multirow[t]{2}{*}{14} & 0.675883 & 0.744094 & 0.5258809 & 0.4728967 & 0.01939576 & 12.6469 \\
\hline & $(0.0000)$ & $(0.00000)$ & & & & (0.9986) \\
\hline
\end{tabular}


Table 16

\begin{tabular}{|c|c|}
\hline Instrument Set & Instruments \\
\hline 1 & $\pi_{t-1}, \pi_{t-2}, m c_{t-1}, m c_{t-2}$ \\
\hline 2 & $\pi_{t-1}, \pi_{t-2}, \pi_{t-3}, m c_{t-1}, m c_{t-2}, m c_{t-3}$ \\
\hline 3 & $\pi_{t-1}, \pi_{t-2}, \pi_{t-3}, m c_{t-1}, m c_{t-2}, m c_{t-3}, x_{t-1}, x_{t-2}, x_{t-3}$ \\
\hline 4 & $\pi_{t-1}, \pi_{t-2}, \pi_{t-3}, m c_{t-1}, m c_{t-2}, m c_{t-3}, \varepsilon_{t-1}, \varepsilon_{t-2}, \varepsilon_{t-3}$ \\
\hline 5 & $\pi_{t-1}, \pi_{t-2}, \pi_{t-3}, m c_{t-1}, m c_{t-2}, m c_{t-3}, x_{t-1}, x_{t-2}, x_{t-3}, \varepsilon_{t-1}, \varepsilon_{t-2}, \varepsilon_{t-3}$ \\
\hline 6 & $\begin{array}{l}\pi_{t-1}, \pi_{t-2}, \pi_{t-3}, m c_{t-1}, m c_{t-2}, m c_{t-3}, x_{t-1}, x_{t-2}, x_{t-3}, \varepsilon_{t-1}, \varepsilon_{t-2}, \varepsilon_{t-3} \\
i_{t-1}, i_{t-2}, i_{t-3}, c i_{t-1}, c i_{t-2}, c i_{t-3}\end{array}$ \\
\hline 7 & $\begin{array}{l}\pi_{t-1}, \pi_{t-2}, \pi_{t-3}, m c_{t-1}, m c_{t-2}, m c_{t-3}, x_{t-1}, x_{t-2}, x_{t-3}, \varepsilon_{t-1}, \varepsilon_{t-2}, \varepsilon_{t-3} \\
i_{t-1}, i_{t-2}, i_{t-3}, c i_{t-1}, c i_{t-2}, c i_{t-3}, w i_{t-1}, w i_{t-2}, w i_{t-3}\end{array}$ \\
\hline 8 & $\begin{array}{l}\pi_{t-1}, \pi_{t-2}, \pi_{t-3}, m c_{t-1}, m c_{t-2}, m c_{t-3}, x_{t-1}, x_{t-2}, x_{t-3}, \varepsilon_{t-1}, \varepsilon_{t-2}, \varepsilon_{t-3} \\
i_{t-1}, i_{t-2}, i_{t-3}, w i_{t-1}, w i_{t-2}, w i_{t-3}\end{array}$ \\
\hline 9 & $\pi_{t-1}, m c_{t-1}, x_{t-1}, i_{t-1}, w i_{t-1}, c i_{t-1}$ \\
\hline 10 & $\pi_{t-1}, \pi_{t-2}, m c_{t-1}, m c_{t-2}, x_{t-1}, x_{t-2}, i_{t-1}, i_{t-2}, w i_{t-1}, w i_{t-2}, c i_{t-1}, c i_{t-2}$ \\
\hline 11 & $\begin{array}{l}\pi_{t-1}, \pi_{t-2}, \pi_{t-3}, m c_{t-1}, m c_{t-2}, m c_{t-3}, x_{t-1}, x_{t-2}, x_{t-3}, i_{t-1}, i_{t-2}, i_{t-3} \\
w i_{t-1}, w i_{t-2}, w i_{t-3}, c i_{t-1}, c i_{t-2}, c i_{t-3}\end{array}$ \\
\hline 12 & $\begin{array}{l}\pi_{t-1}, \pi_{t-2}, \pi_{t-3}, \pi_{t-4}, m c_{t-1}, m c_{t-2}, m c_{t-3}, m c_{t-4}, x_{t-1}, x_{t-2}, x_{t-3}, x_{t-4} \\
i_{t-1}, i_{t-2}, i_{t-3}, i_{t-4}, w i_{t-1}, w i_{t-2}, w i_{t-3}, w i_{t-4}, c i_{t-1}, c i_{t-2}, c i_{t-3}, c i_{t-4}\end{array}$ \\
\hline 13 & $\begin{array}{l}\pi_{t-2}, \pi_{t-3}, \pi_{t-4}, \pi_{t-5}, \pi_{t-6}, \pi_{t-7}, \pi_{t-8}, \pi_{t-9}, \pi_{t-10}, m c_{t-4}, m c_{t-5}, m c_{t-6} \\
m c_{t-7}, m c_{t-8}, m c_{t-9}, \varepsilon_{t-5}, \varepsilon_{t-6}, \varepsilon_{t-7}, \varepsilon_{t-8}, \varepsilon_{t-9}, \varepsilon_{t-10}, i_{t-5}, i_{t-6}, i_{t-7}, i_{t-8} \\
i_{t-9}, i_{t-10}\end{array}$ \\
\hline 14 & $\begin{array}{l}\pi_{t-1}, \pi_{t-2}, \pi_{t-3}, \pi_{t-4}, \pi_{t-5}, \pi_{t-6}, \pi_{t-7}, m c_{t-4}, m c_{t-5}, m c_{t-6}, m c_{t-7}, m c_{t-8} \\
m c_{t-9}, m c_{t-10}, m c_{t-11}, \varepsilon_{t-4}, \varepsilon_{t-5}, \varepsilon_{t-6}, \varepsilon_{t-7}, \varepsilon_{t-8}, \varepsilon_{t-9}, \varepsilon_{t-10}, \varepsilon_{t-11}, i_{t-1}, i_{t-2} \\
i_{t-3}, i_{t-4}, i_{t-5}, i_{t-6}, i_{t-7}, i_{t-8}, i_{t-9}, i_{t-10}\end{array}$ \\
\hline
\end{tabular}

Note: $\pi_{t}$ represents CPI inflation, $m c_{t}$ the real marginal cost gap, $x_{t}$ the output gap, $\varepsilon_{t}$ the real exchange rate with the US, $i_{t}$ the 90 day Treasury Bill Rate, $c i_{t}$ commodity price inflation, and $w i_{t}$ wage inflation. 
Irrespective of whether $\beta$ was estimated or imposed, estimates of $\vartheta$ and $\omega$ are consistent with the underlying theory as they lie between zero and one. While consistent with theory, estimates of $\vartheta$ and $\omega$ vary widely depending on estimation routines, orthogonality conditions, and sets of instrumental variables. This case is analogous with that observed when estimating the forward looking NKPC model. Across all estimation routines, $\vartheta$ ranged between 0.48 and 0.88 , while $\omega$ ranged between 0.13 and 0.97 . The excessive variability of these results makes it difficult to determine the proportion of backward looking price setters in the New Zealand economy with any confidence.

Thus far I have made two main findings. Firstly my proxy for marginal cost is unable to estimate $\beta$ that behaves in accordance with theory. The intertemporal discount factor must lie between zero and one for the reason firms future prices are influenced by uncertain movements in future real marginal costs. Unlikely events carry an element of risk which ensures a choice today is worth more than one tomorrow. The second finding is there is overwhelming evidence that there is some portion of firms who sets prices in a backward looking fashion, as all estimates are statistically significant at a $1 \%$ level of significance. In addition, I fail to reject the Hybrid NKPC at a 5\% level of significance using Hansen's J Statistic across a majority of IV sets. The exception lies with the Iterated coefficients estimation routine using IV set 1 for both orthogonality equations. 


\subsection{Fundamental Inflation}

The main drawback to the analysis conducted thus far is that I have no indication of how well each model characterises New Zealand inflation dynamics during the observed period. One method adopted in the literature to assess the model's goodness of fit is to construct a series of fundamental inflation. This empirical approach is closely related to the procedure used by Campbell and Shiller (1987) to test present-value models of stock prices. Fortunately this approach does not involve making assumptions about the structure of the whole economy in the application of maximum likelihood methods or the choice of appropriate instruments in an instrumental variables estimation.

\subsubsection{The forward looking New Keynesian Phillips Curve}

In this model inflation is driven by forward looking behaviour of firms' price setting, meaning current inflation is a function of expected future inflation. The forward looking nature of the inflation process becomes more apparent by iterating the NKPC forward, which shows marginal cost expectations are the driving force behind inflation:

$$
\pi_{t}^{*}=\lambda \sum_{k=0}^{\infty} \beta^{k} E_{t}\left(m c_{t+k}\right)
$$

This benchmark theory implies that inflation should equal a discounted stream of expected future marginal costs. As in the case Campbell and Shiller's present value theory of stock prices, the optimizing sticky price model that I consider here gives rise to a theoretical relationship where the evolution of the aggregate level of prices depends on the discounted sum of 
expected future values of real marginal cost. The theory behind fundamental inflation can be found in Appendix 3.3.

So as to show the reader how well the model fits, Figure 7 plots the estimated series of fundamental inflation with actual inflation when $\vartheta$ is 0.7 and $\beta$ 0.99. $\vartheta$ of 0.7 was used because it was the average estimate and is consistent with prices being sticky for roughly 3.33 quarters. Furthermore, the evolution of theoretical inflation dynamics was obtained using a Vector Autoregression of order one (VAR (1)) in CPI inflation and the real marginal cost gap. A VAR (2) and VAR (3) were experimented with, however the fundamental inflation series failed to improve the correlation coefficient with current inflation. As one can see the forward looking NKPC fails to fully describe inflation dynamics.

\section{Figure 7 - NZ Forward looking NKPC fundamental inflation}

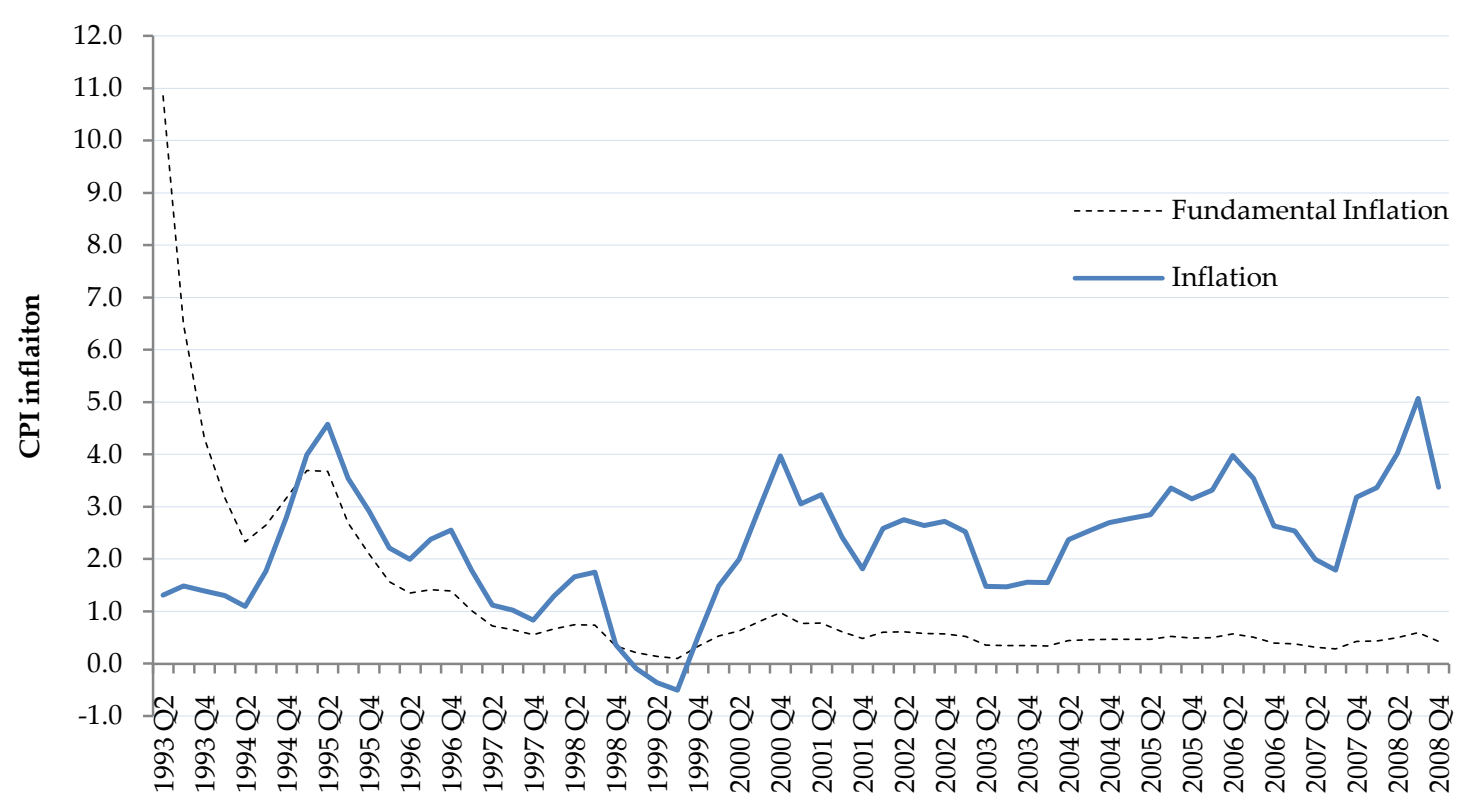




\subsubsection{The Hybrid New Keynesian Phillips Curve}

The specification of the Hybrid NKPC given by the following equations constitutes a second order difference equation:

$$
\pi_{t}=\gamma_{f} E_{t} \pi_{t+1}+\gamma_{b} \pi_{t-1}+\lambda m c_{t}
$$

The measure of fundamental inflation, $\pi_{t}{ }^{*}$, is defined as the standard closed form solution of this equation given by the following expression as derived in Appendix 3.4:

$$
\pi_{t}^{*}=\delta_{1} \pi_{t-1}+\left(\frac{\lambda}{\delta_{2} \gamma_{f}}\right) \sum_{k=0}^{\infty}\left(\frac{1}{\delta_{2}}\right)^{k} E_{t}\left(m c_{t+k} \mid X_{t}\right)
$$

Where $\delta_{1} \leq 1$ and $\delta_{2} \geq 1$ represent the stable and unstable roots which are defined by:

$$
\delta_{1}=\frac{1-\sqrt{1-4 \gamma_{f} \gamma_{b}}}{2 \gamma_{b}}, \quad \delta_{2}=\frac{1+\sqrt{1-4 \gamma_{f} \gamma_{b}}}{2 \gamma_{b}}
$$

As it can be seen by the previous equation, fundamental inflation is determined by the discounted stream of expected future real marginal costs as well as lagged inflation, which arises from the presence of firms who obey a backward looking rule of thumb. Since I was unable to estimate a fixed set of structural estimates I believe it would be beneficial to evaluate fundamental inflation rates implied by all estimated sets of parameters (54 in total). In estimating fundamental inflation I have used a VAR (1) of CPI inflation and the real marginal cost gap. Theoretical inflation series were also estimated using a VAR (2) and VAR (3), but correlation between the VAR (1) series and the VAR (2) and VAR (3) series was 0.99, indicating no additional information was obtained by a longer autoregressive history. A VAR (1) specification also conserves degrees of freedom and obtains a longer fundamental inflation series. For evaluation I have incorporated five measures of goodness of fit; (i) the ratio of the standard deviation of 
fundamental and actual rates of inflation, (ii) the correlation coefficient between the fundamental and actual inflation rates, (iii) a weighted average of the sum of squared differences between fundamental inflation and actual inflation, (iv) the 1 step prediction error of 2009:Q1 inflation, and (v) the 4 step prediction error of 2009:Q1 inflation. Table 17 shows the five top ranked pairs of estimates according to each of the five evaluation criteria.

For the first evaluation criteria, the ratio of the two standard deviations is optimal when it is close to one. Interestingly the top four ranked pairs of estimates are all estimated from specification two which corresponds to the orthogonality condition that represents the theoretical Hybrid NKPC relation. Closely related is the second tool which measures the correlation coefficient between the fundamental inflation series and actual inflation. Overall these were so similar that they ranged between 0.8387 and 0.8410 .

The third evaluation tool measured the average squared difference (ASD) between fundamental and actual inflation. This measure provides an indication of how close the inflation rate implied by the Hybrid NKPC is to actual inflation. In ranked order the best pair of $\vartheta$ and $\omega$ that fitted actual inflation was estimated from the first specification equation using the sequential updating routine and instruments from set 14 . Here, $\vartheta$ was estimated rather low at 0.54 and $\omega$ 0.64. Pairs of estimates ranked second to fifth are increasing in both structural parameters until $\vartheta$ reaches 0.72 and $\omega$ 0.78. As a fitting tool I believe this is the strongest indication of whether the theory can model inflation dynamics. 
Table 17

\begin{tabular}{|c|c|c|c|c|c|c|c|}
\hline & Ranking & Criteria & Type & Specification & Instrument Set & $\vartheta$ & $\omega$ \\
\hline \multirow[t]{5}{*}{ SD/SD } & 1 & 1.002334 & SI & 2 & 9 & 0.484917 & 0.972689 \\
\hline & 2 & 1.000865 & IC & 2 & 9 & 0.581236 & 0.903943 \\
\hline & 3 & 0.9954635 & IC & 2 & 10 & 0.675862 & 0.827849 \\
\hline & 4 & 0.9895082 & IC & 2 & 5 & 0.808389 & 0.869511 \\
\hline & 5 & 0.98573 & SI & 1 & 14 & 0.543795 & 0.644127 \\
\hline \multirow[t]{5}{*}{ CORR } & 1 & 0.8410062 & IC & 1 & 14 & 0.673822 & 0.364843 \\
\hline & 2 & 0.8408993 & IC & 1 & 12 & 0.650509 & 0.410464 \\
\hline & 3 & 0.8406922 & IC & 1 & 13 & 0.649189 & 0.440235 \\
\hline & 4 & 0.8406574 & SI & 1 & 9 & 0.848219 & 0.134733 \\
\hline & 5 & 0.8406461 & IC & 1 & 11 & 0.650903 & 0.44441 \\
\hline \multirow[t]{5}{*}{ ASD } & 1 & 0.4107473 & SI & 1 & 14 & 0.543795 & 0.644127 \\
\hline & 2 & 0.4135771 & SI & 2 & 10 & 0.656422 & 0.688806 \\
\hline & 3 & 0.4138747 & SI & 2 & 14 & 0.675883 & 0.744094 \\
\hline & 4 & 0.4142501 & IC & 2 & 12 & 0.708135 & 0.75994 \\
\hline & 5 & 0.4144782 & IC & 2 & 11 & 0.716949 & 0.776757 \\
\hline \multirow[t]{5}{*}{1 STEP } & 1 & $5.55025 \mathrm{E}-05$ & IC & 1 & 3 & 0.684647 & 0.61879 \\
\hline & 2 & 0.000500104 & SI & 2 & 4 & 0.882298 & 0.769344 \\
\hline & 3 & 0.000582209 & SI & 1 & 8 & 0.762461 & 0.346939 \\
\hline & 4 & 0.000738155 & SI & 2 & 12 & 0.714426 & 0.579874 \\
\hline & 5 & 0.001040708 & IC & 1 & 2 & 0.747247 & 0.61486 \\
\hline \multirow[t]{5}{*}{4 STEP } & 1 & 0.000176358 & IC & 1 & 3 & 0.684647 & 0.61879 \\
\hline & 2 & 0.00023461 & SI & 2 & 4 & 0.882298 & 0.769344 \\
\hline & 3 & 0.000505665 & SI & 2 & 2 & 0.80427 & 0.573473 \\
\hline & 4 & 0.005094391 & SI & 2 & 13 & 0.620336 & 0.548289 \\
\hline & 5 & 0.006443273 & IC & 2 & 8 & 0.79771 & 0.819786 \\
\hline
\end{tabular}


The fourth and fifth evaluation tools measure the mean square error of a one step ahead and four step ahead forecast respectively. Using each estimated pair of structural parameters I attempted to predict the out of sample 2009:Q1 value of CPI inflation. According to the Reserve Bank of New Zealand the 2009:Q1 CPI inflation rate was 3.0\%. Following Rumler (2007) I generated a forecast of fundamental inflation. Obtaining a one step forecast can be obtained by leading the Hybrid NKPC fundamental inflation equation by one period. In addition, using the fact that the one period ahead forecast of $X_{t}$ is $\hat{X}_{t+1}=A X_{t}$ we can express next periods fundamental inflation using current variables. This principle results in a s-step forecast of the fundamental inflation rate:

$$
\hat{\pi}_{t+s}^{*}=\delta_{1} \hat{\pi}_{t+s-1}^{*}+\left(\frac{\lambda}{\delta_{2} \gamma_{f}}\right) e_{1}^{\prime}\left(1-\frac{1}{\delta_{2}} A\right)^{-1} A^{s} X_{t}
$$

If we consider Table 17, the top five ranked one step ahead forecasts is represented by 1 Step and the top five ranked four step ahead forecasts is represented by 4 Step. One can see the top two best pairs of $\vartheta$ and $\omega$ that forecast inflation for 2009:Q1 (one and four step forecasts) were the same. The main concerning feature with the top five pairs of estimates is that they are not similar and range widely.

The analysis I have conducted to this point has been overly restrictive. Given all criteria I am unable to establish a pair of estimates which consistently rank high in Table 17. Each of the sample statistics I have employed highlight particular characteristics between fundamental and actual inflation, although I cannot identify the best pair that perform well across all. In order to gauge how well the GMM estimates fit CPI inflation I have calculated an average ranking across all evaluation tools. Table 18 shows the top five ranked pairs of estimates from this calculation. Most importantly, the top three in this list were estimated from specification 2, which 
corresponds to the theoretical Hybrid NKPC. One could consider this group to be biased given the inclusion of the first evaluation tool. As discussed before the relative standard deviation of fundamental inflation to actual is biased towards one as the degree of backward looking approaches one. Instead I compute an average ranking with the remaining criteria which minimise squared differences and errors. Table 19 presents the top five ranked estimates according to average ranking using the last three evaluation tools.

\begin{tabular}{cccccc} 
Table 18 & \multicolumn{5}{c}{} \\
\hline Ranking & Type & Specification & Instrument Set & $\vartheta$ & $\omega$ \\
\hline 1 & IC & 2 & 8 & 0.79771 & 0.819786 \\
2 & SI & 2 & 4 & 0.882298 & 0.769344 \\
3 & IC & 2 & 5 & 0.808389 & 0.869511 \\
4 & IC & 1 & 1 & 0.766034 & 0.597183 \\
5 & IC & 1 & 3 & 0.684647 & 0.61879 \\
\hline
\end{tabular}

Table 19

\begin{tabular}{cccccc}
\hline Ranking & Type & Specification & Instrument Set & $\vartheta$ & $\omega$ \\
\hline 1 & IC & 2 & 8 & 0.79771 & 0.819786 \\
2 & SI & 2 & 4 & 0.882298 & 0.769344 \\
3 & IC & 2 & 5 & 0.808389 & 0.869511 \\
4 & IC & 2 & 1 & 0.822222 & 0.700897 \\
5 & IC & 2 & 2 & 0.787553 & 0.737355 \\
\hline
\end{tabular}

From Table 19 one finds taking an equal weighted average across the last three evaluation tools has identified the best five sets of estimates that describe inflation dynamics. The best all round set of structural estimates finds the degree of price stickiness $(\vartheta)$ to be 0.80 and the degree of backward 
looking price setters $(\omega)$ 0.82. This particular level of price stickiness implies prices tend to be fixed for five quarters or fifteen months. Additionally, as it has been estimated the proportion of firms who set prices in a backward looking rule of thumb fashion is approximately $82 \%$, one could use this as direct evidence against forward looking NKPC theory. I have constructed a measure of fundamental inflation using assuming $\vartheta=0.79771, \omega=$ 0.819786 , and $\beta=0.99$. Figure 8 plots fundamental inflation $\left(\pi_{t}^{*}\right)$ versus actual inflation $\left(\pi_{t}\right)$.

Figure 8 - NZ Hybrid NKPC fundamental inflation

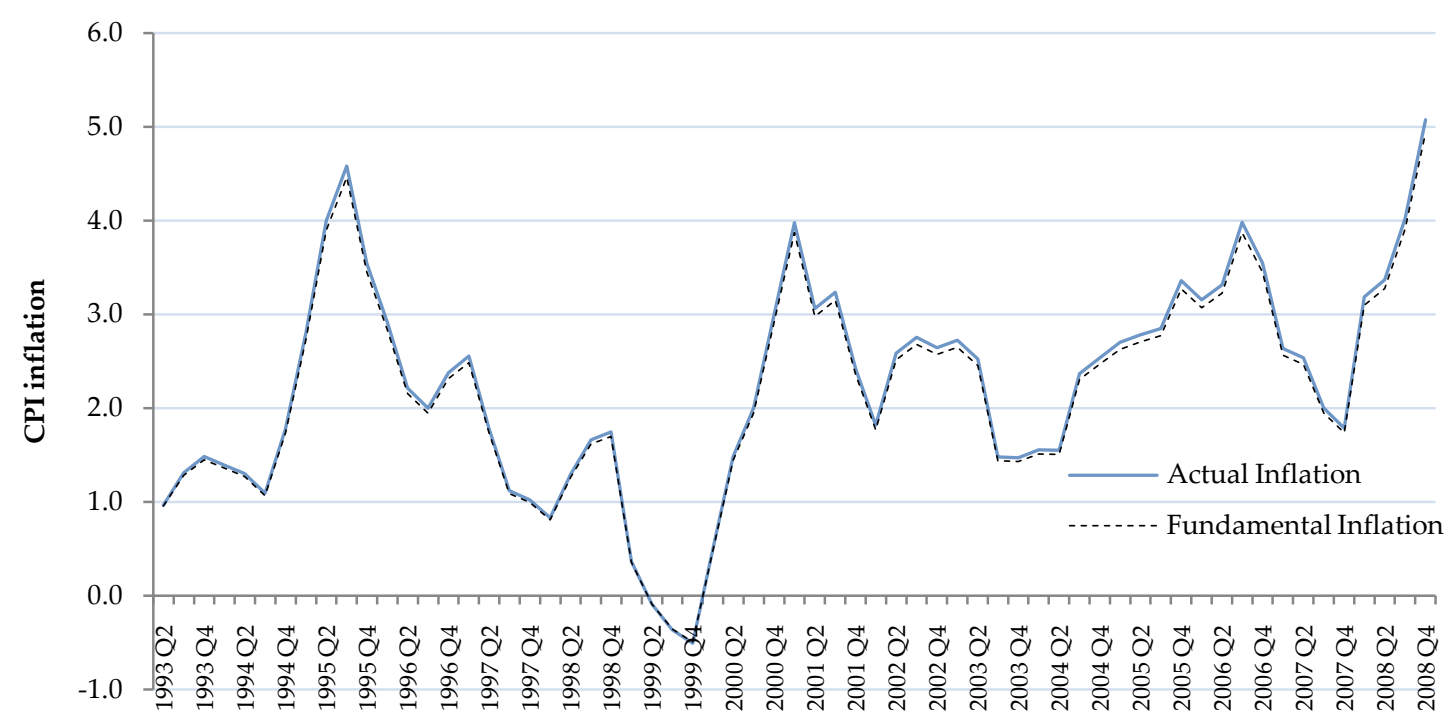

Figure 8 shows fundamental inflation tracks very closely. The correlation coefficient between the two is 0.99 . The combined theory of backward looking and forward looking price setters is capable of tracking deviations in inflation with the structural parameters discussed above. The one step ahead forecast for 2009:Q1 inflation, implied by the optimal pair of $\vartheta$ and $\omega$, predicted by the Hybrid NKPC was $2.9304 \%$ and the four step ahead forecast was 3.0803\%. These predictions are similar to the actual 2009:Q1 inflation rate of 3\%, suggesting the theoretical properties of the Hybrid NKPC are highly relevant. Another benefit from using this approach 
is I am able to identify an optimal set of instrumental variables (set eight) and GMM estimation routine (iterated coefficient method). The set of instrumental variables used in estimation contained the first three lags of inflation, real marginal cost gap, output gap, real exchange rate with the US, 90 day Treasury Bill Rate, and wage inflation.

\subsection{Critique}

\subsubsection{Theoretical critique}

Hybrid New Keynesian Phillips Curves are rarely used by themselves in practice. Usually they are incorporated into a larger scale macroeconomic model. The main theoretical weakness of the Hybrid NKPC is it does not allow for non zero movements in steady state inflation. Bakhshi, BurrielLlombart, Khan, and Rudolf (2003) consider an optimising model with Calvo price setting in which there are both nominal and real rigidities, and assess the consequences of positive trend (steady state) inflation. Under the Calvo assumption, firms receive an exogenous probabilistic signal every period as to when they can adjust their price. This adjustment probability is constant and independent across firms and time. The assumption of an exogenous adjustment signal is considered reasonable if the inflation environment is founded on a steady state inflation rate of zero (Woodford, 2002). However Bakhshi et al (2003) argue in the presence of positive trend inflation, firms with fixed nominal prices experience erosion in their relative prices and are likely to reset their nominal prices more frequently. In response, Bakhshi et al (2003) believe the Calvo assumption that firms cannot choose the timing and frequency of price changes places an upper bound on trend inflation for which the model can be solved. 
Bakhshi et al (2003) extend Woodford (2002) to an economy with positive trend inflation to study the interaction between trend inflation and Calvo price-setting. Their macroeconomic environment is characterised by strategic complementarities in firms' pricing decisions. Using baseline parameters it was found the critical inflation rate is under 5.5\%. In contrast Ascari (2000) finds the upper bound under strategic substitutability (common factor markets) is approximately $12.5 \%$. Therefore by considering nominal and real rigidities one reduces the upper bound for which optimal relative prices are defined.

Bakhshi et al (2003) derive their refined NKPC when it is assumed steady state trend inflation is below the upper bound. They obtain two different forms of the traditional NKPC, one in which strategic complementarities are present and the other when there is strategic substitutability. In applying both types of price stickiness they find higher trend inflation is associated with a flatter NKPC and greater probability of price stickiness.

Their central finding under exogenous price stickiness is optimal pricing behaviour becomes more forward looking in the presence of positive trend inflation. Current marginal costs matter relatively less for setting the optimal price under positive trend inflation compared with the case with no trend inflation. This is because price setting firms are more concerned about the erosion of future markups. The relatively small effect of marginal cost on inflation in the presence of trend inflation is due to the interaction between exogenous price stickiness and forward looking price setting behaviour. As a result Bakhshi et al (2003) believe the implication that the slope of the Phillips curve falls with a rise in inflation would also apply to other models of exogenous price stickiness. 
Ascari (2003) extends Bakhshi et al (2003) by considering a model in which trend inflation is non zero (instead of being strictly positive). The motivation behind his model arises from preliminary analysis which claims a majority of international datasets possess trend inflation series which have moved away from zero over the last four decades. It is also claimed developed economies show positive levels of average inflation since World War Two. This revelation has lead Ascari (2003) to believe that a majority of authors in the field do not care to take account of low levels of trend inflation. In light of this, Ascari (2003) investigates the implications of trend inflation in a standard Calvo (1983)-Rotemberg (1982) sticky price specification; one that is most common in the literature.

By allowing steady state inflation to change, Ascari (2003) analyses both long run and short run properties of time dependent staggered price models. Ascari (2003) makes three key observations as trend inflation approaches an identified upper bound of $8 \%$ : (i) the size of the short run effect becomes substantially larger, (ii) the impact effect of a positive money shock becomes negative, and (iii) the model fails to satisfy the Blanchard-Kahn conditions and instead produces explosive behaviour. Explosive behaviour is caused by generating the number of roots bigger than the number of nonpredetermined variables. This evidence suggests trend inflation is highly material for the dynamics of log linearised models. Specifically, these findings propose log linearised models depend on the steady state it is has been $\log$ linearised about.

Ascari's findings dampen the usefulness of the estimated model in this section. If the model estimated in this section were to be employed in practice using the estimates I have recommended as calibration coefficients, then one might find the model's dynamics are not being fully described 
given the presence of an underlying trend. The underlying trend in New Zealand is driven by the Policy Target Agreement which is an agreement between the Reserve Bank Governor and the Finance Minister to maintain inflation between 1-3\% over the medium term. If the findings by Bakhshi et al (2003) are thought be true for New Zealand, then one could suggest my estimates of the degree of backward looking price setters is biased upwards given the presence of positive trend inflation.

\subsubsection{Econometric critique}

The central finding across a range of international datasets has revealed parameter estimates and hypothesis tests are highly sensitive to the theoretical structure, estimation procedure, and the chosen measure of real activity. In a recent publication, Menyhért (2007) explores these issues using Hungarian data so as to establish main ambiguities and problems with conventional instrumental variable techniques. His work largely focuses on the empirical relevance of weak instruments, drawing on work by Stock and Yogo (2001) and Hansen (1982). The main contribution of Menyhért's investigation was the two step GMM estimator was found to yield estimates that were biased and sampling errors highly misleading.

The Menyhért (2007) study incorporated core inflation as opposed to CPI inflation, but it was claimed estimates turn out to be invariant to this choice. As for the driving variable, a theory consistent real unit labour cost was used. Menyhért (2007) claimed GMM estimates are often insignificant and extremely sensitive to asymptotic irrelevant aspects of the orthogonality condition under inspection, such as parameter normalisation and choice of weighting matrix. Because of this, GMM tends to experience declines relative 
to the asymptotic distribution that renders biased estimates and unreliable hypothesis tests.

There is a significant amount of literature which explores problems of small sample GMM estimation due to poor instrument choice. In a review of the literature, Stock, Wright, and Yogo (2002) found weak instruments have severe consequences in regards to sample properties. Often sampling distributions become non-normal which results in point estimates, hypothesis tests, and confidence intervals being unreliable. So as to measure instrument strength Menyhért estimated the first stage reduced form equation of forward looking inflation regressed on the predetermined instruments:

$$
\pi_{t+1}=z_{t}^{\prime} \delta+v_{t}
$$

Monte Carlo simulations conducted by Hall, Rudebusch, and Wilcox (1996) were employed to test for non identification $(\delta=0)$ and found it is an incompetent identifier for weak or underperforming instruments. Given this, Menyhért adopts critical values devised by Stock and Yogo (2001) which account for a certain proportion of bias in the two stage GMM estimates. Stock and Yogo (2001) consider two quantitative definitions of weak instruments; one of which measures the bias of Two Stage Least Squares (TSLS) relative to Ordinary Least Squares (OLS) and the other the size of the nominal TSLS t-test. As I have not conducted this test in my analysis thus far and my concern lies in the accuracy and consistency of estimates, I interpret the weakness of instruments in terms of their relative bias. Table 20 reports Stock and Yogo (2001) critical values for the F-statistic based on the assumption relative bias of GMM estimates do not exceed 30\%.

Similarly to Menyhért (2007), I find the standard joint hypothesis test of $\delta=0$ for all sets of instrumental variables is statistically significant from zero 
at the $1 \%$ level. If one compares Stock and Yogo (2001) critical values with their actual F-statistic we find GMM estimates maintain much of the bias produced by endogeneity in the OLS estimations. Furthermore, for eight out of the fourteen sets of instruments the relative bias is expected to exceed $20 \%$. This finding suggests that two stage GMM is unable to improve upon suspicious OLS estimates. As a result, the applied instrumental variable technique is not considerably improving the econometric estimation of the New Zealand Hybrid New Keynesian Phillips Curve.

Table 20

\begin{tabular}{|c|c|c|c|c|c|}
\hline \multirow[b]{2}{*}{$\begin{array}{l}\text { Instruments } \\
\text { Set }\end{array}$} & \multirow[b]{2}{*}{ F Statistic } & \multicolumn{4}{|c|}{ Stock - Yogo Critical values of relative biasness } \\
\hline & & $5 \%$ & $10 \%$ & $20 \%$ & $30 \%$ \\
\hline 1 & $\begin{array}{l}11.14137 \\
(0.0000)\end{array}$ & 16.85 & 10.27 & 6.71 & 5.34 \\
\hline 2 & $\begin{array}{l}7.388153 \\
(0.0000)\end{array}$ & 19.28 & 11.12 & 6.76 & 5.15 \\
\hline 3 & $\begin{array}{l}7.753548 \\
(0.0000)\end{array}$ & 20.53 & 11.46 & 6.65 & 4.92 \\
\hline 4 & $\begin{array}{l}6.304141 \\
(0.0000)\end{array}$ & 20.53 & 11.46 & 6.65 & 4.92 \\
\hline 5 & $\begin{array}{l}6.023375 \\
(0.0000)\end{array}$ & 21.01 & 11.52 & 6.53 & 4.75 \\
\hline 6 & $\begin{array}{l}10.03527 \\
(0.0000)\end{array}$ & 21.34 & 11.48 & 6.33 & 4.53 \\
\hline 7 & $\begin{array}{l}9.679901 \\
(0.0000)\end{array}$ & 21.39 & 11.44 & 6.26 & 4.46 \\
\hline 8 & $\begin{array}{l}10.57574 \\
(0.0000)\end{array}$ & 21.34 & 11.48 & 6.33 & 4.53 \\
\hline 9 & $\begin{array}{l}7.244305 \\
(0.0000)\end{array}$ & 19.28 & 11.12 & 6.76 & 5.15 \\
\hline 10 & $\begin{array}{l}9.451475 \\
(0.0000)\end{array}$ & 21.01 & 11.52 & 6.53 & 4.75 \\
\hline 11 & $\begin{array}{l}8.579561 \\
(0.0000)\end{array}$ & 21.34 & 11.48 & 6.33 & 4.53 \\
\hline 12 & $\begin{array}{l}7.890937 \\
(0.0000)\end{array}$ & 21.41 & 11.40 & 6.20 & 4.39 \\
\hline 13 & $\begin{array}{l}6.290834 \\
(0.0000)\end{array}$ & 21.42 & 11.36 & 6.14 & 4.34 \\
\hline 14 & $\begin{array}{l}13.16654 \\
(0.0000) \\
\end{array}$ & 21.42 & 11.29 & 6.04 & 6.26 \\
\hline
\end{tabular}




\subsection{Summary}

The analysis undertaken in this section has shown us that it is difficult to establish the proportion of rule of thumb price setters that are active in the New Zealand economy. Fundamental or implied inflation series were used as the primary fitting method. It was found the fundamental inflation series from the NKPC failed to fully describe inflation dynamics. Using the Hybrid relation, implied inflation series were computed for all estimated coefficients. A set of statistical tools were then used to establish prices are fixed on average for 5 quarters and $82 \%$ of firms who reset prices set those in a backward looking manner. A word of caution is stressed as there remains at least $20 \%$ relative bias from OLS based estimates.

My findings in this section should be treated with caution given the deficiencies of the conventional two step GMM estimator and theoretical concerns. While the relevant single hypothesis tests are statistically significant and I fail to reject the Hybrid NKPC; estimates of $\vartheta$ and $\omega$ range widely making it difficult to establish ideal estimates. The primary reason for obtaining inconsistent estimates of the structural parameters was because of normalisation issues and bias GMM was unable overcome.

The model is criticised mainly on econometric grounds. The theoretical critique focuses on a lesser considered argument of parameter estimates in the presence of trend inflation in an economy wide model. The model in the next section attempts to estimate rule of thumb consumers and firms in a small open economy model of NZ. There we will be able to determine whether the presence of other sectors has any effect on parameter estimates. 
Appendix 3.1 - Forward Looking NKPC

The typical starting point for the derivation of the forward looking NKPC is a market of monopolistically competitive firms that face some type of constraints on price adjustment. The pricing decision evolves explicitly from a monopolistic competitor's profit maximization problem, subject to the constraint of time dependent price adjustment.

Each period, only a random fraction $(1-\vartheta)$ of firms are able to reset their price while all other firms keep their price unchanged. When firms eventually reset their price they must take into account that the price may be fixed for many periods. We assume they do this by choosing a log price, $z_{t}$, that minimises the loss function:

$$
L\left(z_{t}\right)=\sum_{k=0}^{\infty}(\vartheta \beta)^{k} E_{t}\left(z_{t}-z_{t+k}^{*}\right)^{2}
$$

One can choose from many loss functions, although using a quadratic loss function yields mathematically pleasing results which differ little from other loss functions. Here $\vartheta$ is between zero and one, $E_{t}$ is the expectations operator conditional on the information available at time $t, \beta$ is the intertemporal discount factor, and $z_{t+k}^{*}$ is the log of the optimal price that the firm would set in period $t+k$ if there were no price rigidity. The implication that $\beta<1$ implies that the firm places less weight on future losses as opposed to losses today. Future losses are discounted at the rate $(\vartheta \beta)^{k}$, not just $\vartheta^{k}$. This is because the probability that the price will be fixed until $t+k$ is $\vartheta^{k}$, so the loss in period $t+k$ is discounted backwards using the intertemporal discount factor so as to account for time value. The term $E_{t}\left(z_{t}-z_{t+k}^{*}\right)^{2}$ describes the expected loss in profits for the firm at time $t+k$ given the firm is unable to set a frictionless optimal price in that period. 
Given the loss function the optimal value of $z_{t}$ can be obtained by differentiating with respect to the choice variable $z_{t}$ and solving when the derivative is set to zero:

$$
L^{\prime}\left(z_{t}\right)=2 \sum_{k=0}^{\infty}(\vartheta \beta)^{k} E_{t}\left(z_{t}-z_{t+k}^{*}\right)
$$

Separating out the $z_{t}$ terms and seeing we have an infinite geometric progression:

$$
\sum_{k=0}^{\infty}(\vartheta \beta)^{k}=\frac{1}{1-\vartheta \beta}
$$

We can re-write the first order condition for the optimal price:

$$
z_{t}=(1-\vartheta \beta) \sum_{k=0}^{\infty}(\vartheta \beta)^{k} E_{t} z_{t+k}^{*}
$$

This equation says that the optimal pricing solution for the firm is to set its price equal to a weighted average of prices that it would have expected to set in a future world with no price rigidities. As firms are unable to change prices each period, they choose to try and keep close on average to the optimal price $z_{t}^{*}$. It is also assumed the firm's optimal pricing strategy involves setting a fixed mark-up over marginal cost $\left(m c_{t}\right)$. Therefore the optimal reset price can be written as:

$$
z_{t}=(1-\vartheta \beta) \sum_{k=0}^{\infty}(\vartheta \beta)^{k} E_{t}\left(\mu+m c_{t+k}\right)
$$

This theory suggests that price adjustment is based on current and expected future marginal costs. Aggregating over individual behaviour leads to a relationship where the aggregate price level in the economy $\left(p_{t}\right)$ is a weighted average of last period's aggregate price level and the new optimal reset price.

$$
\begin{aligned}
& p_{t}=\vartheta p_{t-1}+(1-\vartheta) z_{t} \\
& z_{t}=\frac{1}{1-\vartheta}\left(p_{t}-\vartheta p_{t-1}\right)
\end{aligned}
$$


By rewriting the aggregate price level equation we can obtain an expression for the optimal reset price:

$$
z_{t}=\vartheta \beta E_{t} z_{t+1}+(1-\vartheta \beta)\left(\mu+m c_{t}\right)
$$

Substituting this expression for $z_{t}$ into the aggregate price level equation we obtain:

$$
\frac{1}{1-\vartheta}\left(p_{t}-\vartheta p_{t-1}\right)=\frac{\vartheta \beta}{1-\vartheta}\left(E_{t} p_{t+1}-\vartheta p_{t}\right)+(1-\vartheta \beta)\left(\mu+m c_{t}\right)
$$

Rearranging this equation yields the forward looking NKPC:

$$
\pi_{t}=\beta E_{t} \pi_{t+1}+\frac{(1-\vartheta)(1-\vartheta \beta)}{\vartheta}\left(\mu+m c_{t}-p_{t}\right)
$$

The fundamental difference between the formulation of the New Keynesian Phillips Curve and the traditional Phillips curve is the NKPC relies on future inflation in determining current inflation, while the traditional Phillips curve is solely backward looking. 
As with the forward looking NKPC, I continue to assume each firm is able to adjust its price in any given period with a fixed probability $(1-\vartheta)$ that is independent of the time the price has been fixed. To address the issue of inflation persistence, Gali and Gertler (1999) and Gali, Gertler, and Salido (2001) extend the model by assuming a constant fraction, $\omega$, use a backward looking rule of thumb to set their prices, and a fraction $(1-\omega)$ set their price by solving an optimisation problem that leads them to consider the expected future behaviour of marginal costs. I refer to these firms as 'forward looking'. The aggregate price level now evolves according to:

$$
p_{t}=\vartheta p_{t-1}+(1-\vartheta) \bar{p}_{t}^{*}
$$

Where $\bar{p}_{t}^{*}$ is an index for the prices newly set in period $t$. Let $p_{t}^{f}$ denote the price set by a forward looking at time $t$ and $p_{t}^{b}$ the price set by a backward looking firm. The index for newly set prices may be expressed as:

$$
\bar{p}_{t}^{*}=(1-\omega) p_{t}^{f}+\omega p_{t}^{b}
$$

Forward looking firms behave exactly as in the baseline Calvo model described earlier. Accordingly, $p_{t}^{f}$, may be expressed as:

$$
p_{t}^{f}=(1-\vartheta \beta) \sum_{k=0}^{\infty}(\vartheta \beta)^{k} E_{t}\left(m c_{t+k}^{n}\right)
$$

This model specification assumes backward looking firms obey a rule of thumb that has the following two features: (1) no persistent deviations between the rule and optimal behaviour; i.e. in a steady state equilibrium the rule is consistent with optimal behaviour; (2) the price in period $t$ given by the rule depends only on information dated $t-1$ or earlier. It is also assumed that the firms is unable to tell whether any individual competitor is backward looking or forward looking. Under this design the addition of rule of thumb setters enables us to measure the departure from the baseline 
forward looking model similar to the way Campbell and Mankiw (1989) used rule of thumb consumers to test the permanent income hypothesis. These considerations leads to a rule that is based on the recent pricing behaviour of the firms competitors:

$$
p_{t}^{b}=\bar{p}_{t-1}^{*}+\pi_{t-1}
$$

This equation says a backward looking firm at $t$ sets its price equal to the average price set in the most recent round of price adjustments, $\bar{p}_{t-1}^{*}$, with a correction for inflation. Lagged inflation is used as a correction to forecast current inflation. Gali and Gertler (1999) claim while it is a rather ad hoc rule it has some appealing features. One should find as long as inflation is stationary, the rule converges to optimal behaviour over time. This is because the rule implicitly incorporates information about the future since the price index $\bar{p}_{t-1}^{*}$ is partly determined by forward looking price setters.

One can obtain the hybrid representation of the forward looking NKPC by combining the prior four equations:

$$
\begin{gathered}
\pi_{t}=\left(\frac{\vartheta \beta}{\vartheta+\omega(1-\vartheta(1-\beta))}\right) E_{t} \pi_{t+1}+\left(\frac{\varpi}{\vartheta+\omega(1-\vartheta(1-\beta))}\right) \pi_{t-1}+\left(\frac{(1-\omega)(1-\beta \vartheta)(1-\vartheta)}{\vartheta+\omega(1-\vartheta(1-\beta))}\right) r m c_{t} \\
\text { or } \\
\pi_{t}=\gamma_{f} E_{t} \pi_{t+1}+\gamma_{b} \pi_{t-1}+\lambda r m c_{t}
\end{gathered}
$$


Appendix 3.3 - Forward Looking NKPC Fundamental Inflation

In determining Fundamental Inflation it is assumed that the information contained in a small atheoretical bivariate Vector Autoregression (VAR) is a subset of the market's full information set. Letting the information set of agents be described by past realisations of inflation and real marginal cost:

The vector $X_{t}=\left[\pi_{t}, m c_{t}, \ldots, \pi_{t-q+1}, m c_{t-q+1}\right]^{\prime}$ follows a $\operatorname{VAR}(q)$ in companion form:

$$
X_{t+1}=A X_{t}+\Gamma_{X_{t+1}}
$$

Where $\Gamma_{\mathrm{X}_{\mathrm{t}+1}}=\left[\eta_{\mathrm{t}}, 0, \ldots, 0\right]^{\prime}$ and the companion matrix, $\mathrm{A}$, has dimensions $2 q \times 2 q$ and takes the following form:

$$
A=\left[\begin{array}{ccccc}
\Phi_{1} & \Phi_{2} & \cdots & \Phi_{q-1} & \Phi_{q} \\
I & 0 & \cdots & 0 & 0 \\
\cdots & \cdots & \ddots & \vdots & \vdots \\
0 & 0 & \cdots & I & 0
\end{array}\right]
$$

Using the iterated form of the forward looking NKPC as a basis for fundamental inflation we can use the information we have established to form an estimate of the discounted stream of expected future real marginal costs. Since expectations of future marginal costs are not observable we cannot construct a direct measure of $\pi_{t}^{*}$. However if we let $q$ represent a restricted information set observable to the econometrician, it follows from the iterating forward looking NKPC:

$$
\pi_{t}^{*}=\lambda \sum_{k=0}^{\infty} \beta^{k} E_{t}\left(m c_{t+1} \mid X_{t}\right)
$$

If we let $\mathrm{A}$ denote the companion matrix as defined above for the $\operatorname{VAR}(q)$ of $X_{t}$. We can infer $E_{t}\left(m c_{t+k} \mid X_{t}\right)=e_{1}^{\prime} A^{k} X_{t}$, where $e_{1}$ is a vector of dimension $2 q$ with a 1 in its first position and zeros elsewhere. If the model is correct we can obtain: 


$$
\pi_{t}^{*}=\lambda \sum_{k=0}^{\infty} \beta^{k} e_{1}^{\prime} A^{k} X_{t}=\lambda e_{1}^{\prime}\left(I+\beta A+\beta^{2} A^{2}+\cdots\right) X_{t}=\lambda e_{1}^{\prime}(I-\beta A)^{-1} X_{t}
$$

Using the prior statement we can construct a measure of fundamental inflation using structural estimates $\lambda$ and $\beta$ with the addition of the $\operatorname{VAR}(q)$ companion matrix $(A)$. 
Appendix 3.4 - Hybrid NKPC Fundamental Inflation

Following Campbell and Schiller (1987) we can obtain an estimation of this series using a VAR framework. By definition we can embed multiple autoregressive processes within the VAR framework. As in the forward looking NKPC example this can be represented by:

$$
X_{t+1}=A X_{t}+\Gamma_{X_{t+1}}
$$

If we assume that agents use the available information at time $t$ in making decisions then agents expectations can be approximated by the conditional forecast derived from the $\operatorname{VAR}(q)$. From the VAR above it is possible to obtain a representation for $E_{t}\left(m c_{t+k} \mid X_{t}\right)$. If $E_{t}\left(X_{t+i} \mid H_{t}\right)$ represents a linear projection under a set of information given by $H_{t}$, it follows:

$$
\begin{gathered}
E_{t}\left(X_{t+1} \mid H_{t}\right)=E_{t}\left(A X_{t}+\Gamma_{X_{t+1}} \mid H_{t}\right)=A X_{t} \\
E_{t}\left(X_{t+2} \mid H_{t}\right)=E_{t}\left(A X_{t+1}+\Gamma_{X_{t+2}} \mid H_{t}\right)=A^{2} X_{t} \\
\vdots \\
E_{t}\left(X_{t+k} \mid H_{t}\right)=A^{K} X_{t}
\end{gathered}
$$

If we substitute this expression into the fundamental inflation equation we obtain:

$$
\pi_{t}^{*}=\delta_{1} \pi_{t-1}+\left(\frac{\lambda}{\delta_{2} \gamma_{f}}\right) \sum_{k=0}^{\infty}\left(\frac{1}{\delta_{2}}\right)^{k} e_{1}^{\prime} A^{k} X_{t}
$$

Where $e_{1}^{\prime}$ is a vector of dimension $2 q$ with a 1 in its first position and zeros elsewhere. Simplifying the infinite sum on the right hand side of the previous expression, and assuming the inverse of A exists, $\pi_{t}{ }^{*}$ can be expressed as follows:

$$
\pi_{t}^{*}=\delta_{1} \pi_{t-1}+\left(\frac{\lambda}{\delta_{2} \gamma_{f}}\right) e_{1}^{\prime}\left(I-\left(\frac{1}{\delta_{2}}\right) A\right)^{-1} X_{t}
$$




\section{Small open economy model of New Zealand}

Given what we have seen from the analysis of the last two chapters, there is reason to believe there is some proportion of households and firms aggregate behaviour that deviates from established theory. In response to these findings I ask two questions; (i) how do these preferred estimates from the previous two chapters compare, when estimated in an economy wide model? and (ii) what effect does this non optimal behaviour have on the predictions of a small open dynamic stochastic general equilibrium (DSGE) model?

The model constructed in this section is New Keynesian in nature augmented with Non-Ricardian consumers, external habit persistence, backward looking price setters, and a foreign sector. Households decide how much to consume from a choice of domestic and foreign goods and how much labour to supply. Firms choose prices and subsequently produce a sufficient quantity of goods to meet demand. This model is closely linked to the open economy dynamics explored by Di Bartolomeo et al (2006), Gali and Monacelli (2002), and Liu (2006).

\section{$4.1 \quad$ Households}

It is assumed there is a continuum of infinitely lived heterogeneous agents. A constant fraction, $1-\lambda$, of agents consume and accumulate wealth in accord with permanent income theory. The remaining fraction, $\lambda$, is made up of agents who do not own any assets, cannot smooth consumption over time, and thus consume out of current disposable income. These consumers are often labelled in the literature as rule of thumb or credit constrained consumers. In addition I have assumed that Ricardian consumers consumption at time 
$t+i$ depends on habits inherited from past consumption, with the fraction, $h$, depends on lagged aggregate consumption.

The following optimisation problem follows Di Bartolomeo et al (2006) working paper. At time zero representative consumers, indexed by $\mathrm{R}$ for Ricardian consumers and $\mathrm{N}$ for rule of thumb consumers, maximise the following function:

$$
E_{t} \sum_{i=0}^{\infty} \beta^{i} u\left(C_{t+i}^{j}, M_{t+i}^{j} P_{t+i}^{-1}, N_{t+i}^{j}, \phi^{j}\right) \quad j \in\{R, N\}
$$

where $\beta \in(0,1)$ is the intertemporal discount factor, $C_{t}$ represents household consumption at time $t$, while $\frac{M_{t+i}}{P_{t+i}}$ and $N_{t}$ are real money balances and labour supply respectively. $\phi^{j}$ is a binary variable such that when $j=R$, $\phi^{R}=1$ and when $j=N, \phi^{N}=0$. For the sake of simplicity a logarithmic utility function is employed, which enables one to obtain a closed form solution of the model. The following instantaneous utility function is employed.

$$
u(.)=\ln \left(C_{t+i}^{j}-h \phi^{j} C_{t+i-1}^{h}\right)+\varphi \ln \left(1-N_{t+i}^{j}\right)+\phi^{j} \chi \ln \left(M_{t+i}^{j} P_{t+i}^{-1}\right)
$$

where $\chi>0$ and $\varepsilon>0$. The following budget constraint is also assumed to hold.

$$
C_{t}^{j}=\frac{W_{t}}{P_{t}} N_{t}^{j}+\phi^{j}\left[\Pi_{t}^{j}-\frac{M_{t}^{j}-M_{t-1}^{j}}{P_{t}}-\frac{B_{t}^{j}-\left(1+i_{t-1}\right) B_{t-1}^{j}}{P_{t}}\right]
$$

$W_{t}$ represents the nominal wage received at time $t$ and $\Pi_{t}$ represents profit returns by the agent. Real wages are the only source of rule of thumb consumers disposable income, and are thus subject to a static (point in time) budget constraint. Ricardian households, on the other hand, subject their allocation of wealth to a dynamic constraint. By definition, rule of thumb consumers consume all current income and money holdings leaving a zero 
balance at the end of a given the period. By solving the intertemporal optimisation problem given Ricardian behaviour and rule of thumb agents and $\log$ linearising we obtain the following description of the demand side of the economy.

$$
\begin{gathered}
c_{t}=-\frac{1-\mu-\lambda \zeta}{1+\mu}\left(i_{t}-E_{t} \pi_{t+1}\right)+\frac{\mu}{1+\mu} c_{t-1}+\frac{1}{1+\mu} c_{t+1}-\frac{\lambda \zeta}{1+\mu} \Delta\left(w_{t+1}-p_{t+1}\right) \\
w_{t}-p_{t}=v n_{t}+(1-\mu) c_{t}-\mu(1-\mu) c_{t-1}
\end{gathered}
$$

where $i_{t}$ is the domestic nominal interest rate, $\pi_{t}$ is the overall inflation rate, and $w_{t}-p_{t}$ is the real wage. Relevant parameters expressed in the prior equations include; $\mu=h(1-\lambda)$ which represents the habit coefficient in aggregate terms. Note that the habit persistence term is adjusted so as to reflect the lack of habit formation in rule of thumb behaviour. Next is $v=N(1-N)^{-1}=\theta \varphi^{-1}(1-\mu)^{-1}$ which reflects the inverse Frisch elasticity, where $\theta=(\eta-1) \eta^{-1} \in(0,1)$. Here $\eta$ is the elasticity of substitution between domestic and foreign goods, and $\varphi$ disutility of labour. The parameter $\zeta=\varphi(1+\varphi)^{-1}(1+v)(1-\mu)$ is the steady state share of rule of thumb consumption, which is a function of labour supply elasticity, habit persistence, and the proportion of rule of thumb agents.

The first of the two prior equations represents a form of the standard consumption Euler equation, while the second is the consumers' aggregate labour supply. In conventional Euler equations the last term in my equation is usually absent as it can be substituted away. However its presence can be attributed to the hybrid existence of Ricardian and non Ricardian households, and serves as a link between the demand for goods and the real wage. 
If we consider the following economy production function, $y_{t}=a_{H, t}+n_{t}$, I obtain the following representation for the real wage:

$$
w_{t}-p_{t}=v\left(y_{t}-a_{H, t}\right)+(1-\mu) c_{t}-\mu(1-\mu) c_{t-1}
$$

I also use an assumption of complete international financial markets together with perfect capital mobility. Under international risk sharing, a price of similar bonds must be the same in the domestic and foreign economy. This means for forward looking households we can write:

$$
\beta E_{t}\left\{\frac{P_{t}}{P_{t+1}}\left(\frac{C_{t+1}-\mu C_{t}}{C_{t}-\mu C_{t-1}}\right)^{-\sigma}\right\}=E_{t}\left(\frac{\varepsilon_{t+1}}{\varepsilon_{t}}\right) \beta E_{t}\left\{\frac{P_{t}^{*}}{P_{t+1}^{*}}\left(\frac{C_{t+1}^{*}-\mu C_{t}^{*}}{C_{t}^{*}-\mu C_{t-1}^{*}}\right)^{-\sigma}\right\}
$$

where $\varepsilon_{t}$ is the nominal exchange rate. Following Liu (2006) I obtained the following amendment:

$$
C_{t}-\mu C_{t-1}=\imath\left(C_{t}^{*}-\mu C_{t-1}^{*}\right) Q_{t}^{-\frac{1}{\sigma}}
$$

where $\iota$ is a constant depending on initial assets positions. Log-linearising the prior equation around steady-state yields:

$$
c_{t}-\mu c_{t-1}=\left(c_{t}^{*}-\mu c_{t-1}^{*}\right)-\frac{1-\mu}{\sigma} q_{t}
$$

Letting $y_{t}^{*}=c_{t}^{*}$ we obtain:

$c_{t}-\mu c_{t-1}=\left(y_{t}^{*}-\mu y_{t-1}^{*}\right)-\frac{1-\mu}{\sigma} q_{t}$

\subsection{Firms}

To address the issue of firm behaviour and inflation persistence I follow Gali and Gertler (1999). The derivation is supplied in Appendix 3.2. If one recalls in Gali and Gertler's Hybrid NKPC firms operate in a monopolistically competitive environment and cannot fully adjust their prices each period. The Calvo assumption is imposed to represent the fact that a constant proportion of firms, $\vartheta$, do not adjust prices each period. In addition their 
theory extends conventional standard NKPC theory by assuming that of the $(1-\vartheta)$ fraction of firms that are able to adjust their price, a fraction $\omega$ use a backward looking rule of thumb to set their prices, while the remainder set their price by solving an optimisation problem which considers expected future marginal costs. As I have shown, the inflation process can be described as the following:

$\pi_{H, t}=\gamma_{f} E_{t} \pi_{H, t+1}+\gamma_{b} \pi_{H, t-1}+\lambda m c_{H, t}$

where:

$$
\gamma_{f}=\frac{\beta \vartheta}{\vartheta+\omega(1-\vartheta(1-\beta))}, \gamma_{b}=\frac{\omega}{\vartheta+\omega(1-\vartheta(1-\beta))}, \lambda=\frac{(1-\omega)(1-\vartheta)(1-\beta \vartheta)}{\vartheta+\omega(1-\vartheta(1-\beta))}
$$

This hybrid form of the NKPC will be applied to both domestic inflation and foreign inflation. Given the widespread econometric success in the models ability to describe inflation dynamics my decision in employing it is well founded.

\subsection{Domestic inflation, CPI inflation, and the real exchange rate}

I begin by defining the effective terms of trade as:

$$
S_{t}=\frac{P_{F, t}}{P_{H, t}} \text { or } s_{t}=p_{F, t}-p_{H, t} \text { in logs }
$$

The terms of trade is the price of foreign goods per unit of home good. Note that an increase in $s_{t}$ is equivalent to an increase in competitiveness for the domestic economy because of a relative domestic price fall or foreign price increase. Log linearising the CPI formula around a symmetric steady state satisfying the purchasing power parity condition $P_{H, t}=P_{F, t}$ yields.

$$
\begin{aligned}
p_{t} & \equiv(1-\alpha) p_{H, t}+\alpha p_{F, t} \\
& =p_{H, t}+\alpha s_{t}
\end{aligned}
$$


As derived in Appendix 4.1 it follows that domestic inflation - defined as the rate of change in the index of domestic goods prices, i.e. $\pi_{H, t}=p_{H, t}-p_{H, t-1}-$ and CPI inflation are linked according to:

$$
\begin{aligned}
\pi_{t} & =\pi_{H, t}+\alpha \Delta s_{t} \\
& =\pi_{H, t}+\alpha\left(\pi_{F, t}-\pi_{H, t}\right) \\
& =(1-\alpha) \pi_{H, t}+\alpha \pi_{F, t}
\end{aligned}
$$

This manipulation makes the gap between domestic inflation and foreign inflation the percentage change in the terms of trade, with the coefficient of the proportionality given by the degree of openness. In addition it is also shown this is equivalent to CPI inflation being a weighted average of domestic and foreign inflation weighted by the degree of openness.

I assume that the law of one price holds for individual goods at all times (for both import and export prices), which implies $P_{i, t}(j)=\varepsilon_{i, t} P_{i, t}^{i}(j)$ for all $i, j \in[0,1]$, where $\varepsilon_{i, t}$ is the bilateral nominal exchange rate, and $P_{i, t}^{i}(j)$ is the price of country i's good $j$ expressed in the producer's currency. By definition the bilateral nominal exchange rate is the price of country $i$ 's currency in terms of the domestic currency. If we substitute the prior expression into the definition of $P_{i, t}$ one obtains.

$$
P_{i, t}=\varepsilon_{i, t} P_{i, t}^{i}
$$

where

$$
P_{i, t}^{i}=\left(\int_{0}^{1} P_{i, t}^{i}(j)^{1-\varepsilon} d j\right)^{\frac{1}{1-\varepsilon}}
$$

If we substitute this into the definition of $p_{F, t}$ and log linearising around the symmetric steady state we obtain.

$$
\begin{aligned}
p_{F, t} & =\int_{0}^{1}\left(e_{i, t}+p_{i, t}^{i}\right) d i \\
& =e_{t}+p_{t}^{*}
\end{aligned}
$$


where $e_{t} \equiv \int_{0}^{1} e_{i, t} d i$ is the log nominal effective exchange rate, $p_{i, t}^{i} \equiv \int_{0}^{1} p_{i, t}^{i}(j) d j$ is the $\log$ domestic price index for country $i$ expressed in terms of its currency, and $p_{t}^{*}=\int_{0}^{1} p_{i, t}^{i} d i$ is the log world price index. If we combine the previous results with the definition of the terms of trade we obtain the following.

$s_{t}=e_{t}+p_{t}^{*}-p_{H, t}$

The last expression of importance is the relationship between the real exchange rate and the terms of trade. First I begin by defining the bilateral real exchange rate with country $i$ as $Q_{i, t} \equiv \frac{\varepsilon_{i, t} P_{t}^{i}}{P_{t}}$, i.e. the ratio of two countries' consumer price indexes expressed in domestic currency. Letting $q_{t}=\int_{0}^{1} q_{i, t} d i$ be the $\log$ effective real exchange rate, where $q_{i, t}=\log Q_{i, t}$. It thus follows that.

$$
\begin{aligned}
q_{t} & =\int_{0}^{1}\left(e_{i, t}+p_{t}^{i}-p_{t}\right) d i \\
& =e_{t}+p_{t}^{*}-p_{t} \\
& =s_{t}+p_{H, t}-p_{t} \\
& =(1-\alpha) s_{t}
\end{aligned}
$$

Using this relation it is implicitly assumed uncovered interest rate parity (UIP) holds.

\subsection{Technology}

Aggregate output is described by the constant elasticity of substitution (CES) function:

$$
Y_{t}=\left[\int_{0}^{1} Y_{t}(i)^{\frac{\varepsilon-1}{\varepsilon}} d i\right]^{\frac{\varepsilon-1}{\varepsilon}}
$$

for $t=0,1,2, \ldots$, where $\varepsilon$ is the elasticity between different types of goods. 
All firms, irrespective of which country they reside, produce a differentiated good with linear technology represented by the following production function.

$$
Y_{t}(j)=A_{t} N_{t}(j)
$$

where $a_{t}=\log A_{t}$ adheres to the following interdependent process.

$a_{H, t}=\rho_{a} a_{H, t-1}+\varepsilon_{t}^{a_{H}}+\tau \varepsilon_{t}^{a_{F}}$

The inclusion of a correlated foreign shock term, $\varepsilon_{t}^{a_{F}}$, provides additional variability in domestic productivity. One can argue that this additional component is justifiable given many firms operate across many different countries, often exploiting the market conditions of smaller, underdeveloped countries.

The determination of real marginal cost as a function of domestic output in the small open economy differs from that of a closed economy, given the existence of a wedge between output and consumption and between domestic and consumer prices. Given the model assumptions, sticky price equilibrium real marginal costs are given by:

$$
\begin{aligned}
m c_{H, t} & =w_{t}-p_{H, t}-a_{t} \\
& =\left(w_{t}-p_{t}\right)+\left(p_{t}-p_{H, t}\right)-a_{t} \\
& =v\left(y_{t}-a_{t}\right)+(1-\mu) c_{t}-\mu(1-\mu) c_{t-1}+\alpha s_{t}-a_{t} \\
& =v y_{t}+(1-\mu) c_{t}-\mu(1-\mu) c_{t-1}+\alpha s_{t}-(1+v) a_{t}
\end{aligned}
$$

Since this model assumes the mark-up is constant in steady state, in a flexible price equilibrium log linearised marginal costs are equal to zero. 


\subsection{The Central Monetary Authority}

A domestic central monetary authority is the third agent in the model. The central bank implements monetary policy to stabilise both inflation and output. The Taylor rule instructs the central bank how to adjust interest rates if there is an output gap or movement in inflation from its target level. The behaviour of the central bank in this model is similar to that implemented in many other small open economy models, with two minor differences. First nominal interest rates are assumed to follow some AR(1) process, and second both inflation and output are targeted. The domestic central banks reaction function is as follows:

$$
i_{H, t}=\rho_{r} i_{H, t-1}+\phi_{\pi} \pi_{H, t}+\phi_{y} y_{H, t}
$$

\subsection{Aggregate Demand and Output Determination}

In the foreign sector preferences of the representative household assumed to be only forward looking, but with a negligible weight on the goods imported from the small economy. The foreign sector's IS equation is as follows.

$$
y_{t}^{*}=E_{t} y_{t}^{*}-\frac{1}{\sigma}\left(i_{F, t}-E_{t} \pi_{t+1}\right)+\varepsilon_{y^{*}, t}
$$

which can be solved forward to obtain:

$$
y_{t}^{*}=-\frac{1}{\sigma} E_{t}\left\{\sum_{k=0}^{\infty}\left(i_{F, t+k}-E_{t} \pi_{t+1+k}\right)\right\}
$$

As in the standard closed economy model, world consumption is inversely related to current and anticipated world real interest rates. The domestic goods market clearing condition is derived in Appendix 4.2. Given a series of assumptions is shown that: 


$$
\begin{aligned}
y_{t} & =y_{t}^{*}+\frac{1+\alpha(\sigma \eta-1)(2-\alpha)}{\sigma} s_{t} \\
& =y_{t}^{*}+\frac{\varpi}{\sigma} s_{t}
\end{aligned}
$$

\subsection{Foreign Sector}

The key equations that represent the foreign sector are assumed to have been derived from fully optimising consumers with no rule of thumb behaviour nor habit preferences. In addition firms are assumed to set prices in accordance with Calvo pricing, although in the world economy it is assumed that there are a subset of price setters which set in a backward looking manner. 


\subsection{Linearised System}

The log linearised model consists of 17 equations rearranged and completed by exogenous domestic and foreign shocks. The system is as follows:

$$
\begin{aligned}
& c_{t}=-\frac{1-\mu-\lambda \zeta}{1+\mu}\left(i_{t}-E_{t} \pi_{t+1}\right)+\frac{\mu}{1+\mu} c_{t-1}+\frac{1}{1+\mu} c_{t+1}-\frac{\lambda \zeta}{1+\mu} \Delta\left(v\left(y_{t+1}-a_{H, t+1}\right)+(1-\mu) c_{t+1}-\mu(1-\mu) c_{t}\right) \\
& c_{t}-\mu c_{t-1}=\left(y_{t}^{*}-\mu y_{t-1}^{*}\right)-\frac{1-\mu}{\sigma} q_{t} \\
& \pi_{H, t}=\gamma_{f} E_{t} \pi_{H, t+1}+\gamma_{b} \pi_{H, t-1}+\lambda m c_{H, t}+\varepsilon_{\pi_{H}, t} \\
& m c_{H, t}=v y_{t}+(1-\mu) c_{t}-\mu(1-\mu) c_{t-1}+\alpha s_{t}-(1+v) a_{t} \\
& a_{H, t}=\rho_{a} a_{H, t-1}+\varepsilon_{a_{H}, t}+\tau \varepsilon_{a_{F}, t} \\
& i_{H, t}=\rho_{i} i_{H, t-1}+\phi_{\pi} \pi_{H, t}+\phi_{y} y_{t}+\varepsilon_{i_{H}, t} \\
& y_{t}=y_{t}^{*}+\frac{\varpi}{\sigma} s_{t}+\varepsilon_{y, t} \\
& \pi_{t}=(1-\alpha) \pi_{H, t}+\alpha \pi_{F, t} \\
& q_{t}=(1-\alpha) s_{t}+\varepsilon_{q, t} \\
& s_{t}-s_{t-1}=e_{t}-e_{t-1}+\pi_{F, t}-\pi_{H, t} \\
& p_{H, t}=p_{H, t-1}+\pi_{H, t} \\
& \pi_{C P I, t}=\pi_{C P I, t-1}+\pi_{t} \\
& y_{t}^{*}=E_{t} y_{t}^{*}-\frac{1}{\sigma}\left(i_{F, t}-E_{t} \pi_{F, t+1}\right)+\varepsilon_{y^{*}, t} \\
& \pi_{F, t}=\gamma_{f}^{*} E_{t} \pi_{F, t+1}+\gamma_{b}^{*} \pi_{F, t-1}+\lambda^{*} m c_{F, t}+\varepsilon_{\pi_{F}, t} \\
& m c_{F, t}=(\sigma+\varphi) y_{F, t}-(1+\varphi) a_{F, t} \\
& i_{F, t}=\phi_{F, \pi} \pi_{F, t+1}+\phi_{F, y} y_{F, t}+\varepsilon_{i_{F}, t} \\
& a_{F, t}=\rho_{a_{F}} a_{F, t-1}+\varepsilon_{a_{F}, t}
\end{aligned}
$$


The linearised model consists of 17 equations for 17 endogenous variables: $c_{t}, y_{t}, m c_{H, t}, \pi_{H, t}, a_{H, t}, i_{H, t}, s_{t}, a_{t}, e_{t}, \pi_{t}, y_{t}^{*}, m c_{F, t}, \pi_{F, t}, a_{F, t}, i_{F, t}, p_{H, t}, \pi_{C P I, t}$ There are nine shocks: $\varepsilon_{\pi_{H}, t}, \varepsilon_{a_{H}, t}, \varepsilon_{i_{H}, t}, \varepsilon_{y, t}, \varepsilon_{y^{*}, t^{*}}, \varepsilon_{\pi_{F}, t}, \varepsilon_{i_{F}, t}, \varepsilon_{a_{F}, t}$ and $\varepsilon_{q, t}$. The description of the equations with shocks in the system is as follows:

- Equation (6) - Consumption Euler equation

- Equation (7) - International risk sharing condition

- Equation (8) - Hybrid New Keynesian Phillips Curve

- Equation (9) - Domestic marginal cost function

- Equation (10) - AR(1) process for domestic technological progress

- Equation (11) - Domestic central monetary authority function

- Equation (12) - Goods market clearing condition

- Equation (13) - Overall level of inflation

- Equation (14) - Real exchange rate relation with error term

- Equation (15) - Terms of trade in differenced form

- Equation (16) - Domestic price level relation

- Equation (17) - CPI level of inflation

- Equation (18) - Foreign IS equation with output shock term

- Equation (19) - New Keynesian Phillips Curve (NKPC) for foreign inflation

- Equation (20) - Foreign firms marginal costs

- Equation (21) - Foreign central bank reaction function with error term

- Equation (22) - $\mathrm{AR}(1)$ process for foreign technological progress 
Table 21 shows a short overview of the parameters in the linearised model.

Table 21

\begin{tabular}{|c|c|c|c|}
\hline Parameter & Equation & Interpretation & Restriction \\
\hline $\bar{\sigma}$ & $\begin{array}{l}\text { (6), (7), (9), (12), } \\
(18),(20)\end{array}$ & $\begin{array}{c}\text { Inverse elasticity of } \\
\text { intertemporal substitution }\end{array}$ & $\langle 0 ; \infty\rangle$ \\
\hline$\varphi$ & $(6),(9),(12),(20)$ & $\begin{array}{l}\text { Inverse elasticity of labour } \\
\text { supply }\end{array}$ & $\langle 0 ; \infty\rangle$ \\
\hline$\beta$ & (9) & Intertemporal discount factor & $\langle 0 ; 1\rangle$ \\
\hline$\vartheta$ & (8) & $\begin{array}{c}\text { Fraction of non optimising } \\
\text { domestic firms }\end{array}$ & $\langle 0 ; 1\rangle$ \\
\hline$\omega$ & (8) & $\begin{array}{l}\text { Fraction of domestic backward } \\
\text { looking price setters }\end{array}$ & $\langle 0 ; 1\rangle$ \\
\hline$h$ & $(6),(7),(9),(12)$ & $\begin{array}{l}\text { Habit formation parameter in } \\
\text { consumption }\end{array}$ & $\langle 0 ; 1\rangle$ \\
\hline$\lambda$ & $(6),(7),(9),(12)$ & $\begin{array}{l}\text { Fraction of rule of thumb } \\
\text { consumers }\end{array}$ & $\langle 0 ; 1\rangle$ \\
\hline$\eta$ & (6), (9), (12) & $\begin{array}{l}\text { Elasticity of substitution } \\
\text { between home and foreign } \\
\text { goods }\end{array}$ & $\langle 0 ; \infty\rangle$ \\
\hline$\alpha$ & $(12),(13),(14)$ & Degree of openness & $\langle 0 ; 1\rangle$ \\
\hline$\rho_{a}$ & $(10)$ & $\begin{array}{c}\text { Inertia of domestic technology } \\
\text { development }\end{array}$ & $\langle 0 ; 1\rangle$ \\
\hline$\tau$ & (10) & $\begin{array}{c}\text { Correlation coefficient between } \\
\text { domestic and foreign } \\
\text { technology }\end{array}$ & $\langle 0 ; 1\rangle$ \\
\hline$\rho_{i}$ & (11) & Inertia of domestic interest rates & $\langle 0 ; 1\rangle$ \\
\hline$\phi_{\pi}$ & (11) & $\begin{array}{l}\text { Elasticity of domestic interest } \\
\text { rates to inflation }\end{array}$ & $\langle 1 ; \infty\rangle$ \\
\hline$\phi_{y}$ & (11) & $\begin{array}{l}\text { Elasticity of domestic interest } \\
\text { rates to output }\end{array}$ & $\langle 0 ; \infty\rangle$ \\
\hline
\end{tabular}




\subsection{Bayesian Estimation}

There are various econometric procedures that have been proposed to estimate DSGE models. Those which are most often employed include GMM estimation of equilibrium relationships, minimum distance estimation based on the difference between VAR and DSGE model impulse response functions, and full-information likelihood-based estimations. Unlike those methods I focus on Bayesian estimation, which has three main characteristics; (i) unlike GMM estimation of equilibrium relationships, Bayesian analysis is system-based and fits the solved DSGE model to a vector of aggregate time series, (ii) the estimation is based on the likelihood function generated by the DSGE model, and (iii) prior distributions can be used to incorporate additional information into the parameter estimation.

\subsubsection{Data and Priors}

NZ, Australian, and US data employed from 1992:Q4 to 2009:Q1 is outlined in Appendix 4.3. In a broad sense, Quarterly observations on domestic (New Zealand) output per capita, domestic CPI inflation, domestic interest rates were obtained from Statistics New Zealand and the Reserve Bank of New Zealand. Foreign output, Foreign interest rates, Foreign inflation, the real exchange rate, and terms of trade were obtained by weighting $80 \%$ to US data and the remaining 20\% to Australian data. All variables were subsequently re-scaled to have a mean of zero. This enables one to interpret an approximate percentage deviation from the mean.

Prior distributions are important when estimating DSGE models. Put simply priors reflect ones beliefs and confidence we have in regards to a location of a particular structural variable. In addition, priors also add curvature to a 
likelihood function and therefore strongly influence the shape of the posterior distribution. This is vastly different from VAR estimation, as priors are used to reduce the dimensionality of the econometric model and sampling variability of parameter estimates. In practice most priors are chosen based on some observations. Priors are made from both my own observations and those which have been implemented in various other small open economy models in the literature. Papers which have highly influenced the construction of my list of priors include The Reserve Bank of New Zealand's FRS and newly developed KITT model (Lees, 2009), Phillips Liu's Small Open Economy model (Liu, 2006), and Vasicek and Musil (2006) model of the Czech economy. Beta distributions were selected for parameters between nought and one, Gamma distributions were selected for parameters that exist in a positive real space, and an Inverse Gamma distribution was selected for the precision of shock variables.

\subsubsection{Posterior computations}

I consider a Random Walk Metropolis Hastings (RW-MH) algorithm to generate draws from the posterior distribution of $\theta$. The non-normalisation posterior density proceeds in two steps. First, the linear rational expectations system is solved to obtain the state transition equation. If the parameter value $\theta$ implies indeterminacy (or non-existence of a stable rational expectations solution), then $L(\theta \mid Y) p(\theta)$ is set to zero. If a unique stable solution exists, then the Kalman filter is used to evaluate the likelihood function associated with the linear state-state system. Since the prior is generated from well-known densities, the computation of $p(\theta)$ is straightforward. 
The RW-MH algorithm belongs to the more general class of $\mathrm{MH}$ algorithms. The RW-MH algorithm was first used to generate draws from the posterior distribution of DSGE model parameters by Schorfheide (2000). In a practical sense, I fitted my canonical model, which consists of placing a prior distribution on structural parameters, $\theta$, the estimates of which are then updated using the data according to Bayes rule:

$p\left(\theta \mid Y^{T}\right)=\frac{p\left(Y^{T} \mid \theta\right)}{p\left(Y^{T}\right)} \propto L\left(\theta \mid Y^{T}\right) p(\theta)$

Under fairly general regularity conditions, the posterior distribution of $\theta$ will be asymptotically normal. The algorithm constructs a Gaussian approximation around the posterior mode and uses a scaled version of the asymptotic covariance matrix as the covariance matrix for the proposal distribution. This allows for an efficient exploration of the posterior distribution at least in the neighbourhood of the mode.

Given the data and prior specifications I have generated three parallel 300,000 draws of Markov chains using the method discussed. The Markov chain is generated conditional on the degree of openness $(\alpha)$ being is fixed at 0.4. In addition foreign time preference, $\left(\beta^{*}\right)$, foreign degree of price stickiness $\left(\vartheta^{*}\right)$, and foreign proportion of backward looking price setters $\left(\omega^{*}\right)$ are fixed at $0.909,0.834$, and 0.486 respectively in accordance to estimates obtain by Gali and Gertler (1999) using US data. Prior and posterior estimates are displayed in Table 22. Figure 9 presents prior and posterior distributions. The vertical green line indicates the posterior mean, the grey line shows the prior distribution, while the black shows the posterior distribution. 


\begin{tabular}{|c|c|c|c|c|c|}
\hline & $\begin{array}{c}\text { Prior } \\
\text { density }\end{array}$ & $\begin{array}{l}\text { Prior } \\
\text { mean }\end{array}$ & $\begin{array}{l}\text { Prior } \\
\text { s.d. }\end{array}$ & $\begin{array}{l}\text { Posterior } \\
\text { mean }\end{array}$ & $\begin{array}{c}\text { Posterior } 90 \% \\
\text { interval }\end{array}$ \\
\hline$\beta$ & B & 0.95 & 0.05 & 0.9973 & [0.9967; 0.9978$]$ \\
\hline$\varphi$ & G & 3.0 & 0.2 & 1.9176 & {$[1.8975 ; 1.9376]$} \\
\hline$\eta$ & G & 1.0 & 0.2 & 1.0601 & {$[0.5447 ; 1.5628]$} \\
\hline$\lambda$ & B & 0.2 & 0.05 & 0.3379 & {$[0.3362 ; 0.3391]$} \\
\hline$h$ & B & 0.9 & 0.05 & 0.8956 & {$[0.8398 ; 0.9432]$} \\
\hline$\tau$ & B & 0.7 & 0.1 & 0.6746 & {$[0.4518 ; 0.8969]$} \\
\hline$\omega$ & B & 0.6 & 0.1 & 0.7011 & {$[0.6967 ; 0.7545]$} \\
\hline$\vartheta$ & B & 0.6 & 0.1 & 0.7823 & {$[0.7519 ; 0.7763]$} \\
\hline$\sigma$ & G & 1.0 & 0.05 & 0.7334 & {$[0.7319 ; 0.7349]$} \\
\hline$\phi_{\pi}$ & G & 1.5 & 0.3 & 1.4049 & {$[1.3974 ; 1.4151]$} \\
\hline$\phi_{y}$ & G & 0.4 & 0.1 & 0.4352 & {$[0.1724 ; 0.6643]$} \\
\hline$\rho_{i}$ & B & 0.7 & 0.1 & 0.7184 & {$[0.6968 ; 0.7387]$} \\
\hline$\rho_{a}$ & B & 0.7 & 0.1 & 0.6793 & {$[0.4548 ; 0.9073]$} \\
\hline$\sigma_{y_{H}, t}$ & $\mathrm{IG}$ & 2.0 & $\infty$ & 1.2565 & {$[1.4234 ; 2.0940]$} \\
\hline$\sigma_{\pi_{H}, t}$ & IG & 2.0 & $\infty$ & 1.6523 & {$[1.6121 ; 1.7814]$} \\
\hline$\sigma_{i_{H}, t}$ & IG & 2.0 & $\infty$ & 2.1351 & {$[2.0548 ; 2.2555]$} \\
\hline$\sigma_{q, t}$ & IG & 2.0 & $\infty$ & 2.2811 & {$[2.1690 ; 2.3572]$} \\
\hline$\sigma_{y_{F}, t}$ & IG & 2.0 & $\infty$ & 3.1379 & [2.9957; 3.3185] \\
\hline$\sigma_{\pi_{F}, t}$ & IG & 2.0 & $\infty$ & 2.1674 & {$[2.1521 ; 2.3121]$} \\
\hline$\sigma_{i_{F, t}}$ & IG & 2.0 & $\infty$ & 15.7529 & {$[2.8860 ; 19.937]$} \\
\hline
\end{tabular}

Density acronyms: B (Beta), G (Gamma), IG (Inverse Gamma) 
Figure 9 - Prior and Posterior distributions
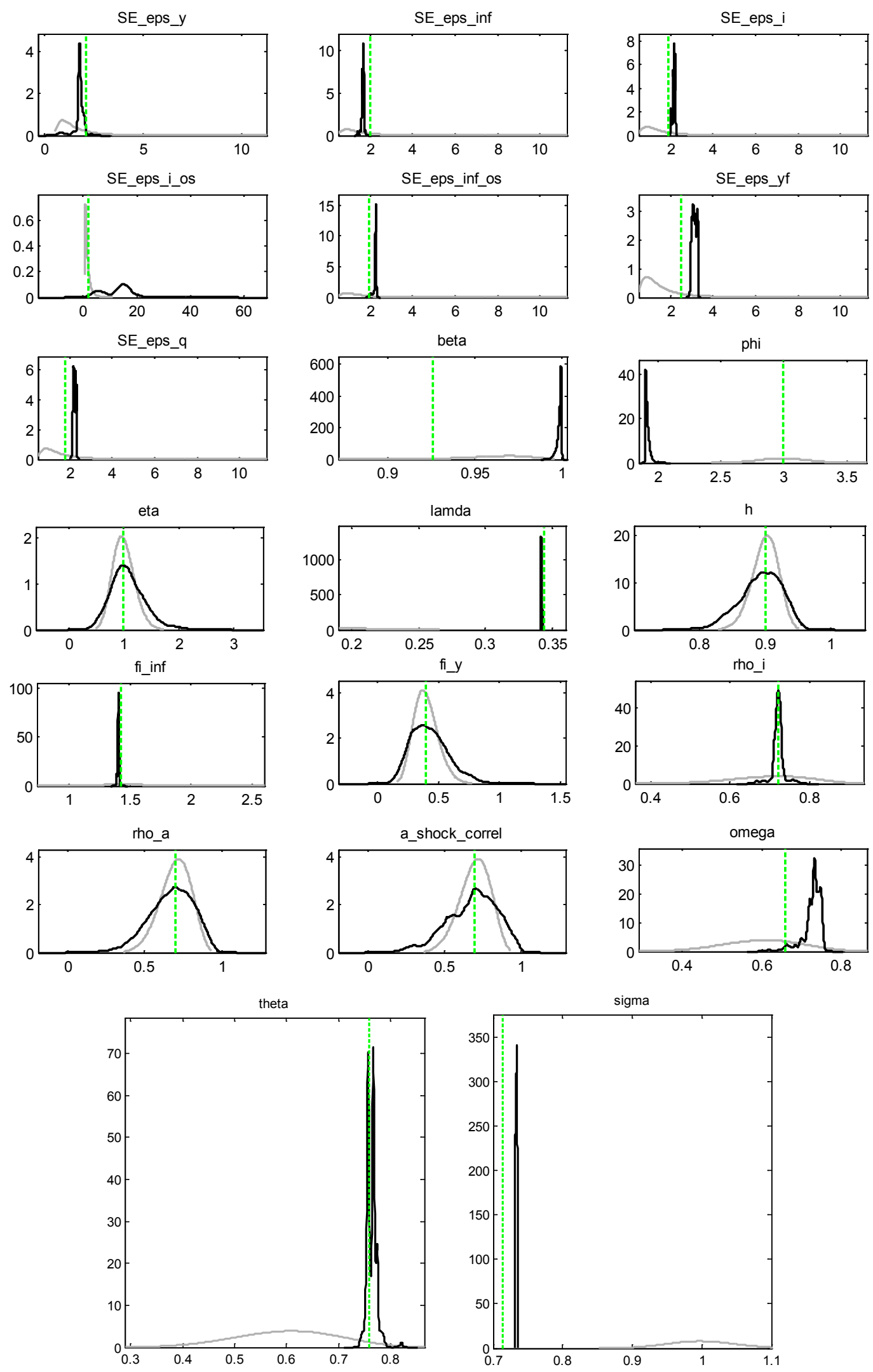


\subsection{Estimation results}

Based on three independent Markov chains; prior distributions, posterior means, and $90 \%$ probability intervals for each of the parameters of interest are provided in Table 22. Upon inspection of Figure 9, one finds posterior marginal densities are much more concentrated compared to the prior distributions. While $\beta$ is not usually estimated in DSGE models, I took the opportunity to estimate it. As expected its posterior mean was very close to 0.99 .

My results indicate there is a high degree of external habit persistence with the posterior mean reaching 0.9. This result is consistent with Liu (2006), who finds an external habit persistent parameter of 0.92 . The posterior mean of the elasticity of intertemporal substitution, $\sigma$, is estimated to be 0.73 . Values of $\sigma$ close to one imply households are less willing to accept variations from a stable trend in consumption over time. Combining this argument with my estimated coefficient for external habit persistence makes this result seem more plausible.

The posterior mean for the elasticity of substitution between home and foreign goods, $\eta$, was found to be 1.0601. While Liu (2006) found this parameter was 0.85 , Liu's study omitted the last four years which included a downturn in economic activity. In this time one could infer New Zealand's consumption basket composition has changed to incorporating more domestic commodities as opposed to foreign. Similarly to Liu (2006), my estimated inverse elasticity of substitution for labour, $\varphi$, was found to be significantly greater than one. My analysis found the estimated mean of $\varphi$ to be 1.9, while Liu estimated it at 1.8. This elasticity implies a one percent increase in the real wage will result in a very small change in labour supply.

One of the more interesting findings was the estimated proportion of rule of thumb consumers. In my initial GMM study in the first part of this thesis, I 
concluded the proportion of rule of thumb consumers in New Zealand was approximately 0.21 . However conducting Bayesian analysis of this DSGE model has found the proportion to be 0.34 . One important consideration is that the GMM analysis was conducted with data relating to disposable income, while here it is conducted in a series of simultaneous equations where the relevant driving variable is demeaned output. One can infer the output data includes consumption of durable goods, which theory suggests should be omitted in estimating parameters relating income and consumption. In addition, demeaned output is influenced by movements in government expenditure, investment, exchange rate movements, and traded goods and services; all of which should not be in a relation determining consumer behaviour. This belief is also seen in the data as one will find the standard deviation of New Zealand Disposable Income per capita relative to Real GDP per capita (expenditure method) between 1992:Q1 and 2008:Q4 is 0.4515. On the other hand my DSGE model includes external habit persistence which Campbell and Mankiw's model didn't consider. Therefore one could also suggest combined habit persistence and the elasticity of intertemporal substitution has had an effect in raising the estimated proportion of rule of thumb consumers.

On the firm side, the estimated probability of not changing price or firms that do not re-optimise their price for a given quarter is around 78 percent of domestic firms. This is very similar to Liu's estimate of 0.75 and my GMM estimate of 0.8 . In addition, the mean estimate for the proportion of backward looking price setters came to 0.7 . While this is lower than my GMM estimate of 0.82 , it is plausible relative to the other GMM results from various sets of instrumental variables.

The central banks reaction function used in this model provides an acceptable description of monetary policy over the length of the data. The posterior mean for the autoregressive coefficient on domestic interest rates was 0.72 . This is exactly the same posterior mean as obtained by Liu (2006). One finds its distribution is 
much more narrow and defined about its posterior mean. This estimate is unsurprising given the Reserve Bank has managed to keep interest rates very smooth over the inspected time period. The estimated means for the monetary authority's weights on inflation and output respectively came to 1.4 and 0.44 respectively. Both these estimates are very close to Liu's as his estimates came to 1.45 and 0.41 respectively.

\subsection{Impulse Response Functions}

The second aim of this chapter is to establish whether the inclusion of rule of thumb firms and consumers produces more realistic impulse responses in response to external shocks. For the following temporary shocks the blue line represents the impulse response when posterior means are used. The red line reflects responses when the proportion of rule of thumb consumers is set to zero. The green line reflects responses when the proportion of backward looking price setters is set to zero. The purple line reflects responses when both proportions of rule of thumb consumers (credit constrained) and firms (backward looking price setters) is set to zero.

\subsubsection{Domestic inflation shock}

Figure 10 shows the impact of a positive domestic inflation shock. The $1 \%$ increase in domestic inflation increases overall inflation just over $0.9 \%$ when posterior means are used for parameter calibration (blue line). Following the impact of inflation expectations, domestic inflation initially increases by over $1.5 \%$. Since the model is characterised as being a small open economy, the large increase in domestic inflation is principally translated to a deterioration of the terms of trade by over $2.5 \%$. One finds because of the sharp increase in domestic inflation, competitiveness in the small open economy worsens 
before recovering because of the response of the monetary authority. Initially the monetary authority responds to an increase in domestic inflation by raising nominal interest rates by $0.8 \%$. Because of the strong presence of external habit persistence and rule of thumb behaviour, domestic output moves in a familiar humped shaped response and returns to equilibrium after approximately 20 periods given the drawn out response by the monetary authority. As a special case; when $\omega$ is restricted to zero domestic and overall inflation responds significantly less to the initial inflation shock, thus muting the response of all variables of interest.

On the supply side domestic inflation influences production costs. The marginal cost of the domestic producers falls sharply in response to a sharp decrease in real wages. In addition the appreciation in the domestic currency allows firms to import foreign goods at a lower cost, thus lowering marginal costs further. Domestic output is negatively affected by $2.5 \%$ in response to tighter monetary stance, which also worsened of the terms of trade and appreciated the domestic currency. Compared to the case where $\omega$ is restricted to zero, output takes almost twice as long to return to steady state. The impact of greater backward looking price setters makes the models dynamics more prolonged. The consequent impact of the initial inflation shock raises the nominal price level to a new steady state, although prices are considerably higher when there are backward looking price setters.

\subsubsection{Domestic interest rate shock}

Figure 11 shows the effect of a $1 \%$ positive domestic nominal interest rate shock. Because it is a restrictive policy, both overall inflation and output fall. Domestic inflation decreases by $0.5 \%$ and output by $1.2 \%$. These changes are immediate and are relatively short because they only last for eight quarters. 
Since there is a negative impact on inflation and output, the initial $1 \%$ nominal interest rate shock results in only a $0.7 \%$ change in the interest rate. This is similar to the impact when other restrictions are made, although is much stronger compared to when both $\lambda$ and $\omega$ are bound to zero. Higher interest rates flow through the system causing the exchange rate to appreciate. This has an impact on firms by contributing to a fall in domestic output and marginal costs. Although domestic inflation is lower, the appreciation of domestic currency is high such that the competitive position of domestic producers worsens. This is represented by the terms of trade improving after several periods, and the exchange rate while initially returning to steady state depreciates over time.

As a final point, the magnitude at which inflation falls is dependent upon the relevant theoretical parameter restrictions. One finds both domestic and overall inflation fall considerably greater when both $\lambda$ and $\omega$ are bound to zero. This is to be expected as both consumers and price setters are purely forward looking, making their relevant consumption and price setting plans more reactive to current economic conditions.

\subsubsection{Domestic productivity shock}

Figure 12 shows a $1 \%$ positive domestic productivity shock. In response domestic output improves marginally by $0.4 \%$ and domestic inflation falls by $0.05 \%$. The significant increase in output encourages the monetary authority to raise interest rates, ever so slightly, in accordance to its rule by almost $0.06 \%$. Following this, output decreases over time remaining above trend for over 40 quarters. The strong persistence in the impulse response can be explained by the autocorrelation of the productivity shock. While marginal costs initially increase because of greater output, lower costs of production 
that arise from the increase in productivity maintain positive output growth over a considerable period.

Domestic inflation falls gradually until the monetary authority responds. It then continues to fall in response to rising nominal interest rates, before returning to steady state after 40 quarters. The impact across all theoretical restrictions is largely the same. The nominal exchange rate initially appreciates because of initial monetary tightening, then depreciates as nominal interest rates are allowed to fall. This response is matched by a deterioration of competitiveness initially until interest rates fall and the nominal exchange rate begins to depreciate. The nominal price level continues to fall over time from its initial position, although the rate at which prices fall lessens as monetary loosening weakens after 10 quarters. The impulse responses under posterior means are marginally smaller compared to responses when $\lambda$ is set to zero (red line). This results in prices responding slower to initial propagations in the system. In the absence of backward looking price setters all variables return to steady state (with the exception of the nominal exchange rate) slightly faster compared to other analysed series.

\subsubsection{Foreign interest rate shock}

Figure 13 shows the impact of a 1\% positive foreign interest rate shock. According to the differenced terms of trade condition, the increase of the foreign interest rate by $1 \%$ induces a strong depreciation of domestic currency by approximately $3 \%$. The nominal exchange rate returns to a new steady state when the initial shock dissolves. The strong depreciation enables domestic producers to export more goods, which helps drive domestic inflation upwards by $0.05 \%$ and marginal costs of production by $1.3 \%$. The combined effect increases overall inflation, depending on the theoretical 
restriction, either in the first period by $0.8 \%$ or a delayed climb up to $0.5 \%$. When posterior means are used for calibration overall inflation climbs by just over $0.02 \%$ after three quarters. The higher domestic inflation leads to a reaction of the central bank by increasing interest rates by $0.03 \%$ and steadily increasing until inflation and output begin their respective descents to their steady state levels.

As a special case, when there are no rule of thumb consumers one finds that domestic output falls by more, thus muting the response of the monetary authority. In each case the response is to reduce short term interest rates.

\subsubsection{Foreign output shock}

Figure 14 shows the impact of a $1 \%$ positive foreign output shock. Higher foreign production is connected with higher prices, represented by an increase in foreign inflation by approximately $1 \%$. Higher foreign output encourages greater domestic production by $0.04 \%$. Since there is insufficient productive capacity the initial increase in domestic production is followed by a decline. The very small increase in inflation combined with the sharp increase in marginal costs encourages the central bank to raise interest rates by approximately $0.03 \%$. Higher domestic interest rates and foreign inflation help appreciate the nominal exchange rate by $0.8 \%$. Given the developments of domestic and foreign inflation, the change in competitiveness for domestic firms is not favourable. The very strong and sharp appreciation of domestic currency and fall in terms of trade are the main contributors to falling domestic output. With respect to the models restrictions, one finds output responds less significantly when $\lambda$ is set to zero. In addition the monetary authorities response is lower when a restriction is made. 


\subsubsection{Foreign inflation shock}

Figure 15 shows a $1 \%$ temporary increase in foreign inflation. Both domestic inflation and overall inflation are higher on impact by $0.005 \%$ and $0.5 \%$ respectively. Lower competitiveness from an appreciating nominal exchange rate raises import costs for domestic firms, thus raising production costs by approximately $0.15 \%$. The follow on effect of this rise in production costs lowers domestic output by $0.3 \%$. Part of this decline reflects consumers substituting domestically produced goods for foreign alternatives. The monetary authority responds to the relatively larger decline on domestic output to the domestic inflation increase by lowering domestic interest rates slightly by $0.005 \%$. The subsequent increase in domestic interest rates and overall inflation appreciate the nominal exchange rate to a new steady state, approximately $1.2 \%$ higher than its original level. With respect to cases where parameter restrictions are made, one finds restricting $\lambda$ increases the decline in domestic output and thus marginal costs. Meanwhile restricting $\omega$ restricts the response to domestic inflation and domestic output. 
Figure 10 - Domestic inflation shock
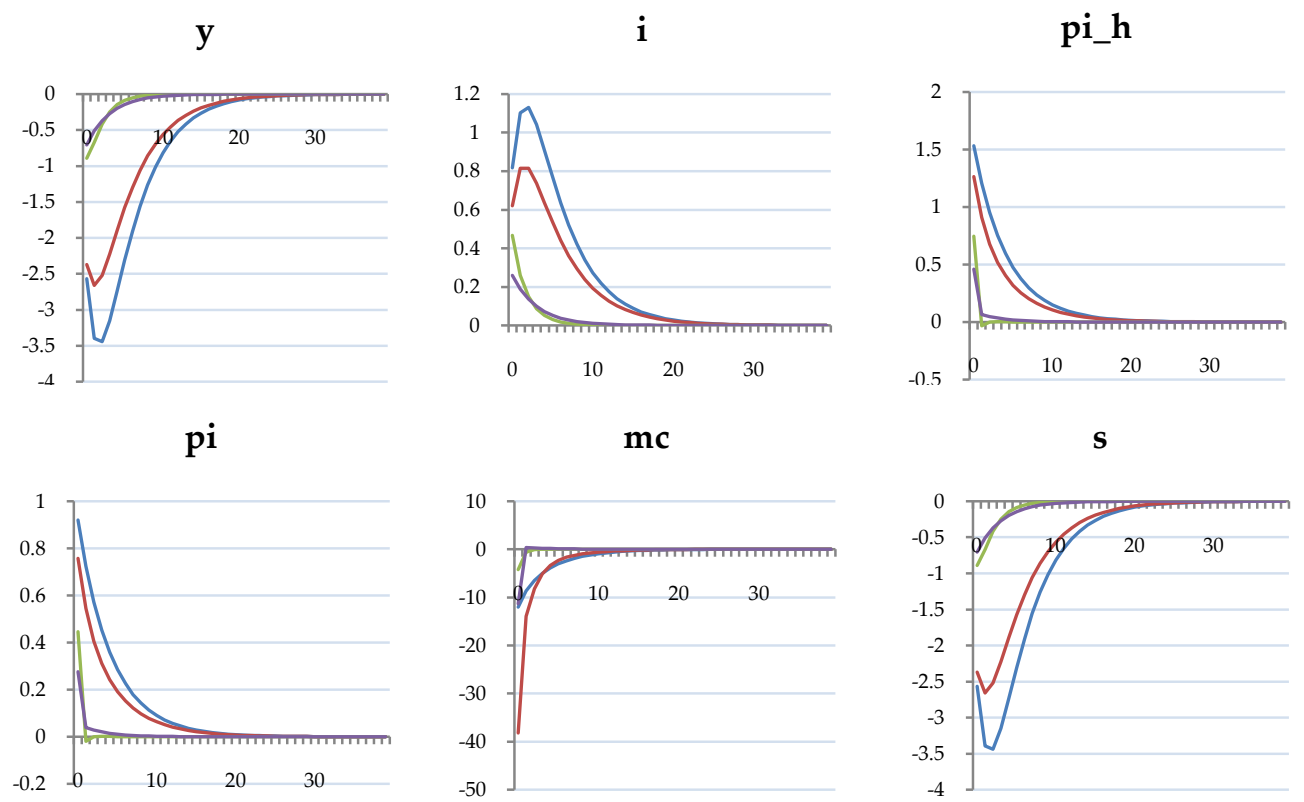

Figure 11 - Domestic interest rate shock
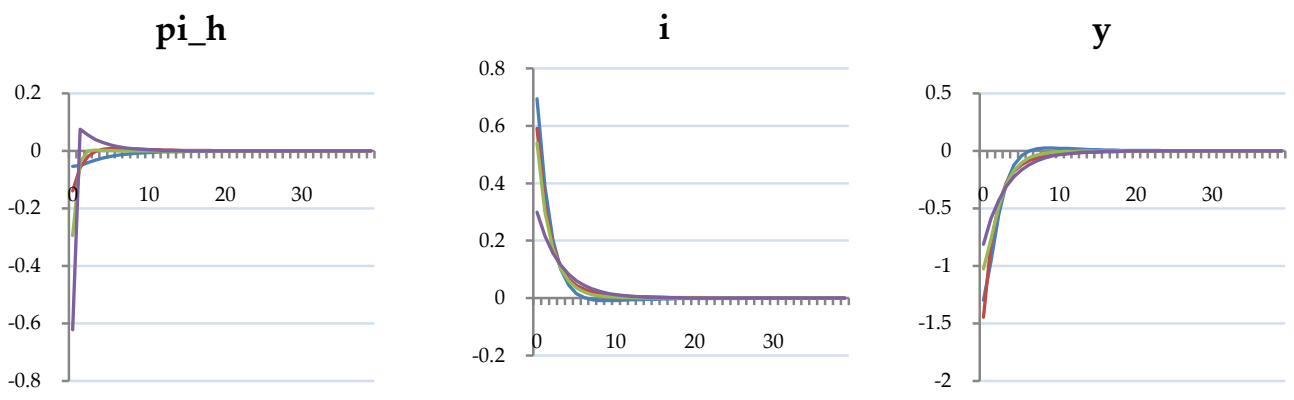

pi

mc

S
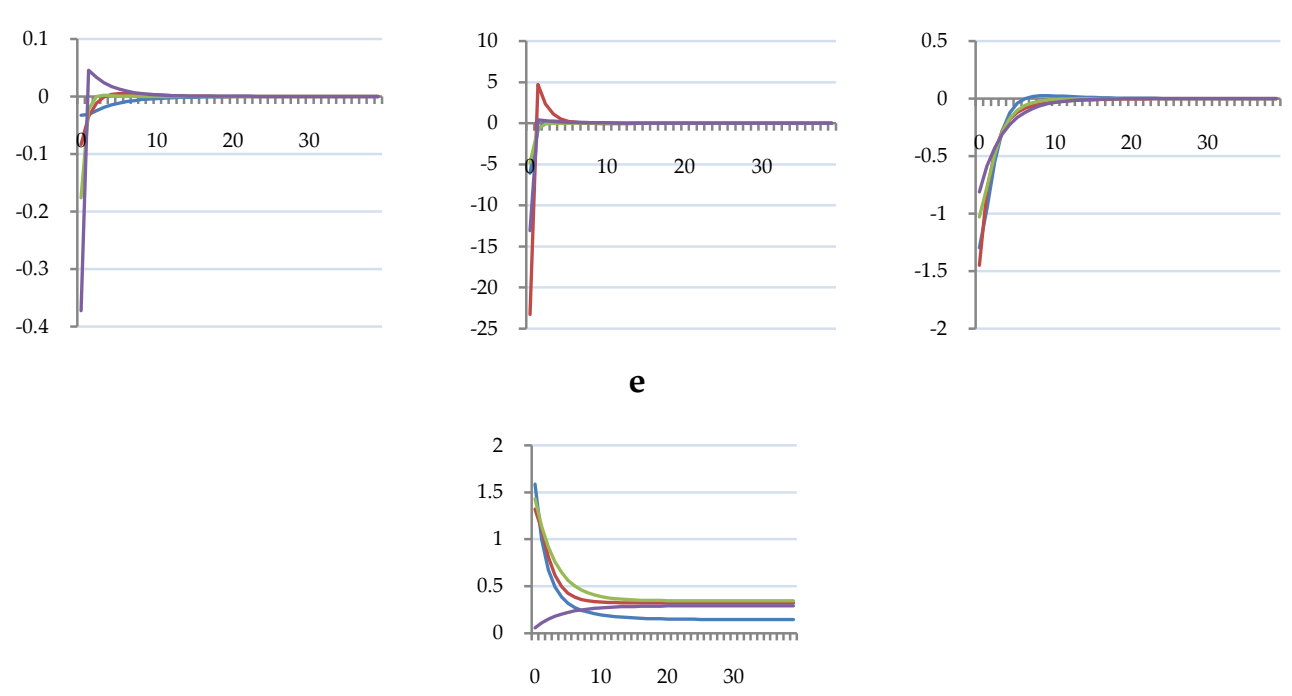
Figure 12 - Domestic productivity shock

y

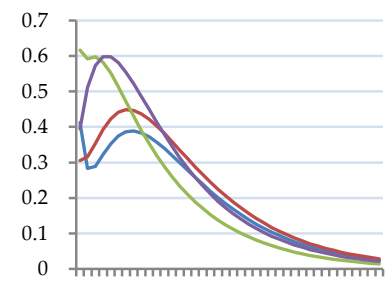

$\mathbf{S}$

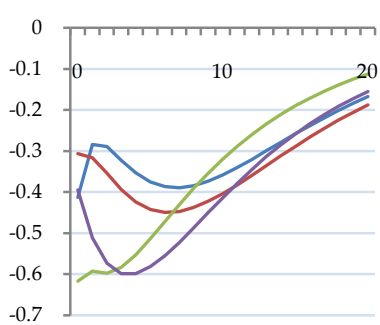

e

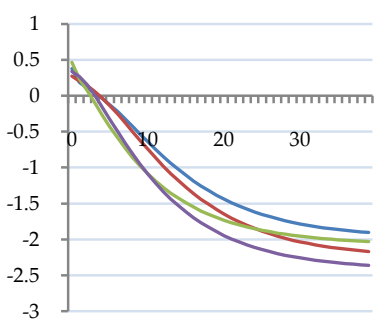

pi_h

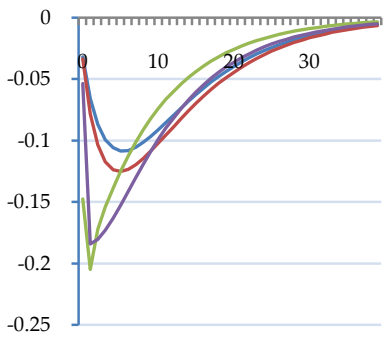

pi

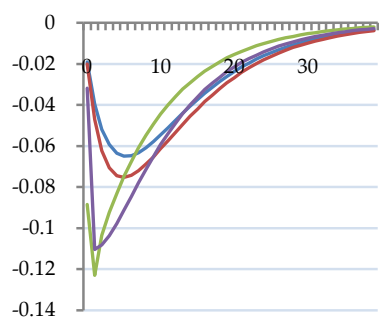

p_h

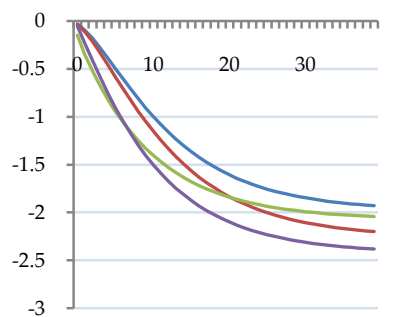

i

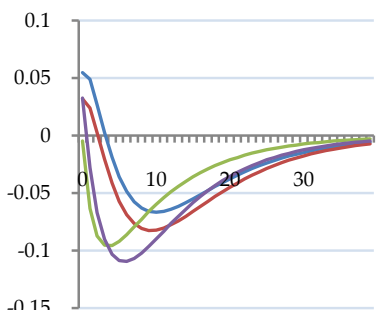

mc

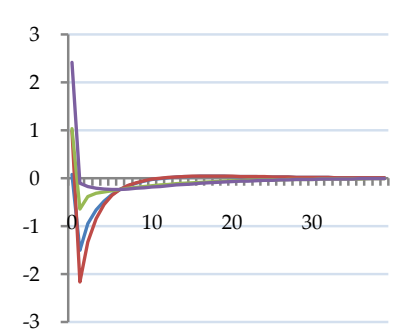

Figure 13 - Foreign interest rate shock

i

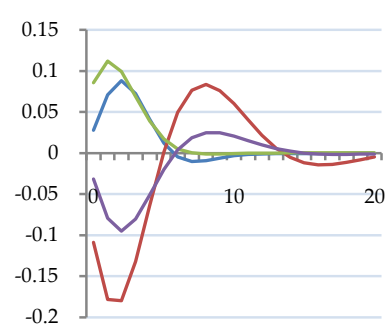

e

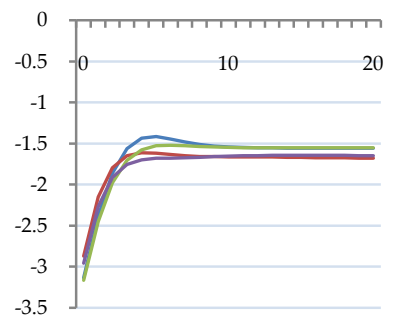

pi_h

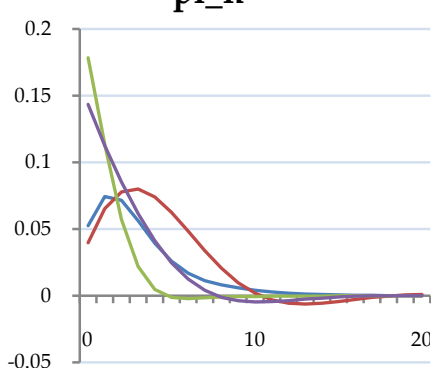

pi

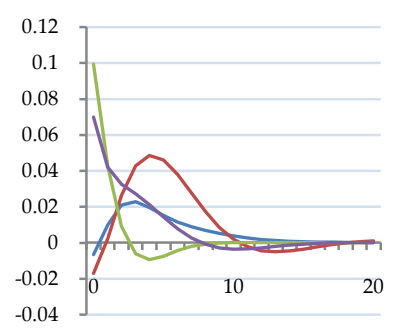

$\mathbf{s}$

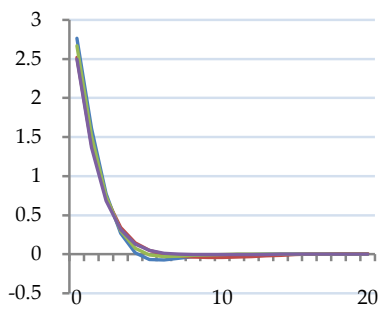

p_h

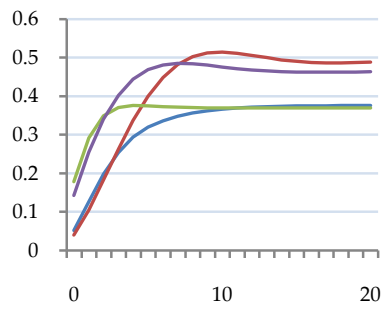


Figure 14 - Foreign output shock

y

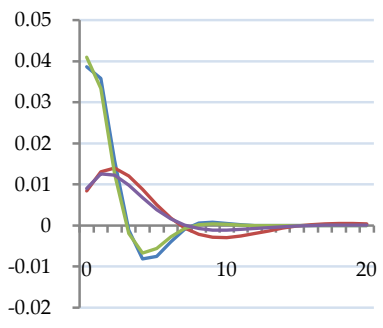

e

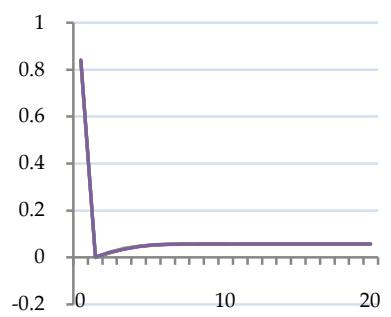

S

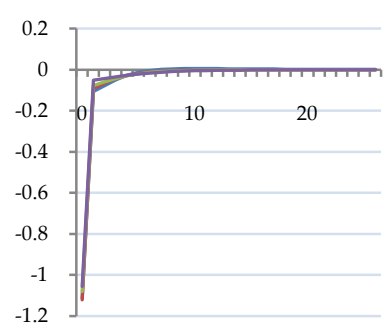

pi_h

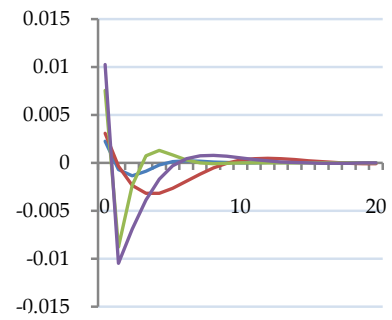

pi

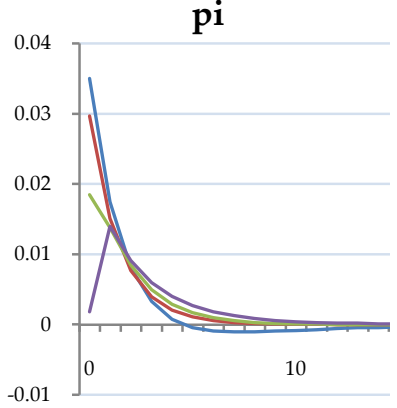

i

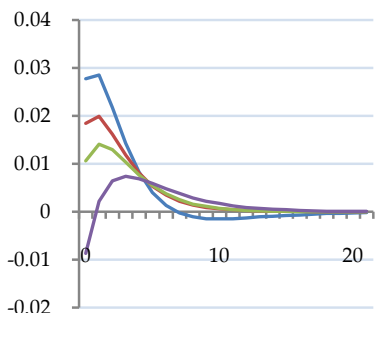

mc

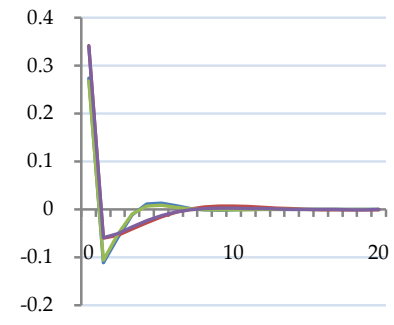

Figure 15 - Foreign inflation shock

i

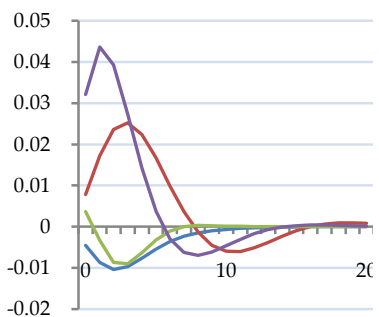

e

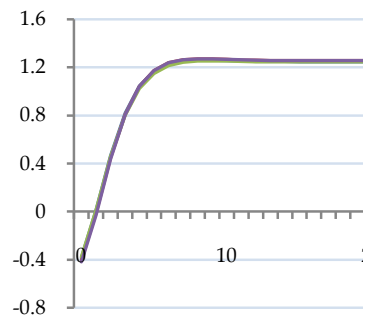

$\mathbf{y}$

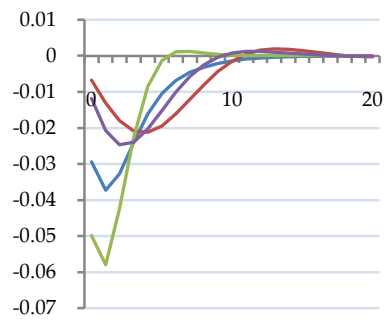

pi_h

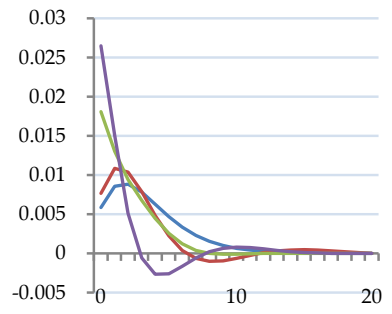

mc

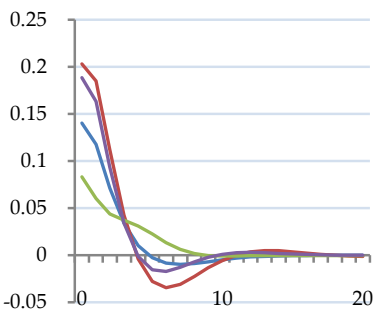

S

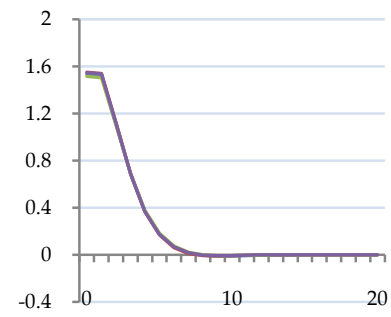




\subsection{Monte Carlo Markov Chain diagnostics}

The following analysis employs the CODA package available in the statistical package R. CODA is designed to analyse chain output from MCMC estimation by producing graphical and numeric diagnostic statistics. My analysis is conducted by addressing four particular areas where problems usually arise. For the following analysis I have estimated a small sample of 30 chains with 20,000 iterations.

\subsubsection{Heidelberger-Welch}

The first diagnostic employed uses the Cramer-von-Mises statistic to test whether my data is from a stationary distribution. This statistic sequentially discards $10 \%, 20 \%, \ldots, 50 \%$ of each chain and tests the remaining iterations for stationarity. The desired level of accuracy is represented by $\varepsilon$, which is used in the literature to represent the ratio of half the confidence internal to the mean. The value I have chosen is 0.1 , one that is often used in practice (Heidelberg and Welch, 1983). If the confidence interval is a sufficiently small proportion of the mean then the diagnostic test has passed. The output from the Heidelberg-Welch diagnostics, as shown in Table 23 below, are supportive of convergence for this sample size. This implies that my much larger chains were also converging. Overall the chains employed in this small sample pass, suggesting we should fail to reject the null hypothesis of stationarity.

One can also conduct a half-width test, which tries to determine whether the chain has been run sufficiently long to achieve a desired level of accuracy. This test uses the portion of the chain that passed Heidelberg-Welch stationary test to compute 95 percent confidence intervals on parameter means. Half of the width of this interval is then compared to the mean. If the 
ratio between the half-width and the mean is lower than the $p$-value given in the first statistic, then the test passes. This time we find disturbance terms for foreign interest rates and foreign inflation fail. This casts doubt into the stationarity of distributions when analysing the entire length of the chain. Furthermore, $\eta$ failed to yield a solvable result. While I failed to reject stationarity for the initial Heidelberg-Welch test, failure for the half-width test casts doubt into the stationarity of these parameters.

\subsubsection{Gelman-Rubin}

The Gelman-Rubin (1992) diagnostic analyses the variance among multiple chains starting from different initial values. The general idea behind this diagnostic is to search for multimodality in the parameter space. This occurs by examining whether individual chains have mixed enough to look like the mixture of all chains (Gelman and Rubin, 1992). The degree of mixing, or convergence, is determined by computing a shrink factor. Values near one indicate convergence and values substantially above one indicate an area of concern. From the Table 23 one can see that there are five areas of concern. Shrink factor values for $\sigma_{\pi_{H}}, \sigma_{i_{F}}, \sigma_{q}, \rho_{i}$, and $\omega$ are considerably above one, suggesting parameter values are having problems converging to a stable mean and variance. I believe problems capturing $\sigma_{q}$ can be attributable to a poor theoretical relation between the real exchange rate and the terms of trade. Often in economy-wide models a form of uncovered interest parity is used. Here I have used a somewhat blunt method to relate the two series.

One should bear in mind the shrink factor calculation is dependent on how long the chain is run. Therefore one should expect a lower shrink factor when applied to the full estimation routine of 300,000 iterations. That is of course assuming that the chain is remotely consistent in the first place. Upon 
further examination I can confirm that the shrink factor is lower for $\rho_{r}$ and $\omega$ when estimated with 100,000 iterations from three chains. Shrink factor values for this sample were found to be 1.22 and 1.32 respectively, which is a significant improvement from this smaller sample. Convergence paths of this diagnostic can be found by referring to Figure 16 at the end of this section. Upon inspection we find the areas of concern I highlighted have problems converging, and the 97.5 percent quartile emphasises this concern.

\subsubsection{Raftery-Lewis}

Raftery and Lewis' (1992) diagnostic test estimates how long MCMC chains needs to be run in order to estimate quantiles to a specified level of accuracy and probability. For this exercise I assumed the quantile was 5\%, with an accuracy level of 0.005 with a probability of 0.95 . Table 24 provides the findings of Raftery and Lewis's diagnostic test. The total length estimate is the suggested length to run the chain for the desired level of accuracy. As one can tell, 300,000 iterations (the number used in the main estimation routine) is sufficiently large enough to satisfy Raftery and Lewis's diagnostic. The lower bound suggests how many samples that are needed if the chains were identically and independently distributed instead of autocorrelated. The dependence factor indicates whether the chains are having problems with mixing. Raftery and Lewis suggest values above five are problematic, although I feel that as long as the recommended chain length is less than the chain length used in practice there is no issue. The diagnostic also attempts to compute a suggested burn-in. As indicated by the second column these range widely across parameters. The parameter that requires the lowest burn-in is $\sigma_{\pi_{H}}$, only requiring 36 iterations, while $\beta$ demands the longest requiring 131,244 iterations.

4.12.4 Parameter distribution 
The last and most simplest diagnostic often adopted in the literature is to plot the empirical distributions of the parameters against a parametric standard normal (uniform) distribution. Essentially if distributions form a straight line then this indicates that the parametric distribution is a better fit for the empirical distribution function. Upon inspection of Figure 11 one finds the standard deviation of the real exchange rate measurement error $\left(\sigma_{q}\right)$ and the standard deviation of the domestic inflation measurement error $\left(\sigma_{\pi_{H}}\right)$ may be better suited to a parametric normal distribution. All other parameters have acceptable empirical distribution functions. Figure 17 shows relative parameter distribution functions. 
Table 23

\begin{tabular}{|c|c|c|c|c|c|c|c|c|c|}
\hline & & \multicolumn{2}{|c|}{ Gelman - Rubin (1992) } & \multicolumn{6}{|c|}{ Heidelberg - Welch (1983) } \\
\hline & Rejection Rate & Scale Factor & 97.5\% Quantile & Stationarity & Start iteration & p-value & Halfwidth Test & Mean & p-value \\
\hline$\sigma_{y_{H}}$ & 0.7611 & 1.02 & 1.04 & passed & 1 & $1.07 \mathrm{e}-01$ & passed & 1.576 & 0.069431 \\
\hline$\sigma_{\pi_{H}}$ & 0.7465 & 2.91 & 3.68 & passed & 1 & $8.57 \mathrm{e}-02$ & passed & 1.683 & $6.62 \mathrm{e}-02$ \\
\hline$\sigma_{r_{H}}$ & 0.7485 & 1.11 & 1.16 & passed & 1 & $9.41 \mathrm{e}-02$ & passed & 2.359 & 0.050291 \\
\hline$\sigma_{i_{F}}$ & 0.7454 & 2.22 & 2.89 & passed & 1 & $5.32 \mathrm{e}-01$ & failed & 13.38 & $1.12 \mathrm{e}+00$ \\
\hline$\sigma_{\pi_{F}}$ & 0.7460 & 1.67 & 1.96 & passed & 1 & $9.61 \mathrm{e}-02$ & failed & 2.230 & $7.58 \mathrm{e}-01$ \\
\hline$\sigma_{y_{F}}$ & 0.7601 & 1.03 & 1.04 & passed & 1 & $1.12 \mathrm{e}-01$ & passed & 3.047 & 0.069277 \\
\hline$\sigma_{q}$ & 0.7453 & 1.66 & 2.04 & passed & 1 & $4.32 \mathrm{e}-01$ & passed & 0.987 & $7.49 \mathrm{e}-02$ \\
\hline$\beta$ & 0.7493 & 1.01 & 1.02 & passed & 1 & $1.11 \mathrm{e}-01$ & passed & 0.966 & $2.64 \mathrm{e}-03$ \\
\hline$\varphi$ & 0.7454 & 1.03 & 1.04 & passed & 4001 & $1.23 \mathrm{e}-01$ & passed & 2.025 & $4.19 \mathrm{e}-03$ \\
\hline$\eta$ & 0.7454 & 1.18 & 1.27 & passed & 1 & $1.75 e-01$ & N/A & N/A & N/A \\
\hline$\lambda$ & 0.6861 & 1.03 & 1.05 & passed & 1 & $1.09 \mathrm{e}-01$ & passed & 0.342 & $2.43 e-04$ \\
\hline$h$ & 0.7453 & 1.15 & 1.23 & passed & 1 & $2.42 \mathrm{e}-01$ & passed & 0.898 & $1.28 \mathrm{e}-02$ \\
\hline$\phi_{\pi}$ & 0.7457 & 1.23 & 1.34 & passed & 1 & $1.01 \mathrm{e}-01$ & passed & 1.485 & $5.23 e-04$ \\
\hline$\phi_{y}$ & 0.7454 & 1.22 & 1.34 & passed & 1 & $4.54 \mathrm{e}-01$ & passed & 0.438 & $2.46 \mathrm{e}-05$ \\
\hline$\rho_{i}$ & 0.7458 & 3.55 & 4.60 & passed & 1 & $2.04 \mathrm{e}-01$ & passed & 0.772 & $6.67 \mathrm{e}-05$ \\
\hline$\rho_{a}$ & 0.7453 & 1.06 & 1.09 & passed & 1 & $5.45 \mathrm{e}-02$ & passed & 0.700 & $4.45 \mathrm{e}-02$ \\
\hline$\tau$ & 0.7453 & 1.07 & 1.12 & passed & 1 & 3.33e-01 & passed & 0.648 & $6.37 \mathrm{e}-02$ \\
\hline$\omega$ & 0.7457 & 2.86 & 3.77 & passed & 1 & $1.04 \mathrm{e}-01$ & passed & 0.758 & $3.30 \mathrm{e}-05$ \\
\hline$\vartheta$ & 0.7469 & 1.04 & 1.07 & passed & 1 & $1.28 \mathrm{e}-01$ & passed & 0.771 & $2.17 \mathrm{e}-05$ \\
\hline$\sigma$ & 0.7348 & 1.43 & 1.75 & passed & 4001 & $1.13 \mathrm{e} 01$ & passed & 0.709 & $8.69 \mathrm{e}-02$ \\
\hline
\end{tabular}


Table 24

\begin{tabular}{ccccc}
\hline & Burn-in & Total & Lower Bound & Dependence Factor \\
\hline$\sigma_{y_{H}}$ & 6926 & 6926 & 7299 & 0.95 \\
$\sigma_{\pi_{H}}$ & 36 & 75972 & 7299 & 10.4 \\
$\sigma_{i_{H}}$ & 6919 & 6919 & 7299 & 0.95 \\
$\sigma_{i_{F}}$ & 56 & 109312 & 7299 & 15.0 \\
$\sigma_{\pi_{F}}$ & 6932 & 6932 & 7299 & 0.95 \\
$\sigma_{y_{F}}$ & 6926 & 6926 & 7299 & 0.95 \\
$\sigma_{q}$ & 48 & 101294 & 7299 & 13.9 \\
$\beta$ & 131244 & 131244 & 7299 & 18.0 \\
$\varphi$ & 7105 & 7105 & 7299 & 0.97 \\
$\eta$ & 112 & 234816 & 7299 & 32.2 \\
$\lambda$ & 34584 & 130961 & 7299 & 17.9 \\
$h$ & 162 & 148084 & 7299 & 20.3 \\
$\phi_{\pi}$ & 8072 & 8072 & 7299 & 1.11 \\
$\phi_{y}$ & 9820 & 9820 & 7299 & 1.35 \\
$\rho_{i}$ & 6345 & 6345 & 7299 & 0.87 \\
$\rho_{a}$ & 86 & 182764 & 7299 & 25.0 \\
$\tau$ & 102 & 218156 & 7299 & 29.9 \\
$\omega$ & 8155 & 8155 & 7299 & 1.12 \\
$\vartheta$ & 130001 & 130001 & 7299 & 17.7 \\
$\sigma$ & 92073 & 92073 & 7299 & 12.6 \\
\hline
\end{tabular}

Figure 16 - Gelman and Rubin diagnostic tests
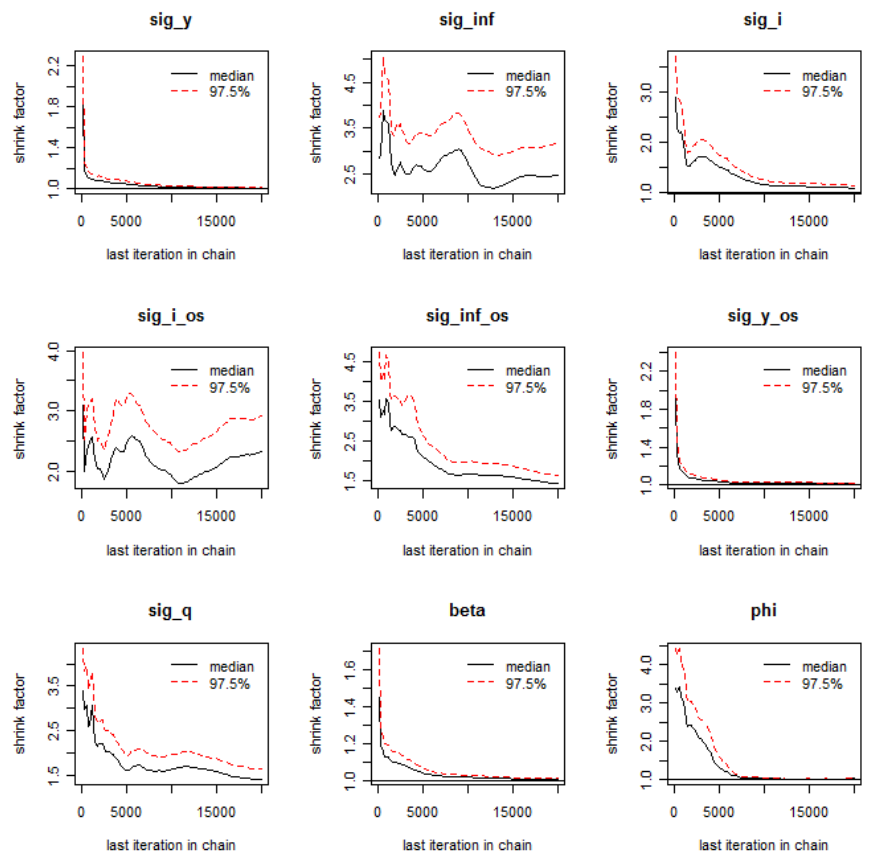

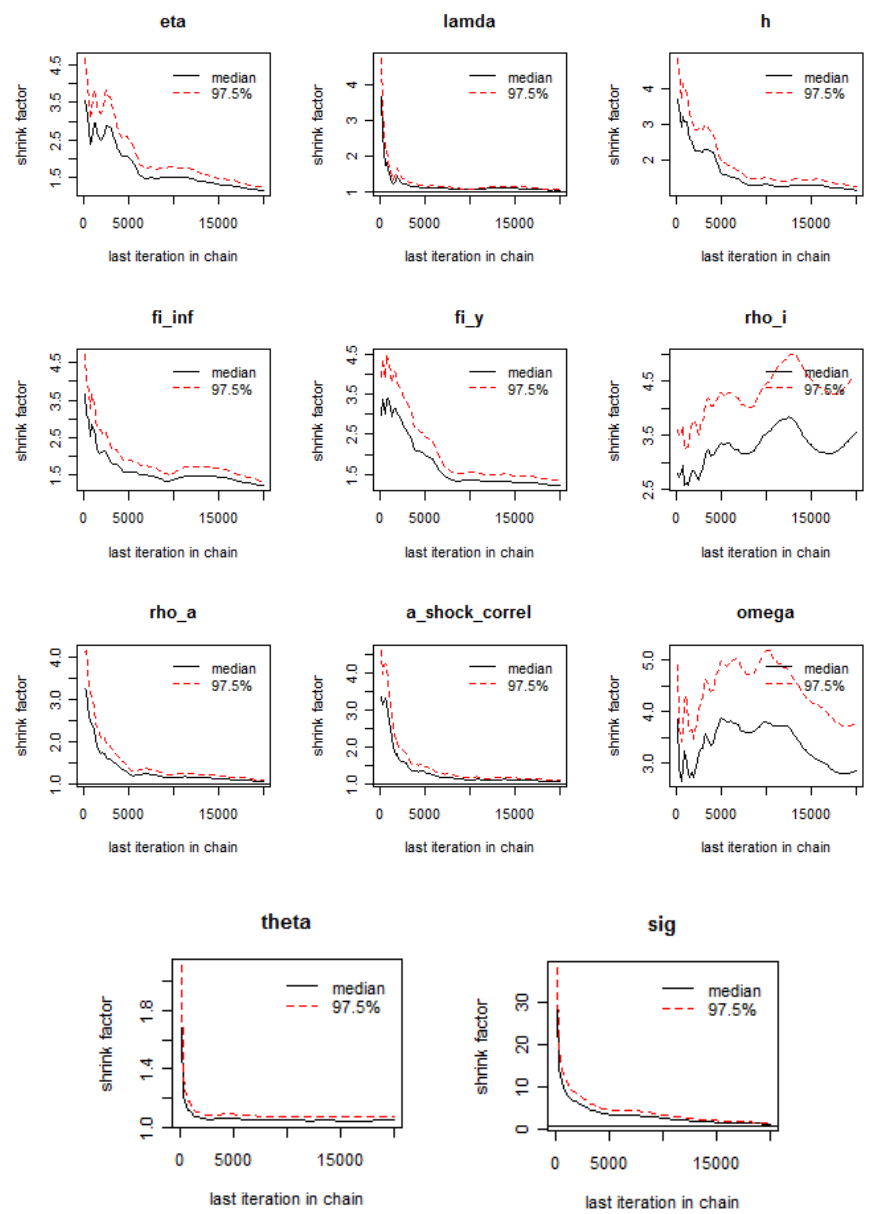

Figure 17 - Parameter distribution diagnostic

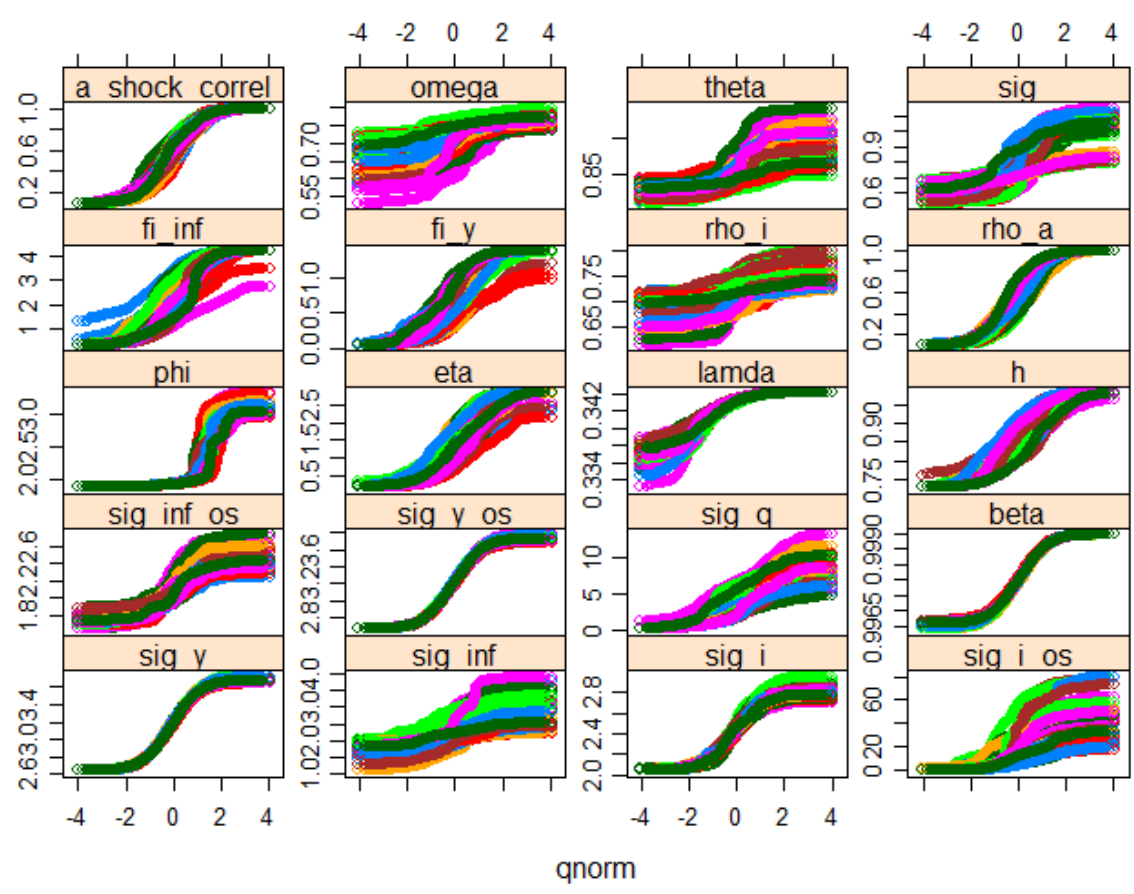




\subsection{Summary}

In this chapter I have used a Bayesian method of estimation to combine prior information with historical New Zealand, Australian, and American data. Unlike other models in the field, this model incorporated rule of thumb or credit constrained households, external habit persistence, and backward looking price setters. An assessment of the literature finds that there has been no other model that has all three of these characteristics. By adopting a Bayesian approach I have been able to insert prior information from Chapters 2 and 3, together with estimates from Liu (2006) and calibrations from the RBNZ's FPS model, to guide the Metropolis-Hastings algorithm to solve for posterior means and distributions. I believe the model and its estimated set of parameters can be used as a guide to understanding macroeconomic behaviour in New Zealand.

My estimated parameters are highlighted by a high degree of external habit persistence (0.9), a relatively high proportion of credit constrained households relative to GMM estimates (0.34), and relative to GMM estimates a lower proportion of backward looking price setters $(0.70)$. The impulse response functions presented in this chapter suggest allowing for some deviation from the Permanent Income Hypothesis and forward looking price setting, enables one to describe movements in key variables (such as output, inflation, marginal costs, and the terms of trade) more in line with that observed in reality. In addition they enable one to describe the response of the monetary authority to external shocks.

While diagnostic tests are largely favourable, there is some concern regarding consistency and stationarity of parameter chains. Diagnostics 
suggest that chains must be run for a considerable length in order for all parameters to be stationary. Running long chains is time consuming, with the main estimation of 300,000 iterations for each of three chains taking upwards of seven hours to complete. Overall, though, the diagnostic tests presented here are positive. 
Appendix 4.1 - CPI Inflation

At this point we know that together all households have the following optimal allocation functions:

$$
C_{H, t}=(1-\alpha)\left(\frac{P_{H, t}}{P_{t}}\right)^{-\eta} C_{t} \quad C_{F, t}=\alpha\left(\frac{P_{F, t}}{P_{t}}\right)^{-\eta} C_{t}
$$

Households total consumption consists of both domestic and foreign produced goods described by the now familiar relationship:

$$
C_{t}=\left[(1-\alpha)^{\frac{1}{\eta}} C_{H, t}^{\frac{\eta-1}{\eta}}+\alpha^{\frac{1}{\eta}} C_{F, t}^{\frac{\eta-1}{\eta}}\right]^{\frac{\eta}{\eta-1}}
$$

Combining these three equations together yields the following:

$$
\begin{aligned}
& C_{t}=\left[(1-\alpha)^{\frac{1}{\eta}} C_{H, t}^{\frac{\eta-1}{\eta}}+\alpha^{\frac{1}{\eta}} C_{F, t}^{\frac{\eta-1}{\eta}}\right]^{\frac{\eta}{\eta-1}} \\
& =\left[(1-\alpha)^{\frac{1}{\eta}}\left((1-\alpha)\left(\frac{P_{H, t}}{P_{t}}\right)^{-\eta} C_{t}\right)^{\frac{\eta-1}{\eta}}+\alpha^{\frac{1}{\eta}}\left(\alpha\left(\frac{P_{F, t}}{P_{t}}\right)^{-\eta} C_{t}\right)^{\frac{\eta-1}{\eta}}\right]^{\frac{\eta}{\eta-1}} \\
& =\left[(1-\alpha)^{\frac{1}{\eta}}(1-\alpha)^{\frac{\eta-1}{\eta}}\left(\frac{P_{H, t}}{P_{t}}\right)^{-\eta\left(\frac{\eta-1}{\eta}\right)} C_{t}^{\frac{\eta-1}{\eta}}+\alpha^{\frac{1}{\eta}} \alpha^{\frac{\eta-1}{\eta}}\left(\frac{P_{F, t}}{P_{t}}\right)^{-\eta\left(\frac{\eta-1}{\eta}\right)} C_{t}^{\frac{\eta-1}{\eta}}\right]^{\frac{\eta}{\eta-1}} \\
& C_{t}^{\frac{\eta-1}{\eta}}=(1-\alpha)^{\frac{1}{\eta}+\frac{\eta-1}{\eta}}\left(\frac{P_{H, t}}{P_{t}}\right)^{-(\eta-1)} C_{t}^{\frac{\eta-1}{\eta}}+\alpha^{\frac{1}{\eta}+\frac{\eta-1}{\eta}}\left(\frac{P_{F, t}}{P_{t}}\right)^{-(\eta-1)} C_{t}^{\frac{\eta-1}{\eta}} \\
& =(1-\alpha)^{\frac{\eta}{\eta}}\left(\frac{P_{H, t}}{P_{t}}\right)^{1-\eta} C_{t}^{\frac{\eta-1}{\eta}}+\alpha^{\frac{\eta}{\eta}}\left(\frac{P_{F, t}}{P_{t}}\right)^{1-\eta} C_{t}^{\frac{\eta-1}{\eta}} \\
& 1=(1-\alpha)\left(\frac{P_{H, t}}{P_{t}}\right)^{1-\eta}+\alpha\left(\frac{P_{F, t}}{P_{t}}\right)^{1-\eta} \\
& P_{t}^{1-\eta}=(1-\alpha) P_{H, t}^{1-\eta}+\alpha P_{F, t}^{1-\eta} \\
& P_{t}=\left[(1-\alpha) P_{H, t}^{1-\eta}+\alpha P_{F, t}^{1-\eta}\right]^{\frac{1}{1-\eta}}
\end{aligned}
$$


The last equation can be rearranged to form:

$$
\begin{aligned}
P_{t} & =\left[(1-\alpha) P_{H, t}^{1-\eta}+\alpha P_{F, t}^{1-\eta}\right]^{\frac{1}{1-\eta}} \\
P_{t}^{1-\eta} & =(1-\alpha) P_{H, t}^{1-\eta}+\alpha P_{F, t}^{1-\eta} \\
\frac{P_{t}^{1-\eta}}{P_{H, t}^{1-\eta}} & =(1-\alpha)+\alpha \frac{P_{F, t}^{1-\eta}}{P_{H, t}^{1-\eta}} \\
\left(\frac{P_{t}}{P_{H, t}}\right)^{1-\eta} & =(1-\alpha)+\alpha\left(\frac{P_{F, t}}{P_{H, t}}\right)^{1-\eta}
\end{aligned}
$$

Using a Taylor approximation one can rewrite the prior equation as:

$$
\begin{gathered}
\left(\frac{P}{P_{H}}\right)^{1-\eta} e^{(1-\eta)\left(p_{t}-p_{H, t}\right)}=(1-\alpha)+\alpha\left(\frac{P_{F}}{P_{H}}\right)^{1-\eta} e^{(1-\eta)\left(p_{F, t}-p_{H, t}\right)} \\
\left(\frac{P}{P_{H}}\right)^{1-\eta}\left[1+(1-\eta)\left(p_{t}-p_{H, t}\right)\right]=(1-\alpha)+\alpha\left(\frac{P_{F}}{P_{H}}\right)^{1-\eta}\left[1+(1-\eta)\left(p_{F, t}-p_{H, t}\right)\right] \\
\left(\frac{P}{P_{H}}\right)^{1-\eta}+\left(\frac{P}{P_{H}}\right)^{1-\eta}(1-\eta)\left(p_{t}-p_{H, t}\right)=(1-\alpha)+\alpha\left(\frac{P_{F}}{P_{H}}\right)^{1-\eta}+\alpha\left(\frac{P_{F}}{P_{H}}\right)^{1-\eta}(1-\eta)\left(p_{F, t}-p_{H, t}\right) \\
\text { Since }\left(\frac{P_{t}}{P_{H, t}}\right)^{1-\eta}=(1-\alpha)+\alpha\left(\frac{P_{F, t}}{P_{H, t}}\right)^{1-\eta}, \text { in steady state }\left(\frac{P}{P_{H}}\right)^{1-\eta}=(1-\alpha)+\alpha\left(\frac{P_{F}}{P_{H}}\right)^{1-\eta}
\end{gathered}
$$

also holds. Therefore I am able to use this result in the prior manipulation to obtain:

$$
\begin{aligned}
\left(\frac{P}{P_{H}}\right)^{1-\eta}(1-\eta)\left(p_{t}-p_{H, t}\right) & =\alpha\left(\frac{P_{F}}{P_{H}}\right)^{1-\eta}(1-\eta)\left(p_{F, t}-p_{H, t}\right) \mathrm{k} \\
P^{1-\eta}\left(p_{t}-p_{H, t}\right) & =\alpha P_{F}^{1-\eta}\left(p_{F, t}-p_{H, t}\right) \\
p_{t}-p_{H, t} & =\alpha\left(p_{F, t}-p_{H, t}\right) \\
p_{t} & =\alpha p_{F, t}-\alpha p_{H, t}+p_{H, t} \\
& =(1-\alpha) p_{H, t}+\alpha p_{F, t}
\end{aligned}
$$

The last equation is the linearised version of overall CPI used for the derivation of the relationship between the terms of trade and inflation. During the derivation I have assumed that in steady state $P=P_{H}=P_{F}$, or equivalently $\pi=\pi_{H}=\pi_{F}$. 
Appendix 4.2 - Goods Market Equilibrium

The goods market equilibrium for the domestic economy requires a condition that domestic production, $Y_{t}$, amounts to the domestic consumption $\left(C_{H, t}\right)$ and foreign consumption of domestically produced goods $\left(C_{H, t}^{*}\right)$. Households aim to allocate their expenditure for the total consumption between domestically produced and imported consumption goods. All households decide about the optimal allocation of expenditures between domestic and foreign goods by attempting to minimise total expenditure $P_{t} C_{t}=P_{H, t} C_{H, t}+P_{F, t} C_{F, t}$ subject to a possible consumption:

$$
C_{t}=\left((1-\alpha)^{\frac{1}{\eta}} C_{H, t}^{\frac{\eta-1}{\eta}}+\alpha^{\frac{1}{\eta}} C_{F, t}^{\frac{\eta-1}{\eta}}\right)^{\frac{\eta}{\eta-1}}
$$

The Lagrangian and its partial derivatives take the following forms (with a multiplier $\left.\lambda_{t}\right)$ :

$$
\begin{aligned}
L_{t}\left(C_{H, t}, C_{F, t}, \lambda_{t}\right) & =\left((1-\alpha)^{\frac{1}{\eta}} C_{H, t}^{\frac{\eta-1}{\eta}}+\alpha^{\frac{1}{\eta}} C_{F, t}^{\frac{\eta-1}{\eta}}\right)^{\frac{\eta}{\eta-1}}+\lambda_{t}\left(P_{t} C_{t}-P_{H, t} C_{H, t}-P_{F, t} C_{F, t}\right) \\
\frac{\partial L_{t}}{\partial C_{H, t}} & =\frac{\eta}{\eta-1}\left((1-\alpha)^{\frac{1}{\eta}} C_{H, t}^{\frac{\eta-1}{\eta}}+\alpha^{\frac{1}{\eta}} C_{F, t}^{\frac{\eta-1}{\eta}}\right)^{\frac{\eta}{\eta-1}-1}(1-\alpha)^{\frac{1}{\eta}}\left(\frac{\eta-1}{\eta}\right) C_{H, t}^{\frac{\eta-1}{\eta}-1}-\lambda_{t} P_{H, t} \\
\frac{\partial L_{t}}{\partial C_{F, t}} & =\frac{\eta}{\eta-1}\left((1-\alpha)^{\frac{1}{\eta}} C_{H, t}^{\frac{\eta-1}{\eta}}+\alpha^{\frac{1}{\eta}} C_{F, t}^{\frac{\eta-1}{\eta}}\right)^{\frac{\eta}{\eta-1}-1} \alpha^{\frac{1}{\eta}}\left(\frac{\eta-1}{\eta}\right) C_{F, t}^{\frac{\eta-1}{\eta}-1}-\lambda_{t} P_{F, t}
\end{aligned}
$$

Setting both derivates equal to zero yields:

$$
\begin{aligned}
& 0=\frac{\eta}{\eta-1}\left((1-\alpha)^{\frac{1}{\eta}} C_{H, t}^{\frac{\eta-1}{\eta}}+\alpha^{\frac{1}{\eta}} C_{F, t}^{\frac{\eta-1}{\eta}}\right)^{\frac{1}{\eta-1}}(1-\alpha)^{\frac{1}{\eta}}\left(\frac{\eta-1}{\eta}\right) C_{H, t}^{-\frac{1}{\eta}}-\lambda_{t} P_{H, t} \\
& \lambda_{t}=\frac{1}{P_{H, t}} \frac{\eta}{\eta-1}\left((1-\alpha)^{\frac{1}{\eta}} C_{H, t}^{\frac{\eta-1}{\eta}}+\alpha^{\frac{1}{\eta}} C_{F, t}^{\frac{\eta-1}{\eta}}\right)^{\frac{1}{\eta-1}}(1-\alpha)^{\frac{1}{\eta}}\left(\frac{\eta-1}{\eta}\right) C_{H, t}^{-\frac{1}{\eta}}
\end{aligned}
$$

and 


$$
\begin{aligned}
& 0=\frac{\eta}{\eta-1}\left((1-\alpha)^{\frac{1}{\eta}} C_{H, t}^{\frac{\eta-1}{\eta}}+\alpha^{\frac{1}{\eta}} C_{F, t}^{\frac{\eta-1}{\eta}}\right)^{\frac{1}{\eta-1}} \alpha^{\frac{1}{\eta}}\left(\frac{\eta-1}{\eta}\right) C_{F, t}^{-\frac{1}{\eta}}-\lambda_{t} P_{F, t} \\
& \lambda_{t}=\frac{1}{P_{F, t}} \frac{\eta}{\eta-1}\left((1-\alpha)^{\frac{1}{\eta}} C_{H, t}^{\frac{\eta-1}{\eta}}+\alpha^{\frac{1}{\eta}} C_{F, t}^{\frac{\eta-1}{\eta}}\right)^{\frac{1}{\eta-1}} \alpha^{\frac{1}{\eta}}\left(\frac{\eta-1}{\eta}\right) C_{F, t}^{-\frac{1}{\eta}}
\end{aligned}
$$

Then using the lagrange multiplier one can obtain:

$$
\begin{aligned}
\alpha^{\frac{1}{\eta}} C_{F, t}^{-\frac{1}{\eta}} \frac{1}{P_{F, t}} & =(1-\alpha)^{\frac{1}{\eta}} C_{H, t}^{-\frac{1}{\eta}} \frac{1}{P_{H, t}} \\
\frac{P_{H, t}}{P_{F, t}} & =\frac{\alpha^{-\frac{1}{\eta}} C_{H, t}^{-\frac{1}{\eta}}}{(1-\alpha)^{-\frac{1}{\eta}} C_{F, t}^{-\frac{1}{\eta}}} \\
\left(\frac{P_{H, t}}{P_{F, t}}\right)^{-\eta} & =\frac{\alpha C_{H, t}}{(1-\alpha) C_{F, t}}
\end{aligned}
$$

Using the prior equation I can now formulate demand functions using the aggregate budget constraint. For domestic goods the demand function is the following:

$$
\begin{aligned}
\left(\frac{P_{H, t}}{P_{F, t}}\right)^{-\eta} & =\frac{\alpha C_{H, t}}{(1-\alpha) \frac{P_{t} C_{t}-P_{H, t} C_{H, t}}{P_{F, t}}} \\
\left(\frac{P_{H, t}}{P_{F, t}}\right)^{-\eta} & =\frac{\alpha P_{F, t} C_{H, t}}{(1-\alpha) P_{t} C_{t}-P_{H, t} C_{H, t}} \\
\left(\frac{P_{H, t}}{P_{F, t}}\right)^{-\eta}(1-\alpha) P_{t} C_{t} & =C_{H, t}\left[\alpha P_{F, t}+\left(\frac{P_{H, t}}{P_{F, t}}\right)^{-\eta}(1-\alpha) P_{H, t}\right] \\
C_{H, t} & =\frac{\left(\frac{P_{H, t}}{P_{F, t}}\right)^{-\eta}(1-\alpha) P_{t} C_{t}}{\alpha P_{F, t}+\left(\frac{P_{H, t}}{P_{F, t}}\right)^{-\eta}(1-\alpha) P_{H, t}} \\
C_{H, t}= & \frac{\left(\frac{P_{H, t}}{P_{F, t}}\right)^{-\eta}(1-\alpha) \frac{P_{t} C_{t}}{P_{F, t}}}{\alpha+\left(\frac{P_{H, t}}{P_{F, t}}\right)^{-\eta}(1-\alpha) \frac{P_{H, t}}{P_{F, t}}} \\
C_{H, t}= & \frac{(1-\alpha) \frac{P_{t} C_{t}}{P_{F, t}}\left(\frac{P_{H, t}}{P_{F, t}}\right)^{-\eta}}{\alpha+\left(\frac{P_{H, t}}{P_{F, t}}\right)^{1-\eta}(1-\alpha)}
\end{aligned}
$$


For foreign goods the demand function can be derived in a similar process:

$$
\begin{aligned}
& \left(\frac{P_{H, t}}{P_{F, t}}\right)^{-\eta}=\frac{\alpha \frac{P_{t} C_{t}-P_{F, t} C_{F, t}}{P_{H, t}}}{(1-\alpha) C_{F, t}} \\
& \left(\frac{P_{H, t}}{P_{F, t}}\right)^{-\eta}=\frac{\alpha\left(P_{t} C_{t}-P_{F, t} C_{F, t}\right)}{(1-\alpha) P_{H, t} C_{F, t}} \\
& \left(\frac{P_{H, t}}{P_{F, t}}\right)^{-\eta}(1-\alpha) P_{H, t} C_{F, t}=\alpha\left(P_{t} C_{t}-P_{F, t} C_{F, t}\right) \\
& {\left[\left(\frac{P_{H, t}}{P_{F, t}}\right)^{-\eta}(1-\alpha) P_{H, t}+\alpha P_{F, t}\right] C_{F, t}=\alpha P_{t} C_{t}} \\
& C_{F, t}=\frac{\alpha P_{t} C_{t}}{\left(\frac{P_{H, t}}{P_{F, t}}\right)^{-\eta}(1-\alpha) P_{H, t}+\alpha P_{F, t}} \\
& C_{F, t}=\frac{\alpha \frac{P_{t} C_{t}}{P_{F, t}}}{\alpha+\left(\frac{P_{H, t}}{P_{F, t}}\right)^{1-\eta}(1-\alpha)}
\end{aligned}
$$

Using the relationship for overall CPI:

$$
\begin{aligned}
P_{t} & =\left[(1-\alpha) P_{H, t}^{1-\eta}+\alpha P_{F, t}^{1-\eta}\right]^{\frac{1}{1-\eta}} \\
P_{t}^{1-\eta} & =(1-\alpha) P_{H, t}^{1-\eta}+\alpha P_{F, t}^{1-\eta} \\
\left(\frac{P_{t}}{P_{F, t}}\right)^{1-\eta} & =(1-\alpha)\left(\frac{P_{H, t}}{P_{F, t}}\right)^{1-\eta}+\alpha \\
(1-\alpha)\left(\frac{P_{H, t}}{P_{F, t}}\right)^{1-\eta} & =\left(\frac{P_{t}}{P_{F, t}}\right)^{1-\eta}-\alpha \\
\left(\frac{P_{H, t}}{P_{F, t}}\right)^{1-\eta} & =\frac{1}{(1-\alpha)}\left[\left(\frac{P_{t}}{P_{F, t}}\right)^{1-\eta}-\alpha\right]
\end{aligned}
$$


Substituting the previous equation into the domestic goods demand function:

$$
\begin{aligned}
C_{H, t}= & \frac{(1-\alpha) \frac{P_{t} C_{t}}{P_{F, t}}\left(\frac{P_{H, t}}{P_{F, t}}\right)^{-\eta}}{\alpha+(1-\alpha)\left(\frac{P_{H, t}}{P_{F, t}}\right)^{1-\eta}} \\
= & \frac{(1-\alpha) \frac{P_{t} C_{t}}{P_{F, t}}\left(\frac{P_{H, t}}{P_{F, t}}\right)^{-\eta}}{\alpha+(1-\alpha) \frac{1}{(1-\alpha)}\left[\left(\frac{P_{t}}{P_{F, t}}\right)^{1-\eta}-\alpha\right]} \\
= & (1-\alpha) \frac{P_{t} C_{t}}{P_{F, t}}\left(\frac{P_{H, t}}{P_{F, t}}\right)^{-\eta}\left(\frac{P_{F, t}}{P_{t}}\right)^{1-\eta} \\
= & (1-\alpha) \frac{P_{t} C_{t}}{P_{F, t}}\left(\frac{P_{H, t}}{P_{F, t}}\right)^{-\eta}\left(\frac{P_{F, t}}{P_{t}}\right)^{\eta} \frac{P_{F, t}}{P_{t}} \\
= & (1-\alpha)\left(\frac{P_{H, t}}{P_{F, t}}\right)^{-\eta} C_{t}
\end{aligned}
$$

For foreign consumption goods:

$$
\begin{aligned}
C_{F, t}= & \frac{\alpha \frac{P_{t} C_{t}}{P_{F, t}}}{\alpha+(1-\alpha)\left(\frac{P_{H, t}}{P_{F, t}}\right)^{1-\eta}} \\
= & \frac{\alpha \frac{P_{t} C_{t}}{P_{F, t}}}{\alpha+(1-\alpha) \frac{1}{(1-\alpha)}\left[\left(\frac{P_{t}}{P_{F, t}}\right)^{1-\eta}-\alpha\right]} \\
= & \frac{\alpha \frac{P_{t} C_{t}}{P_{F, t}}}{\left(\frac{P_{t}}{P_{F, t}}\right)^{1-\eta}} \\
= & \alpha \frac{P_{t} C_{t}}{P_{F, t}}\left(\frac{P_{F, t}}{P_{t}}\right)^{1-\eta} \\
= & \alpha \frac{P_{t} C_{t}}{P_{F, t}}\left(\frac{P_{F, t}}{P_{t}}\right)^{-\eta}\left(\frac{P_{F, t}}{P_{t}}\right) \\
= & \alpha\left(\frac{P_{F, t}}{P_{t}}\right)^{-\eta \eta} C_{t}
\end{aligned}
$$


In this way it is possible to derive foreign consumption of domestic production $\left(C_{H, t}^{*}\right)$ that is influenced by the amount of total consumption in the bigger economy $\left(C_{t}^{*}\right)$, the degree of openness $(\alpha)$, the elasticity of substitution between domestic and foreign consumption goods $(\eta)$, and the relative price of domestic goods that is purchased to the aggregate price level in the bigger economy $\frac{A_{t} P_{H, t}}{P_{t}^{*}}$. Thus I can write:

$$
C_{H, t}^{*}=\alpha\left(\frac{A_{t} P_{H, t}}{P_{t}^{*}}\right)^{-\eta} C_{t}^{*}
$$

The goods market clearing condition holds for the $i^{\text {th }}$ domestic product and can be expressed in the following form:

$$
Y_{t}(i)=C_{H, t}(i)+C_{H, t}^{*}(i)
$$

Substituting the demand functions above in the previous representation we obtain:

$$
Y_{t}(i)=\left(\frac{P_{H, t}(i)}{P_{H, t}}\right)^{-\varepsilon} C_{H, t}+\left(\frac{P_{H, t}(i)}{P_{H, t}}\right)^{-\varepsilon} C_{H, t}^{*}
$$

Then using the foreign consumption equation above in conjunction with the equations (a) and (b) we can eliminate $C_{H, t}$ and $C_{H, t}^{*}$ :

$$
\begin{aligned}
Y_{t}(i) & =\left(\frac{P_{H, t}(i)}{P_{H, t}}\right)^{-\varepsilon}(1-\alpha)\left(\frac{P_{H, t}}{P_{t}}\right)^{-\eta} C_{t}+\left(\frac{P_{H, t}(i)}{P_{H, t}}\right)^{-\varepsilon} \alpha\left(\frac{A_{t} P_{H, t}}{P_{t}^{*}}\right) C_{t}^{*} \\
Y(i)_{t} & =\left(\frac{P_{H, t}(i)}{P_{H, t}}\right)^{-\varepsilon}\left[(1-\alpha)\left(\frac{P_{H, t}}{P_{t}}\right)^{-\eta} C_{t}+\alpha\left(\frac{A_{t} P_{H, t}}{P_{t}^{*}}\right) C_{t}^{*}\right] \\
Y_{t}(i)^{\frac{\phi-1}{\phi}} & =\left(\frac{P_{H, t}(i)}{P_{H, t}}\right)^{-\varepsilon\left(\frac{\phi-1}{\phi}\right)}\left[(1-\alpha)\left(\frac{P_{H, t}}{P_{t}}\right)^{-\eta} C_{t}+\alpha\left(\frac{A_{t} P_{H, t}}{P_{t}^{*}}\right) C_{t}^{*}\right]^{\frac{\phi-1}{\phi}}
\end{aligned}
$$

Substituting the CES production function described in section 3.4 for aggregate output given by:

$$
Y_{t}=\left[\int_{0}^{1} Y_{t}(i)^{\frac{\phi-1}{\phi}} d i\right]^{\frac{\phi-1}{\phi}}
$$




$$
\begin{aligned}
Y_{t} & =\left[\int_{0}^{1}\left(\frac{P_{H, t}(i)}{P_{H, t}}\right)^{-\varepsilon\left(\frac{\phi-1}{\phi}\right)}\left((1-\alpha)\left(\frac{P_{H, t}}{P_{t}}\right)^{-\eta} C_{t}+\alpha\left(\frac{A_{t} P_{H, t}}{P_{t}^{*}}\right)^{-\eta} C_{t}^{*}\right)^{\frac{\phi-1}{\phi}} d i\right]^{\frac{\phi}{\phi-1}} \\
Y_{t}^{\frac{\phi-1}{\phi}} & =\int_{0}^{1}\left(\frac{P_{H, t}(i)}{P_{H, t}}\right)^{-\varepsilon\left(\frac{\phi-1}{\phi}\right)}\left((1-\alpha)\left(\frac{P_{H, t}}{P_{t}}\right)^{-\eta} C_{t}+\alpha\left(\frac{A_{t} P_{H, t}}{P_{t}^{*}}\right)^{-\eta} C_{t}^{*}\right)^{\frac{\phi-1}{\phi}} d i \\
Y_{t} & =\int_{0}^{1}\left(\frac{P_{H, t}(i)}{P_{H, t}}\right)^{-\varepsilon}\left((1-\alpha)\left(\frac{P_{H, t}}{P_{t}}\right)^{-\eta} C_{t}+\alpha\left(\frac{A_{t} P_{H, t}}{P_{t}^{*}}\right)^{-\eta} C_{t}^{*}\right)^{\frac{\phi-1}{\phi}} d i \\
Y_{t} & =\left(\frac{1}{P_{H, t}}\right)^{-\varepsilon}\left((1-\alpha)\left(\frac{P_{H, t}}{P_{t}}\right)^{-\eta} C_{t}+\alpha\left(\frac{A_{t} P_{H, t}}{P_{t}^{*}}\right)^{-\eta} C_{t}^{*}\right)_{0}^{1} \int_{H, t}(i)^{-\varepsilon} d i \\
Y_{t} & =\left(\frac{1}{P_{H, t}}\right)^{-\varepsilon}\left((1-\alpha)\left(\frac{P_{H, t}}{P_{t}}\right)^{-\eta} C_{t}+\alpha\left(\frac{A_{t} P_{H, t}}{P_{t}^{*}}\right)^{-\eta} C_{t}^{*}\right) P_{H, t}^{-\varepsilon} \\
Y_{t} & =(1-\alpha)\left(\frac{P_{H, t}}{P_{t}}\right)^{-\eta} C_{t}+\alpha\left(\frac{A_{t} P_{H, t}}{P_{t}^{*}}\right)^{-\eta} C_{t}^{*} \\
Y_{t} & =C_{H, t}+C_{H, t}^{*}
\end{aligned}
$$

The total differential of the first order condition yields for all $t$ :

$$
\begin{aligned}
Y y_{t} & =C_{H} c_{H, t}+C_{H}^{*} c_{H, t}^{*} \\
y_{t} & =\frac{C_{H}}{Y} c_{H, t}+\frac{C_{H}^{*}}{Y} c_{H, t}^{*} \\
y_{t} & =\frac{C_{H}}{C} c_{H, t}+\frac{C_{H}^{*}}{C} c_{H, t}^{*} \\
y_{t} & =(1-\alpha) c_{H, t}+\alpha c_{H, t}^{*}
\end{aligned}
$$

According to the last expression, an increase in aggregate output is divided between an increase in domestic and foreign consumption with respect to the openness of the economy, i.e. some part is consumed at home and the rest is exported. If we combine the prior expression with log linearising the composite consumption index:

$$
C_{t}=\left[(1-\alpha)^{\frac{1}{\eta}} C_{H, t}^{\frac{\eta-1}{\eta}}+\alpha^{\frac{1}{\eta}} C_{F, t}^{\frac{\eta-1}{\eta}}\right]^{\frac{\eta}{\eta-1}}
$$

We obtain: 


$$
\begin{aligned}
y_{t} & =c_{t}+\alpha\left(c_{H, t}^{*}-c_{F, t}\right) \\
& =(1-\alpha) c_{t}+\alpha c_{t}^{*}+\alpha\left[\left(c_{H, t}^{*}-c_{t}^{*}\right)-\left(c_{F, t}-c_{t}\right)\right]
\end{aligned}
$$

Noticing that $c_{F, t}-c_{t}=-\eta p_{F, t}=-\eta(1-\alpha) s_{t}$ and $c_{H, t}^{*}-c_{t}^{*}=-\eta p_{H, t}^{*}=\eta s_{t}$ we can thus write:

$$
y_{t}=(1-\alpha) c_{t}+\alpha c_{t}^{*}+\alpha \eta(2-\alpha) s_{t}
$$

Therefore output can be expressed as a weighted average of domestic and foreign expenditures plus an expenditure switching factor, which is proportional to the terms of trade. Note that all variables are expressed as percentage deviations from their steady state values.

In the rest of the world a representative household faces a problem identical to the one outlined above with the exception there are no rule of thumb households or habit persistence. While it has been shown that both of these characteristics are econometrically important in international studies, including both characteristics in this model would overcomplicate matters and draw attention away from my focus on the small open economy.

If we assume the world economy's representative agent maximises its utility function subject to a dynamic constraint with no habit persistence or rule of thumb consumers, one could obtain the following optimality conditions:

$$
C_{t}^{* \sigma} N_{t}^{* \varphi}=\frac{W_{t}^{*}}{P_{t}^{*}}
$$

$$
\beta\left(\frac{C_{t+1}^{*}}{C_{t}^{*}}\right)^{-\sigma}\left(\frac{P_{t}^{*}}{P_{t+1}^{*}}\right)=Q_{t, t+1}
$$

Under the assumption of complete securities market, a first order condition analogous to the second optimality condition above must also hold for consumers in foreign countries: 
$\beta\left(\frac{C_{t+1}^{*}}{C_{t}^{*}}\right)^{-\sigma}\left(\frac{P_{t}^{*}}{P_{t+1}^{*}}\right)\left(\frac{e_{t}}{e_{t+1}}\right)=Q_{t, t+1}$

If I define the real exchange rate as $q_{t}=\frac{e_{t} P_{t}^{*}}{P_{t}}$. Combining (23) and (24) it follows after iterating that:

$$
c_{t}=\imath c_{t}^{*} q_{t}^{\frac{1}{\sigma}}
$$

for all $t$, where $t$ is a constant that depends on initial conditions. Log linearising the prior equation around steady state yields:

$$
\hat{c}_{t}=\hat{c}_{t}^{*}+\frac{1}{\sigma} \hat{q}_{t}
$$

The assumption of complete markets at the international level leads to a simple relationship between domestic consumption home and abroad and the real exchange rate. Notice that this relationship is impartial to the relative size of the two economies involved and the constant term.

Furthermore, if we combine the latest expression with the goods market clearing condition we can obtain the following form:

$$
\begin{aligned}
y_{t} & =y_{t}^{*}+\frac{1+\alpha(\sigma \eta-1)(2-\alpha)}{\sigma} s_{t} \\
& =y_{t}^{*}+\frac{\varpi}{\sigma} s_{t}
\end{aligned}
$$


Appendix 4.3 - Data description

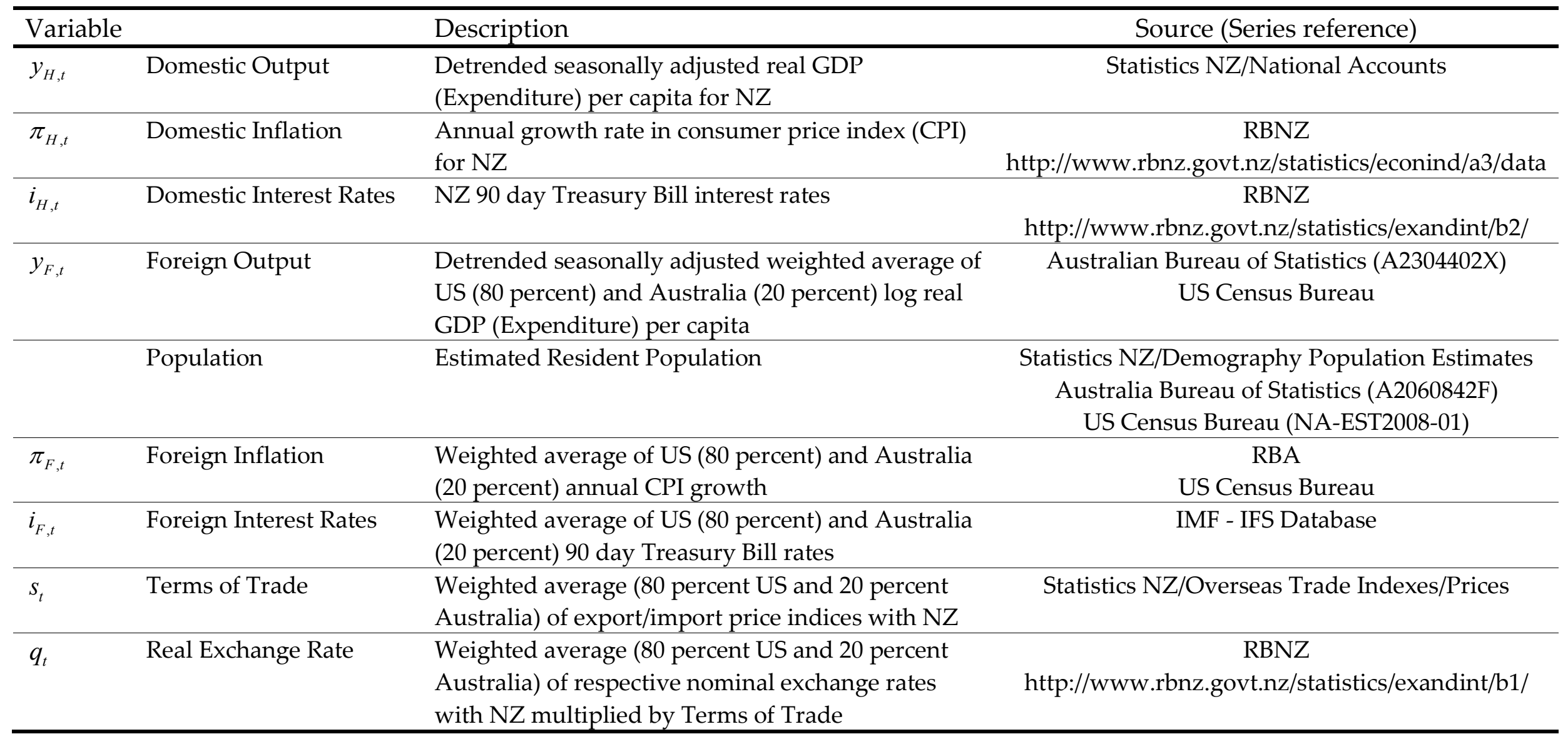




\section{Conclusion}

The purpose of this dissertation was to set a benchmark of rule of thumb firm and consumer estimates, as no single study has pursued such behaviour in NZ. This thesis sought not only to update the estimate of $\lambda$, but also provide an estimate of aggregate firm pricing behaviour that deviates from well accepted New Keynesian theory $(\omega)$. Estimates obtained are well behaved, in that they pass a significant majority of hypothesis tests, and are economically meaningful.

There were three key findings from chapter 2 . Firstly, approximately $21 \%$ of households in NZ follow a rule of thumb. In other words these households are liquidity constrained. This means that classical theory alone is insufficient to describe movements in consumption. Secondly, using the real interest rate as a possible reason for rule of thumb behaviour, it was found there is no relation between changes in consumption and the real interest rate in New Zealand. Thirdly, the main issue raised from chapter 2 concerned reliability of estimating log linearised Euler equations. While the literature is starting to move towards adopting the estimation of non linear Euler equations, the method adopted in this dissertation remains standard practice

From chapter 3 we learned that the Hybrid NKPC is adept at tracking inflation dynamics given the length of my data series. Approximately $82 \%$ of NZ firms set prices in a backward looking manner when given the opportunity to adjust their price. Furthermore, prices are fixed on average for five periods. This particular study shows how important it is to match available data to the underlying concept in economic theory. Furthermore, it 
shows critical thinking into NZ's cost structure allowed me to construct a suitable representation of firm real marginal costs.

The small open economy model in chapter 4 was designed to determine whether estimates obtained in the prior two chapters could be replicated in a larger scale model. The model, featuring rule of thumb consumers, external habit formation, and backward looking price setters, has not been estimated before. While estimates of $\lambda$ and $\omega$ were a little different from GMM estimates (0.34 and 0.7 respectively), positive diagnostic tests mean we cannot discount their importance. There were a couple of concerning points however. Some parameter estimates may be biased because of the absence of other external forces. Given the concern regarding measurement error terms $\sigma_{\pi_{H}}, \sigma_{i_{H}}$, and $\sigma_{q}$, one could consider extending the model to include a more dynamic treatment of the law of one price (LOP). I believe the model could follow Liu (2006) by allowing the LOP to hold for the export sector and incomplete pass-through for imports. Liu (2006) argues in favour of this treatment because New Zealand is a price taker and has limited international market power. One may find real exchange rate movements are followed much more closely under this relation, thus reducing $\sigma_{q}$. Another alternative set up would be to use a Covered Interest Rate Parity (CIP) condition. This may also assist the model in explaining movements in domestic nominal interest rates.

While I could have extended the model to incorporate firm investment behaviour or labour market imperfections; it was my intention for the model's dynamics to focus on household consumption and firm pricing behaviour. Imposing further equations that describe more comprehensive 
macroeconomic behaviour would have diverted the focus away from the questions I was interested in asking. 


\section{References}

Anatolyev, S. (2005). GMM, GEL, Serial Correlation, and Asymptotic Bias. Econometrica, 73(3), 983-1002.

Ascari, G. (2000). Optimising Agents, Staggered Wages and Persistence in the Real Effects of Money Shocks. Economic Journal, 110(465), 664-686.

Ascari, G. (2004). Staggered Prices and Trend Inflation: Some Nuisances. Review of Economic Dynamics, 7(3), 642-667.

Attanasio, O. P. (1995). The intertemporal allocation of consumption: theory and evidence. Carnegie-Rochester Conference Series on Public Policy, 42(1), 3956.

Bakhshi, H., \& Burriel, P. (2003). Endogenous Price Stickiness, Trend Inflation, and the New Keynesian Phillips Curve (Computing in Economics and Finance 2003): Society for Computational Economics.

Boot, J. F., W. and Lisman, J.H.C. (1967). Further Methods of Derivation of Quarterly Figures from Annual Data. Applied Statistics, 16(1), 65-75.

Calvo, G. A. (1983). Staggered prices in a utility-maximizing framework. Journal of Monetary Economics, 12(3), 383-398.

Campbell, J. Y. (1987). Does Saving Anticipate Declining Labor Income? An Alternative Test of the Permanent Income Hypothesis. Econometrica, 55(6), 1249-1273.

Campbell, J. Y., \& Deaton, A. (1989). Why Is Consumption So Smooth? Review of Economic Studies, 56(3), 357-373.

Campbell, J. Y., \& Mankiw, N. G. (1989). Consumption, Income and Interest Rates: Reinterpreting the Time Series Evidence. NBER Macroeconomics Annual 1989, Volume 4, 185-246.

Campbell, J. Y., \& Mankiw, N. G. (1991). The response of consumption to income : A cross-country investigation. European Economic Review, 35(4), 723-756.

Campbell, J. Y., \& Shiller, R. J. (1987). Cointegration and Tests of Present Value Models. Journal of Political Economy, 95(5), 1062-1088.

Carroll, C. D. (1992). The Buffer-Stock Theory of Saving: Some Macroeconomic Evidence. Brookings Papers on Economic Activity, 23(1992-2), 61-156. 
Chow, G. C., \& Lin, A. 1. (1971). Best Linear Unbiased Interpolation, Distribution, and Extrapolation of Time Series by Related Series. The Review of Economics and Statistics, 53(4), 372-375.

Christiano, L. J., Eichenbaum, M., \& Evans, C. L. (2005). Nominal Rigidities and the Dynamic Effects of a Shock to Monetary Policy. Journal of Political Economy, 113(1), 1-45.

Cushing, M. J. (1992). Liquidity Constraints and Aggregate Consumption Behavior. Economic Inquiry, 30(1), 134-153.

Deaton, A. (1988). Life-Cycle Models of Consumption: Is the Evidence Consistent with the Theory? (NBER Working Papers): National Bureau of Economic Research, Inc.

Dennis, R. (2004). Specifying and estimating New Keynesian models with instrument rules and optimal monetary policies (Working Papers in Applied Economic Theory): Federal Reserve Bank of San Francisco.

Denton, F. (1971). Adjustment of monthly or quarterly series to annual totals: An approach based on quadratic minimization. Journal of the American Statistical Association, 66(333), 99-102.

Dibartolomeo, G., Rossi, L., \& Tancioni, M. (2004). Monetary Policy under Rule-ofThumb Consumers and External Habits: An International Empirical Comparison (MPRA Paper): University Library of Munich, Germany.

Dornbusch, R., \& Fischer, S. (1987). Macroeconomics (5 ed.). New York: McGrawHill.

Erceg, C. J., \& Levin, A. T. (2001). Imperfect credibility and inflation persistence (Finance and Economics Discussion Series): Board of Governors of the Federal Reserve System (U.S.).

Fernandez, R. B. (1981). A Methodological Note on the Estimation of Time Series. The Review of Economics and Statistics, 63(3), 471-476.

Fischer, S. (1977). Long-Term Contracts, Rational Expectations, and the Optimal Money Supply Rule. Journal of Political Economy, 85(1), 191-205.

Flavin, M. A. (1981). The Adjustment of Consumption to Changing Expectations about Future Income. Journal of Political Economy, 89(5), 974-1009. 
Francia, M. R., \& García, A. T. (2006). Inflation Dynamics in Mexico: A Characterization Using the New Phillips Curve (Working Papers): Banco de México.

Friedman, M. (1968). The Role of Monetary Policy. American Economic Review, 58(1), 1-17.

Fuhrer, J. C. (1997). The (Un)Importance of Forward-Looking Behavior in Price Specifications. Journal of Money, Credit and Banking, 29(3), 338-350.

Fuhrer, J. C., \& Olivei, G. P. (2005). Estimating forward-looking Euler equations with GMM estimators: an optimal-instruments approach. Proceedings, 87114.

Fuhrer, J., \& Moore, G. (1995). Inflation Persistence. The Quarterly Journal of Economics, 110(1), 127-159.

Fuhrer, J., Moore, G., \& Schuh, S. (1993). Estimating the linear-quadratic inventory model: maximum likelihood versus generalized method of moments (Finance and Economics Discussion Series): Board of Governors of the Federal Reserve System (U.S.).

Galí, J., \& Gertler, M. (1999). Inflation Dynamics: A Structural Economic Analysis (CEPR Discussion Papers): C.E.P.R. Discussion Papers.

Galí, J., \& Monacelli, T. (2002). Monetary Policy and Exchange Rate Volatility in a Small Open Economy (CEPR Discussion Papers): C.E.P.R. Discussion Papers.

Gelman, A., \& Rubin, D. B. (1992). Inference from iterative simulation using multiple sequences. Statistical Science, 7, 457-511.

Ghysels, E. (1987). Unit Root Tests and the Statistical Pitfalls of Seasonal Adjustment: the Case of U.S. Post-War Real GNP (Cahiers de recherche): Universite de Montreal, Departement de sciences economiques.

Gomes, F., \& Issler, J. (2006). A General Test for Rule of Thumb Behavior. Paper presented at the Annals of the 61st European Meeting of the Econometric Society.

Hahn, J., \& Hausman, J. (2003). Weak Instruments: Diagnosis and Cures in Empirical Econometrics. American Economic Review, 93(2), 118-125. 
Hall, R. E. (1978). Stochastic Implications of the Life Cycle-Permanent Income Hypothesis: Theory and Evidence. Journal of Political Economy, 86(6), 971987.

Hall, R. E., \& Mishkin, F. S. (1982). The Sensitivity of Consumption to Transitory Income: Estimates from Panel Data on Households. Econometrica, 50(2), 461-481.

Hansen, L. P. (1982). Large Sample Properties of Generalized Method of Moments Estimators. Econometrica, 50(4), 1029-1054.

Hansen, L. P., \& Singleton, K. J. (1982). Generalized Instrumental Variables Estimation of Nonlinear Rational Expectations Models. Econometrica, 50(5), 1269-1286.

Hansen, L. P., Heaton, J., \& Yaron, A. (1996). Finite-Sample Properties of Some Alternative GMM Estimators. Journal of Business \& Economic Statistics, 14(3), 262-280.

Heidelberger, P., Welch, P.D. (1983). Simulation Run Length Control in the Presence of an Initial Transient. Operations Research Society of America, 31, 1109-1144.

Kirker, M. (2008). Does natural rate variation matter? Evidence from New Zealand. Reserve Bank of New Zealand, DP 2008/17.

Lees, K. (2009). Introducing KITT: The Reserve Bank of New Zealand new DSGE model for forecasting and policy design. Reserve Bank of New Zealand Bulletin, 72, 5-20.

Lewbel, A. (1987). Bliss Levels That Aren't [Stochastic Implications of the Life Cycle-Permanent Income Hypothesis: Theory and Evidence]. Journal of Political Economy, 95(1), 211-215.

Lindé, J. (2001). Estimating New-Keynesian Phillips Curves: A Full Information Maximum Likelihood Approach (Working Paper Series): Sveriges Riksbank (Central Bank of Sweden).

Litterman, R. B. (1983). A random walk, Markov model for the distribution of time series (Staff Report): Federal Reserve Bank of Minneapolis.

Liu, P. (2006). A Small New Keynesian Model of the New Zealand economy (Reserve Bank of New Zealand Discussion Paper Series): Reserve Bank of New Zealand. 
Lucas, R., Jr. (1976). Econometric policy evaluation: A critique. Carnegie-Rochester Conference Series on Public Policy, 1(1), 19-46.

Mankiw, G., \& Shapiro, M. (1985). Trends, random walks, and tests of the permanent income hypothesis. Journal of Monetary Economics, 16(2), 165174.

Mankiw, N. G., \& Reis, R. (2002). Sticky Information Versus Sticky Prices: A Proposal To Replace The New Keynesian Phillips Curve. The Quarterly Journal of Economics, 117(4), 1295-1328.

Mankiw, N. G., \& Reis, R. (2010). Imperfect Information and Aggregate Supply (NBER Working Papers): National Bureau of Economic Research, Inc.

Maravall, A., \& Sánchez, F. J. (2000). An Application of TRAMO-SEATS: Model Selection and Out-of-Sample Performance: the Swiss CPI Series (Banco de España Working Papers): Banco de España.

Menyhért, B. (2008). Estimating the Hungarian New-Keynesian phillips curve. Acta Oeconomica(58:3), 295-318.

Michener, R. (1984). Permanent income in general equilibrium. Journal of Monetary Economics, 13(3), 297-305.

Milani, F. (2004). Persistence in Monetary Policy Models: Indexation, Habits and Learning with Long-Horizon Expectations (Econometric Society 2004 North American Summer Meetings): Econometric Society.

Musil, V. a. (2006). Behavior of the Czech Economy: New Open Economy Macroeconomics DSGE Model. Research Centre for Competitiveness of the Czech Republic (Working Paper No. 23).

Nelson, C. R. (1987). A Reappraisal of Recent Tests of the Permanent Income Hypothesis [Stochastic Implications of the Life Cycle-Permanent Income Hypothesis: Theory and Evidence]. Journal of Political Economy, 95(3), 641-646.

Phelps, E. (1967). Phillips Curves, Expectations of Inflation and Optimal Unemployment over Time. Economica, 34(135), 254-281.

Phillips, A. (1958). The Relationship between Unemployment and the Rate of Change of Money Wage Rates in the United Kingdom, 1861-1957. Economica, 25(100), 283-299. 
Quah, D. (1990). Permanent and Transitory Movements in Labor Income: An Explanation for "Excess Smoothness" in Consumption. Journal of Political Economy, 98(3), 449-475.

Rae, D. (1996). NBNZ-DEMONZ: A dynamic equilibrium model of New Zealand. Economic Modelling, 13(1), 91-165.

Raftery, A. E., \& S. M. Lewis . (1992). How many iterations for the Gibbs sampler?. In J. M. Bernado (Ed.), Bayesian Statistics (pp. 763-73): Oxford University Press.

Roberts, J. M. (1995). New Keynesian Economics and the Phillips Curve. Journal of Money, Credit and Banking, 27(4), 975-984.

Roberts, J. M. (1997). Is inflation sticky? Journal of Monetary Economics, 39(2), 173-196.

Roberts, J. M. (1998). Inflation expectations and the transmission of monetary policy (Finance and Economics Discussion Series): Board of Governors of the Federal Reserve System (U.S.).

Roberts, J. M. (2001). How well does the New Keynesian sticky-price model fit the data? (Finance and Economics Discussion Series): Board of Governors of the Federal Reserve System (U.S.).

Rubene, I., \& Guarda, P. (2004). The New Keynesian Phillips Curve: Empirical Results For Luxembourg (BCL working papers): Central Bank of Luxembourg.

Rumler, F. (2007). Estimates of the Open Economy New Keynesian Phillips Curve for Euro Area Countries. Open Economies Review, 18(4), 427-451.

Santos Silva, J. M. C., \& Cardoso, F. N. (2001). The Chow-Lin method using dynamic models. Economic Modelling, 18(2), 269-280.

Sargent, T. J. (1978). Rational Expectations, Econometric Exogeneity, and Consumption. Journal of Political Economy, 86(4), 673-700.

Sbordone, A. M. (2002). Prices and unit labor costs: a new test of price stickiness. Journal of Monetary Economics, 49(2), 265-292.

Schorfheide, F. (2000). Loss function-based evaluation of DSGE models. Journal of Applied Econometrics, 15(6), 645-670. 
Shapiro, A. H. (2008). Estimating the New Keynesian Phillips Curve: A Vertical Production Chain Approach. Journal of Money, Credit and Banking, 40(4), 627-666.

Stock, J. H., \& Yogo, M. (2002). Testing for Weak Instruments in Linear IV Regression (NBER Technical Working Papers): National Bureau of Economic Research, Inc.

Taylor, J. B. (1980). Aggregate Dynamics and Staggered Contracts. Journal of Political Economy, 88(1), 1-23.

Weber, C. E. (2000). "Rule-of-Thumb" Consumption, Intertemporal Substitution, and Risk Aversion. Journal of Business \& Economic Statistics, 18(4), $497-$ 502.

Weber, C. E. (2002). Intertemporal non-separability and "rule of thumb" consumption. Journal of Monetary Economics, 49(2), 293-308.

West, K. D. (1988). The Insensitivity of Consumption to News About Income (NBER Working Papers): National Bureau of Economic Research, Inc.

Wooldridge, J. (2002). Introductory Econometrics: A Modern Approach . South-Western College Publishing.

Wouters, R., \& Smets, F. (2003). Output gaps: theory versus practice (Computing in Economics and Finance 2003): Society for Computational Economics. 